Portland State University

PDXScholar

3-15-2021

\title{
Virtual Community for Fat People in Outdoor Recreation
}

Amber C. Stephens

Portland State University

Follow this and additional works at: https://pdxscholar.library.pdx.edu/honorstheses

Part of the Communication Technology and New Media Commons, and the Social Media Commons Let us know how access to this document benefits you.

\section{Recommended Citation}

Stephens, Amber C., "Virtual Community for Fat People in Outdoor Recreation" (2021). University Honors Theses. Paper 969.

https://doi.org/10.15760/honors.993

This Thesis is brought to you for free and open access. It has been accepted for inclusion in University Honors Theses by an authorized administrator of PDXScholar. Please contact us if we can make this document more accessible: pdxscholar@pdx.edu. 
Running head: VIRTUAL COMMUNITIES FOR FAT PEOPLE

1

Virtual Community for Fat People in Outdoor Recreation

by

Amber C. Stephens

An undergraduate honors thesis submitted in partial fulfillment of the requirements for the degree of

Bachelor of Science

in

University Honors

And

Communication Studies

Thesis Advisor

Scott Selberg, Ph.D

Portland State University 


\begin{abstract}
This paper examines online virtual communities for fat people within outdoor recreation, and how they provide connection, complex agency, and representation for fat bodies in spaces where their bodies are seen as taboo. Furthermore, it will explore the way fat bodies have been historically viewed, the lack of representation of fat bodies in the outdoors and related communities, and the gate-keeping that occurs to those who are not classified as those who do not conform to traditional stereotypes of an outdoorsy person. Close examination of two different Instagram accounts that highlight the fat body in the outdoors, will reveal three main representational elements that are an integral part of the act of community building: the body, the location, and the caption. Each element works together to create the aspects of creating a community for fat bodies in the outdoors. The importance of these communities is discussed along with the future of these virtual spaces. These communities matter because they carve room for needed representation for fat bodies in the outdoors and they allow support for community members who seek to take up space in the outdoors. This thesis will explore how these virtual communities are built, what they look like, and the existing circumstances within society that led to their creation.
\end{abstract}




\section{The Landscape of Fatness}

One of the continuing taboos within U.S. society, and to an extent worldwide, is that of the fat body in spaces where it is deemed as an 'other' or unwanted. One of the most prominent of these spaces is outdoor recreation. The fat liberation movement is one of the primary forms of rebellion against the norms of society that dictate where fat bodies are allowed to be and where they are prohibited. Fat Liberation started as, and continues to be, an acceptance movement for fat people to discuss and fight against the obstacles they face (Farrell, 2011). Fat liberation is also known as fat acceptance, fat activism, or fat empowerment. Though fat bodies have been more normalized in modern society, the reality is that we are still living in a sizest world that both judges and excludes people from spaces and activities involving fitness, crowds, swimsuits, travel, or adventure.

This is particularly apparent within outdoor recreation and hiking communities, where the norm is white, able-bodied, mostly male, and thin. This norm is reinforced in the representation of these spaces and thus their communities, therefore, these representations often serve as the image people conjure when thinking of outdoor recreation. This stereotypical outdoors person is concocted through the media and subconsciously reinforced by society, and thus works to enforce the stereotype of fat people. The stark difference between these commonly believed stereotypes creates an inhospitable space for fat bodies and people who do not fit these predetermined characteristics in outdoor recreation. This world is off-limits in various ways from the lack of representation, which affects a person's self perception and ability to be a part of this world, as well as basic barriers such as access to gear in larger sizes. Stanley (2020) writes, "yes, the outdoors and public lands belong to all of us, and sure, no one is getting a handwritten invitation to our National Parks and trailheads, but exclusion isn't always verbal. A lot of the 
time, it's about representation ..." (p. 242). Due to this form of gatekeeping and exclusion, virtual communities have begun to emerge that allow inclusion opportunities for the people who are traditionally excluded from outdoor recreation and thus the communities that accompany them. It should be noted that these communities are for anyone who sees themselves as underrepresented in the outdoor community. However, for the purpose of this paper, the focus is fat people and their interaction with this virtual community.

Academic literature has not sufficiently described the intersection between fat liberation, online community building, and representation of fat bodies in the outdoors. This essay aims to fill this gap by exploring the evidence of online community building that creates spaces for fat bodies in outdoor recreation, and the empowerment that comes with community and representation. This work is important because it can show how these virtual communities are fighting against the harmful stigmas and stereotypes of fat bodies in outdoor recreation.

\section{Conversations on Fatness}

The following introduction to the literature on fatness will focus on two themes: fat stigma and fat trauma. The first topic is fat stigma, which is feelings of disgrace for being fat. These feelings can be felt by a fat person or be imposed onto them from others' feelings or judgements about the fat body. Fat trauma is the impact on a person from living in a fat body, with a focus on how society contributes to this trauma by deciding what is an acceptable and worthy body. Fat bodies moving through and existing in the world are viewed as unworthy, unwanted, and deviant, with the inhabitants of these bodies seen as failures.

\section{Fat Stigma And Fat Shame}

A fat body is not something that can be shed and left at home. It lives with a person and is not an invisible identity. The identity of fat is often framed as 'an epidemic,' described in 
words that tend to evoke feelings that fatness is something that can be caught; it is a transferable characteristic and if you get too close you'll be next. This harmful rhetoric placed on fat bodies contributes to the continued stigma and shame that accompanies fat people as they move through the world. Farrell (2011) writes about how fat bodies are seen as 'uncivilized' and have a long history of being mocked, deemed unworthy of human decency, and subject to ridicule. Fat bodies are also weaponized as examples of every stereotypical representation of fatness portraying them as lazy, dirty, unworthy, and as a joke. Farrell (2011) describes this demonization of fat bodies in the United States is so ingrained in our culture that the hatred for fat bodies is innate due to the persisting cycle of representations of fat people as degenerates. Representations in multiple forms of media continue to display fat bodies in ways that give audiences permission to laugh at them, continuing to view them as "a debased being, deserving of little respect or dignity...degenerate, the one who has moved furthest from the pinnacle of a civilized state, the one who requires a 'shake up' to return to the normal progress of human evolution" (Farrell, 2011, p. 118).

This degeneration associated with fat bodies by the media extends to celebrity rise and fall stories, such as Britney Spears and Oprah Winfrey, whose 'value' and status rose when they lost weight. After their bodies were deemed back in line with mainstream standards, they were able to "climb back up the ladder of civilization" (Farrell, 2011, p. 127). Fatness is continued to be used against fat people as an excuse to judge a person and take agency away from their existence. Farrell (2011) writes, “one’s physical body can be read for signs of personal worthiness and quality persists...[there are] insidious ways that these ideas thread their way through cultural practices and beliefs" (p. 136). Fat bodies are made into a problem, a public and 
societal problem that the fat person must deal with or risk punishment of being outcast and judged.

There is a connection between fat bodies, agency and identities. Agency is often reduced down for a fat person and their identities are reduced to being viewed as "the fat one" either through direct or indirect address. This process of being reduced to the stereotypes and stigmas placed upon a fat body further contributes to the ongoing trauma of existing in a fat body. Harris (2015) writes that "to label someone obese obscures that person, all that can be seen is the fat..[this] process turns them into a mere object" (p.55). This 'obscuring' of a person also gives permission to the act of turning fat bodies into a joke or a judgement often both because when reduced to the label of fat, a person's agency and identity are stripped and they are now solely the fat one. It is clear that through the eyes of society and media that fat bodies equal failure, failure of the individual to live up to societal standards.

\section{Trauma of the Fat Body}

This lack of visibility of fat bodies within physical activity settings have effects on fat people who deal with what Meadows and Bombak (2019) referred to as weight stigma and exercise trauma growing up. Meadows and Bombak (2019), write about the trauma that fat people go through when put in physical situations due to the threat and action of stigma, discrimination, and the lack of fitness role models for fat people. Fat people are continually ostracized and othered in a society that remains fatphobic; fat bodies "experienc[e] weight stigma in practically every domain of daily living including work, in education, healthcare, and interpersonal relationships" (p.135). Fat people and fat bodies' relationship with exercise is often seen as one that is weaponized against them no matter if they do or do not take part in physical activity. Most often these traumas about a person's body are first forced onto the fat body from 
external sources. These traumas are then internalized and the person becomes an incubator for societal body expectations and continued trauma.

These external sources of trauma often occur as a child when attempting to engage in a physical setting and then witnessing the social response to these attempts. These responses take different forms, for example verbal discouragement by peers or adults, but also the nonverbal responses or attitudes displayed by others and then interpreted by the child. These experiences also influence what a person believes they are capable of or what is referred to as "self-efficacy" particularly “exercise self-efficacy” (Meadows and Bombak, 2019, p. 136). The 'anti-fat' rhetoric that flows in physical spaces creates environments where fat bodies become conditioned to believe possession of a fat body means these physical spaces are not for them and decimates any confidence they may have had in this setting (Meadows and Bombak, 2019). These experiences also continue the process enforced by society of "obscuring" the person and taking away agency from a person until they are only seen as their body.

This childhood "weight related victimization" trauma is often carried out by peers and teachers in school and throughout life. Due to this, fat people are often conditioned to believe that no matter how hard they try they will fail. This results in little motivation to continue with this kind of activity. The feeling of failure combined with the fear of future stigmatization and ostracization from peers leads to minimal (if any) participation in physical activities or space. Meadows and Bombak (2019) write, "negative assumptions and stereotypical beliefs may well become self-fulfilling as fat youngsters are implicitly and explicitly taught their bodies exclude them from enjoyable and profitable engagement in exercise and sport, and consequently exhibit reduced self-efficacy and engage less frequently in physical activity" ((Meadows \& Bombak, 2019, p. 138). The stigmas that radiate through society about fat bodies create an environment 
where fat people have to continually and consciously be exposed to mental, emotional, and even physical trauma to navigate a fatphobic society. This continued navigation of a fatphobic and sizest society furthers the trauma of weight victimization, and weight stigma remains and thrives through the traumatic experiences that are born from this society.

Even when fat bodies engage in physical activity it is seen as a counter stereotypical behavior that also leaves the person up to societal judgement (Meadows \& Bombak, 2019). No matter how fat bodies move through society they are up for public ridicule and judgement. Meaning that even if a fat body is partaking in physical activity they are vulnerable to "bullying, harrasment, discrimination, and dehaumanization" (Meadows and Bombak, 2019, p. 139) from others in this environment. Despite actively participating in physical activity, fat bodies continue to be ridiculed because society continues to grant permission to do so, especially in settings where their bodies are the outlier. Fat bodies are seen as deviant, undesirable, unwanted, simultaneously hypervisible yet invisible (Meadows and Bombak, 2019, p. 139). Fat people, even those who are not subjected to stigmatizing incidents, are aware of how society views them. When fat bodies enter spaces for physical activity or engage in physical activity, they are hypervisible; up for observation, judgement, and 'considered public property'. There is little agency over the fat body. Society assumes that their activity is solely for the purpose of losing weight, to become a more desirable member of society and to "atone by taking responsibility for fixing their burdensome bodies" (Meadows \& Bombak, 2019, p. 139). Fat bodies in spaces deemed for physical activity are seen as threatening to the space itself and to other non fat bodies that inhabit it.

Meadows and Bombak (2019) also argue that because of this consistent trauma, doubt, and judgement that fat people are subjected to, there is now a lack of fat role models within 
fitness. The authors call this the "erasure of fat exercisers" (p. 140). Throughout history, fat bodies have rarely been portrayed exercising or doing anything physical in the media or in advertisements. Even when they have, exercise content has frequently demonized and villainized fat bodies. Fat bodies exercising are "represented as punitive in nature, and serving the sole purpose of rendering their bodies slimmer and more acceptable" (Meadows \& Bombak, 2019, p. 141). The combination of stigma, trauma, villainization, and lack of representation creates a lack of fat bodies in fitness spaces, and thus, a lack of fat role models to look up to in these spaces as well.

Role models can help people who have similar bodies see what their bodies can be capable of: they serve as a model of a 'possible self' (Meadows \& Bombak, 2019).

Representation is important for everyone because viewing a person similar to you in a space you desire to occupy is powerful, and it allows people to think about what they are capable of; it fosters feelings of belonging in that space. Meadows and Bombak(2019) argue, "viewing similar fat others simply engaging in and enjoying active pursuits could serve to counter prevailing stereotypes and produce a shift in how a non-active fat person views physicality as an option for their own bodies" (Meadows \& Bombak, 2019, p. 139). Therefore, fat role models would deliver the representation needed to provide the clarity and self realization that fat bodies are capable in spaces deemed for physical activity, as well as the permission to be visible and take up space without thinking about the threat of stigmatization and ridicule.

There is an importance in these claims on representation and how they affect the people who identify with them and need them. The emphasis is the virtual part of the community, and the ability to extend to anyone with access to social media is the most crucial element of the community. To find a picture and see themselves within it has a profound impact; to then 
understand and realize that a space that was previously prohibited due to societal norms is now accessible because they saw themselves within it. It opens up a whole new perspective of what a person feels like they can do and creates the desire and the permission to take up space.

Social media has been shown to have profound effects on mental health. Depending on what type of media a viewer is engaging with, their mental health and self image can increase or decrease. Image based platforms like Instagram are common circulators of images that affect body image and mental health. For example, hashtags r like \#fitspiration or \#thinspiration offer a collection of images that represent the "ideal" body. Counter to that, hashtags like \#fatspiration and \#healthateverysize are a result of the emergent body positive movement on Instagram. This movement "aims to challenge dominant appearance ideals, foster acceptance and respect for all bodies regardless of shape, size or features, and focus on appreciating the functionality of the body" (Cohen, Newton-John, \& Slater, 2020, p. 2). It has been observed that when viewing the images associated with \#fitspiration or \#thinspiration it negatively affected the viewers mood and body satisfaction (Cohen, Newton-John, \& Slater, 2020). But viewing images that were associated with more body positive hashtags and accounts "may be associated with psychological and protective benefits" (Cohen, Newton-John, \& Slater, 2020, p. 3). In other words, viewing images that are showing bodies that resemble a viewer's own image can positively affect mental health and body image.

In addition to these communities providing the representation of fat bodies that mass media and outdoor communities lack, they also foster social inclusion and acceptance for fat people. Founders of Fat Girls Hiking describe this creation of community as "empowering in a world where being fat can be isolating" (Greene, 2019). This social isolation and the corresponding ability to find acceptance and inclusion in virtual communities was exemplified in 
a weblog called 'Fatosphere'. The blog created a sense of belonging for users, "through the protection and support that they found within this "safe space" (Dickins et al., 2016, p. 797).

The Fatosphere has been described as "a collection of fat activist and anti-fat-shaming digital media platforms [that] have proliferated in response to [the] 'obesity epidemic' and related fat shaming discourses" (Lupton, 2017). The Fatosphere was one of the first virtual communities for fat people. The community shared life experiences, tips on where to find clothing, words of encouragement and empowerment, and overall feelings about living in a fat body in a fatphobic society. The Fatosphere provided a safe space away from mainstream rhetoric of fatness, a space that held content made by self identifying fat people, made for other fat people (Hynna \& Kryola, 2019). The Fatosphere fostered a feeling of inclusion to those who were interacting. It provided support, comfort, protection, and understanding for fat people from other fat people, and it was a way to find others who were similar to you and even foster friendships (Dickens, et al., 2016). The Fatosphere harbored conversations about alternate ideas and conceptualizations of the fat body. There was support instead of disdain for fat bodies because this was a community of people who can relate to each other through similar life experiences. The Fatosphere also allowed users to share advice and tips on subjects like traveling, shopping, sex, or dealing with fat stigma (Dickens, et al., 2016).

The Fatosphere also created a space where permission was granted to not hate the fat body, to feel differently about it. You did not have to immediately fall in love with your body and wave your fat body flag, participants were simply allowed to "feel in their body". To "feel in your body" has been described as stepping back from society's ideal body pressure, to allow a “powerful critique of contemporary western culture's pull toward treating bodies as objects, to be molded, evaluated, and seen from the outside" (Hynna \& Kyrola, 2019, p. 2). It is taboo and 
frowned upon for fat people to feel anything but hate for their bodies. The opportunity to quiet societal assumptions and judgements about your body is a radical notion that can only be achieved in a space that was built for fat people in response to the continued exclusion experienced by fat people. This opportunity is also a chance to reclaim a fat person's agency which is constantly being taken from them._The Fatosphere promoted feelings of inclusion and normalization for fat bodies by making the fat body visible to everyone, with exposure and by sharing images that displayed the fat body as positive; this helped with the mission of normalizing the fat body. (Afful \& Ricciardelli, 2015). The act of making fat bodies visible is also an act of acknowledgement about how the world sees your body; that a fat body is the first thing society sees of you. This action, birthed from involvement in the Fatosphere, can actually be an act of empowerment.

The internet has expanded and evolved past the Fatosphere and now these communities permeate social media. The support and community that the Fatosphere fostered is still present, but the format has shifted. The rise of social media has also given rise to more opportunities and homes for virtual spaces of inclusion and relatability for fat people. Hashtags on Instagram serve as a link for many to find these communities. Hashtags like \#fatspiration and \#healthateverysize (also known as \#HAES) allow users to easily find one another or add their own images and thoughts to the conversation. Images associated with these hashtags "portra[y] certain qualities reflecting the miltu-faceted nature of fat acceptance" (Webb, et al., 2017, p. 60). The act of posting your body on Instagram and also adding one of these hashtags further the Fatopshere's ideology of visibility; bodies are often the sole focus of the image and the post as a whole (Webb, et al., 2017). Posting images that are all about the fat body continue the fight against 
mainstream interpretations of a body 'ideal' as well as fighting for representation and normalization of the fat body.

\section{Representation (Or Lack Of) of the Fat Body}

The lack of representation of fat bodies in the mainstream creates a homogenous view of an outdoors person, one that does not allow room for anything outside of it. There are different forms of representation, therefore different facets of exclusion. The next two sections address the lack of representation of the dat body in relevant clothing, and in access. Though each form of representation serves a different purpose they often bleed into each other and affect one another, therefore affecting multiple facets of a fat person's experiences throughout life.

An analysis of images in three different outdoor recreation magazines Backpacker, Climbing, and Rock and Ice that were published between 2011 - 2014, resulted in the overwhelming consensus that most images were of white, able-bodied men, with $96 \%$ of images showing white people, $99 \%$ being able bodied, and 60\% being male (Frazer \& Anderson, 2018). These images affect those who view them by creating what an outdoors person 'should' look like and mainstream representation reinforces that image. These images then implicitly create a depiction of the bodies that are absent from the outdoors and thus become a taboo._Frazer and Anderson (2018) write, "Evidence also suggests media, particularly advertising, may reinforce unexamined, particularly racialized assumptions about the demographics of outdoor recreation participation in the United States" (p. 270). This lack of representation and exclusion of fat people in the outdoor world is an implicit way of telling fat people that they are not welcome or wanted in the outdoor community.

This exclusion exists with the simplest of things, like access to gear to be properly equipped to venture outdoors. For example, prior to 2018 REI did not offer plus size clothing at 
all, and currently it only offers extended sizes in 21 of its 154 stores across the United States (Kruger, 2019). Lack of access to gear is just another form of gatekeeping that comes from the outdoor community; it is a statement from these companies that you are not a "valuable market" for them (Greene, 2019). This lack of effort by brands to include bigger sizes can also be classified as viewing extended sizes as 'tainting' their brand: "fitness-wear companies choose to distance their brand from the 'taint' of fatness by refusing to offer their lines in larger sizes or to market them appropriately when they are available" (Meadows \& Bombak, 2019, p. 142).

\section{Where's the Fat Gear?}

Outdoor communities and outdoor brands are scrambling to catch up to the diversity that is desired by many, but fat bodies are still getting left behind and overlooked. In episode thirteen of the Unlikely Hikers podcast, Jenny Bruso, Diandra Oliver, Sam Ortiz, and Tasheon Chillous discuss the very small world of plus size hiking gear and dream over the possibilities of gear they want to be made while thinking of the fat body. There are things that straight sized people might never think of as a barrier. For example, things discussed in this episode are a backpack or day pack that properly fits a fat body, a rain jacket that fits over the stomach, a packable sleeping bag, a one person backpacking tent that fits the fat body, lightweight puffy coats, fully zippable rain pants, and more technical gear (Unlikely Hikers Podcast).

One of the biggest hurdles is the inability to walk into an outdoor store and shop, as most stores do not carry plus size gear in store at all, which excludes the opportunity to try on the clothing or test out the gear before purchasing it. Some fat outdoors people go as far as ordering multiple sizes and returning the one that does not fit. Many people do not have the capital to order multiple pairs of already expensive items, so it may take double or triple the time in filtering through the gear that is available to just simply try it on (Unlikely Hikers Podcast). 
There is also the phenomenon of the 'fat tax', meaning that the gear that is available for fat bodies is often incredibly expensive, as Bruso explains "for most of my life I was too broke to entertain spending $\$ 100$ on one piece of gear" (Unlikely Hikers Podcast). This process of shopping and often knowing that there will be no gear for your body is a traumatizing experience for fat bodies, and this exclusion sends a message to fat people implicitly saying that they should be happy and content with what little is available when this is continuing to make a conscious decision to exclude fat bodies.

When there is gear available for fat bodies, it is not made specifically for fat bodies and oftentimes only reaches a size $3 \mathrm{X}$. Companies who do reach this $3 \mathrm{X}$ status are not taking into account that the overall fit of clothing is not uniform, as "plus size bodies have more variation in shape" (Unlikely Hikers Podcast). By not tailoring the items to fat bodies these clothing options can be seen as an extended straight size, meaning that this $3 \mathrm{X}$ 'plus size' are not meant for a plus size or fat body (Unlikely Hikers Podcast). Companies seem to be just adding $2 \mathrm{X}$ and $3 \mathrm{X}$ sizes to their lines without noting the differences in the fat body, the production side often just takes the straight size pattern and makes it bigger which does not work for a fat body. One guest noted "just because I'm six inches bigger in the waist does not mean I am also six inches bigger in the ankle" (Unlikely Hikers Podcast).

There is also the lack of style options in extended sizes. There are few bold patterns and bright colors available, and by not offering these choices it is "telling fat people to blend in [because there are] no options to be bold or express yourself differently" (Unlikely Hikers Podcast). Bruso, Oliver, Ortiz, and Chillous also go on to discuss their clothing "hacks" in order to either find clothing that fits their bodies for the outdoors or alter clothes in order to make them work. They discuss shopping at Goodwill, thrifting, and then altering the clothes to fit their 
bodies such as adding stretchy fabric to pants through a learned skill of sewing, sale shopping, (meaning shopping for gear in the offseason) and clothing swaps with other fat people. Unlikely Hikers also provides an extensive list of plus size gear that is available and guides to what to wear in different environments.

These structural barriers are embodied within the communities in this study: access to necessary gear is limited even though fat bodies are doing the same thing that straight sized bodies are. For example, one poster in the community Fat Girls Hiking comments on her "makeshift wetsuit" when cave diving in Mexico and jumping in a cenote, writing in her caption “Here's me in my makeshift wetsuit (Cuz they don't make wetsuits for us large folk)"'(see Figure 1). Another community member shared in a post their troubles finding a pack raft that had a weight limit of at least 500 pounds in order for them to feel safe and that the craft was sturdy enough for them (see Figure 2). The stereotype of lazy and inactive is perpetuated because the lack of options for gear make it seem like no fat bodies are exercising or moving, it is the “erasure of fat exercisers as a concept” (Meadows \& Bombak, 2019, p. 142). These physical manifestations of inaccessibility and exclusion presume that no fat body wants to be moving. It is an assumption that because a person is fat they do not want this gear, they are not valid in this sector.

The lack of access reaches across outdoor communities. For example, Sam Ortiz outlines her search for rock climbing harness in the Unlikely Hikers podcast. After extensive research she was able to find one harness that she fits in but this means plus size rock climbers are lacking access to harnesses that properly fit their body, and even less options for technical harnesses. These limits to gear are not only erasure and devaluing of the fat adventurer--purposeful exclusion of their needs and explicitly telling fat bodies they are not welcome--in addition it can 
be dangerous. Issues like not having the correct harness for your body or a lack of brightly colored clothing when venturing deep into nature create dangerous situations. Dressing in all black is a risk when a person goes out hiking, especially alone, but often this is the only option, and if there are extended sizes, the color palette is limited to black, brown, navy, and gray (Unlikely Hikers Podcast). Another Unlikely Hiker community member expresses her frustration in her post's caption, "Finding a pack was harder than finishing my degree and I definitely cried more about it" (see Figure 3). Multiple users' posts contain laments about the lack of gear offered; another strike in the lack of representation of fat bodies in the outdoor community. Fat bodies are forced to not participate because of a lack of access to the same amenities a straight sized body is afforded. It continues the rhetoric that fat people are not active and thus the fault of fatness continues to lie with the fat body that refuses to move. It is an excuse to continue to exclude fat bodies from these spaces because they are unwanted in them while simultaneously continuing to blame fat people for not being in these spaces.

Though there are some bright spots for fat people, however, as outdoor gear and clothing options are slowly becoming available. For example, a backpack that fits a fat body will be available for purchase in spring 2021 from the brand Gregory. Bruso discussed in the podcast episode that she was sent one and that using it was such a profound experience and inclusive moment that it brought her to tears (Unlikely Hikers Podcast). There is also a corresponding emergence of related representation in advertising. While scarce, some ads now display fat bodies as normal, present, accepted: this is a powerful display of representation. What is displayed in this podcast episode is an example of how these virtual communities function, there was sharing of personal experiences and views, vulnerability to personal and community 
VIRTUAL COMMUNITIES FOR FAT PEOPLE

struggles, sharing of wisdom and advice, and support for one another and the community as a whole.

\section{Virtual Communities for Fatness}

Virtual community is framed in this essay as an online space where people with similar backgrounds come together to find support, comfort, connection, inspiration, belonging, acceptance, and representation of themselves within outdoor recreation. These feelings emerge from interactions with these virtual communities, that can then transcend from online into offline action in outdoor recreation spaces. This newfound willingness and ability to enter these outdoor recreation spaces is a result of the representation that is seen within these virtual communities.

This representation is important because it allows users to realize that their bodies are permitted in the outdoors, that it is okay to take up space there, and it is okay to try. You may not see another person who looks like you but you know that they exist, and you have a community symbolically with you and supporting you from your pocket. The connection that is made in a digital space then allows a user to go outdoors, where their bodies are seen as taboo, but they have their portable community pushing them and encouraging them to occupy that space. Community members then share their own ventures into these spaces by taking a picture, posting it, using certain hashtags and tagging certain Instagram pages to tell their own story which, in turn, motivates other users, further meshing the poster into the community.

\section{The Communities}

Though communities for fat people exist across multiple platforms, the primary platform that is used is Instagram. Instagram serves in this study as the main vehicle for the sharing of images and stories that contribute to the creation of community. Due to these communities existing online, there are barriers to access. A community member must have access to the 
internet. Furthermore, because the content is shared over social media, a smartphone is the ideal tool to take part in the community. Therefore a boundary to access exists because a potential community member must have access to the technology to be able to use the platform as well as a level of skill to navigate both the technology and the platform.

Many of the people who post and take part in these communities are women, and they are creating and participating in a virtual community to provide safe spaces and representation, which is an important aspect of these virtual spaces Fat women are often in a state of discomfort while moving through the world, this safe space of an online community serves as a break from that discomfort. (Hynnä \& Kyrölä, 2019). These virtual communities for an "Unlikely Hiker encompasses anyone who doesn't fit that image. Bigger body types, people of color, queer, trans, gender nonconforming folks, differently-abled people and so on. The people you don't see in the outdoorsy ads" (Unlikely Hikers).

These communities offer a chance for fellow members to fill the void of a fat role model in a 'fit' environment. In addition to providing role models to community members, these posts also prompt people to become their own role models, therefore creating a cycle of community members functioning as role models for each other. This cycle, and mutual role model status, allows permission to take up physical space on hiking trails and mental insight into the power of what a body of community members can do.

These communities come with the confirmation that even though you may be the only fat person on the trail you are on, you are not the only fat person on a trail in the world. They help rid the notion that, because you are fat, you must whittle yourself down to palatable bites for society until the fat body is metaphorically and literally occupying as little space as possible. These communities are scoffing at these ideas and instead actively encouraging fat bodies to take 
up space, one community member simply stating, "fat people do not exist with the sole purpose of striving to take up less space" (see Figure 4). Instead these communities celebrate the fat body and the space it takes up in outdoors spaces that have traditionally been off limits to fat bodies. There is encouragement to quell the fear of visibility as one user states:

Hiking helps free me from the soundtrack of 'too fat' that has been constant in my life. I have spent a lot of time trying to hide my size, as if I could spare people the inconvenience of seeing me. It's an exhausting way to live. But out in nature, I've realized I can just concentrate on what I'm doing and I don't feel too fat. In fact, I feel like the right size...(see Figure 5)

There is also a notable effect on mental health when interacting with these communities and learning about fat liberation. Afful and Ricciardelli (2015) report three major benefits from interacting with online fat communities, "a sense of empowerment about their bodies, an increased sense of social connectedness, and improved mental and physical health as well as well-being” (p. 458). A feeling of inclusion, representation, and visibility is cultivated in these communities and fiercely advocated for with every story shared about fellow fat hikers.

The next two sections will highlight two influential Instagram communities that aid to provide representation of the fat body; these are Fat Girls Hiking and Unlikely Hikers. Though seemingly doing similar things for the community there are distinct differences between them.

Though their mission statement describes their community as for all who do not feel welcome in the outdoors, the name 'Fat Girls Hiking' excludes those who feel unwelcome for other reasons. Due to the word 'fat' being in the community name those who post in this community are forced to 'come out' as fat. The name also promotes inclusion in the gender 
binary. Therefore, the name alone creates a barrier for people who do not identify themselves as fat, plus size, bigger, chubby, thick, etc., on the one hand, or girls on the other,

Each community also employs different posting styles. Unlikely Hikers posts more frequently, highlights individual stories of those in the community more often, and also highlights people who are 'unlikely' for reasons other than being fat. Fat Girls Hiking post more meetups with community members, highlights the ambassadors from around the world, and the founder has a stronger presence in the images on the page when compared with Unlikely Hikers. Though existing in the same realm and sharing the same values and formal trends within the community, these two communities serve different purposes within it.

\section{Fat Girls Hiking}

The community of Fat Girls Hiking has a presence on social media as well as their own webpage with a motto of "Trails Not Scales," and a commitment to "take the shame and stigma out of the word FAT and empower it... [and] to create a space where fat and marginalized folks can come together in community to create safer spaces in the outdoors" (Fat Girls Hiking). Fat Girls Hiking began in 2015 and has amassed 33,000 followers on Instagram, 15,000 likes on Facebook, and has created an offline community of 29 ambassador chapters across the United States (Greene, 2019) and also has global ambassador chapters in the United Kingdom, Canada, and Sweden. By posting to this community or being apart of it, there is an outward acknowledgement that the poster 'come out' as fat; "[this] demands fat women recognize they are seen by the world as defined by their fatness" (Afful \& Ricciardelli, 2015, p. 464). To post within the community and to proudly label yourself as a 'fat girl hiking' allows the person to reclaim agency over their fat body and to claim a title that society deems as inferior: to confront that label and not hide from it. 
It began with a hashtag of \#fatgirlshiking, and morphed into a community for those whose bodies are taboo in the outdoors, and helped them to realize that there are no restrictions of who belongs in the outdoors. One of the cofounders, Summer Michaud-Skog, stated in a REI interview, "That's the most important thing for us: Building community, bringing people together, and listening to their journey about how they're struggling, overcoming body shame, how they're learning to love themselves. It's honestly the most amazing thing when you bring people together like that" (Wastradowski).

\section{Community Posts}

This community features posts from members highlighting their experiences and showing the different ways each member feels about being a 'Fat Girl Hiking'. Some showcase the meetup hikes and discuss the constant fatphobia that is being dealt with and produced each day. One such post reads:

Fat Girls Hiking is fat activism. We are radical. We are fat positive. We are body liberation. We celebrate fat bodies \& other marginalized bodies. We want to upset the mainstream narrative that fat-bodied folks should try to change their bodies. If you'd like to consume media that perpetuates fatphobia...you're in luck--it's EVERYWHERE...At

Fat Girls Hiking, we will continue to celebrate fat bodies just as they are...(see Figure 6) Other posts highlight the struggles that community members face on the trail, but this virtual community serves as a reminder of all they are capable of. One poster writes:

Hiking is pretty new to me, but I fell in love with it. But it's not easy to be a \#fatgirlhiking. Especially one with asthma. Sometimes I'm so self-conscious on the trail when I have to stop and others stroll by. But that's why @ fatgirlshiking is so important to me. I get strength from knowing I'm not alone (see Figure 7). 
Another community member declares how she has felt stigma hiking while being fat, but encourages everyone to not shrink away because of it. She describes how has felt stigmatized for wanting to partake in the fitness world and look cute while doing it, but ultimately she refuses to hide her body and wears what she wants (see Figure 8). Showcasing the importance of community support through the thankfulness of it existing and the encouragement to dress for the activity, not to hide.

These posts often focus on the act of taking up space, instead of attempting to make themselves smaller in order to make others feel comfortable. A post declares the continued mission to take up space, "Being out in nature doesn't require me to defend or deny my size. I got grit, and I got girth. The outdoors has helped me live in that largeness. I'm already taking up more space, so I like to tell myself, 'GIRL, START TAKING UP SPACE!' Inhabit it. Live large in it"(see Figure 9). Another community member posts, "I am a fat woman, a person of color, and slow as heck on the trail - and that's ok! We all deserve to be there, taking up space and connecting with nature in the bodies we have today"(see Figure 10). Another simply states, "Fat girls hike too"(see Figure 11). These few captions exemplify the continued support, encouragement, comfort, and solidarity that the community fosters. Taking up this space means you can be fat and express a desire to take up space and not be told to quiet yourself, blend into society, and be grateful for any scraps of inclusion given out.

\section{Unlikely Hikers}

The other prominent example of these online communities is Unlikely Hikers. Though they have a presence on other social media and a website, their biggest platform is their Instagram page. Unlikely Hikers describes their community as "a diverse, anti-racist, body-liberating outdoor community featuring the underrepresented outdoorsperson. the outdoor 
industry and media has, for too long, displayed a very narrow definition of who is "outdoorsy" that isn't representative of most of us" (Unlikely Hikers). Jenny Bruso is the founder of Unlikely Hikers and created the Instagram page in 2016. Five years later, the Instagram page has amassed 118 thousand followers and has created a reach that extends past social media. Unlikely Hikers was founded in Portland, Oregon, and has been featured locally on Oregon Field Guide and in the Portland Mercury as well as in national media outlets like the New York Times and National Geographic. Unlikely Hikers exists on platforms beyond just the page itself, as people utilize specific hashtags that further community growth. The importance of this Instagram page lies within the ability to create a feeling of involvement and representation by those who post, comment, or even just view the pictures posted. There are interactions that also take place just through the hashtags that are associated with Unlikely Hikers, most prominent being \#unlikelyhiker but also under the umbrella of Unlikely Hikers is \#mybodytookmehere, which is a motto for Unlikely Hikers.

Unlikely Hikers now has a reach beyond social media, they have been reported on by multiple media outlets, have merch for sale, their own podcast, create curated lists of hiking gear, and have recently collaborated with the brand Merrel on hiking boots. Pre-COVID-19, Unlikely Hikers also coordinated meetup group hikes around the United States, often offering multiple hiking times that accommodate different skill sets and ability levels. Bruso comments on a post that shares one of these meetups, describing the way people pushed themselves, how the support, advice, and solidarity that was present allowed people to reach beyond what they originally thought they were capable of (see Figure 12). The forethought to provide curated hiking experiences instead of one for everyone shows the continued commitment to the 'unlikely hiker' and the support that is felt within the virtual community into the offline experience as well. 


\section{Community Posts}

The posts are the core of the community, they are at the center of this fight against stereotypes and stigma, and the community members are on the front lines engaging in the act of visibility. These posts create the community and provide the communication needed for this community to exist and thrive. They are the lifeline that branch out to find those who need it. For example, a post on the Unlikely Hikers Instagram cited that viewing this page and seeing this community inspired this person to go out on their first hike nearly five years ago (see Figure 13) and since then, this user has continued to hike and claim their space in the outdoors. Another user exclaims, "Following communities of other unlikely hikers has really been SO inspiring..." (see Figure 14) and another expresses, "I love seeing other unlikely hikers and reading their stories. I love that I found this group of folks who don't fit the mold...”(see Figure 15).

Users often express that they are slow, sweaty, worried, and insecure about being on the trail, but also acknowledge how the importance lies within being out there, moving their bodies, seeing everything they can do instead of being shamed for everything they can not. One user states, "I may be slow, but hiking is just about putting one foot in front of the other after all" (see Figure 16)._Another user on a post showing her on Coffin Mountain ( a 2.5 mile trail with an $1000 \mathrm{ft}$ elevation) in Oregon and on Molalla and Kalapuya land writes:

I completed the 52 hike challenging in December. I didn't break any records in distance or elevation gain, I am almost always in the back and I complain a lot. I worry so much about being able to accomplish things that others do to the point of not wanting to even try. I have spent most of my life looking forward to a time when I will be at some ideal weight or aesthetic and my life can begin. I have apologized in so many ways for just taking up space and even existing. I think hiking has taught me that I am more capable 
than I imagined, I deserve to feel free and to move. I deserve to take up space and enjoy my life now because it is happening and there is no looking back (Figure 17)

Many users also share their accomplishments with the community, often sharing personal milestones and the vulnerability behind why they mean so much. These posts show the mutual vulnerability, sharing, support, body insecurity, body acceptance journey, and encouragement that is afforded by the community. One user states:

I rarely post full-body pictures of myself. They make me uncomfortable. That being said, I have found happiness in recognizing my own strength; the strength this body and spirit have. I have overcome so many physical, mental and emotional obstacles with this body. I am learning to appreciate it, forgive it and love it, one day at a time (see Figure 18) Other accomplishments openly confront the fact that the community members are fat and they did this, "In case people didn't notice, I'm fat. Yup, and I still hiked 5 days on the AT...After the hike, I felt enlivened, empowered, proud of my accomplishment and inspired to challenge myself to more..."(see Figure 19).

Community members share their worries about how they initially would be viewed on the trails and their commitment to continue despite these judgements, "When people look at me, they don't see a hiker, to be honest neither did I. I used to love hiking but I've always been afraid of what other people thought when they saw me huffing and puffing on a trail'(see Figure 20). But still many more posts about overcoming these fears of judgements and how thankful they are that they did not hold themselves back. They discuss how continued interactions with these communities continue to push and inspire them to do the things that society says they can't or aren't allowed to because of their bodies. One post reads: 
"I am thankful I didn't let society's influence tell me that I couldn't go hiking in a 'moderately strenuous' cavern with my $330 \mathrm{lb}$ body because I did it and was rewarded greatly by beautiful stalactites and stalagmites. I am grateful that other fat folks, differently-abled folks and other unlikely hikers around me prove daily the outdoors is for all of us!" (see Figure 21).

There are also themes of appreciating the body you have, thanking and respecting their bodies for all that they are doing, and not getting distracted by what society assumes they can't do. These captions provide the support and realization to viewers of them that you can thank and respect the body you inhabit. Some captions reading:

I've always been a big person. My thighs have always rubbed together and I've always had to breathe harder because I have a body that needs more oxygen. I've often heard whispered doubts about my ability because of my size. But getting out on the trail, I feel small in a good way. My thighs rub the branches and ferns and the oxygen that fills my lungs is restorative. And I always make it to where I need to go (see Figure 22) There is praise for their bodies, admiration for where they have carried themselves, and respect for the work they do each day with each breath and each step taken. One community member describes this journey internally and the physical journey their body takes with each trip:

Being plus-size my entire life, I believed in the lie that I could never lead an active life, that I didn't belong to that 'club.' Once I discovered the great outdoors, my life was forever changed. Never would I have thought that my legs would carry me along dirt paths, meadows, along high ridges, or through deep valleys. Or that my lungs would breathe in deep mountain air and my eyes would gaze upon the darkest of nights as stars danced above my tent. Being out on the trail has given me freedom, love, and joy...It has 
been a joy to discover that my body is capable of so much more than I ever imagined. We are blessed with our bodies, no matter size, race, or gender we are all capable of so much more. To discover, to see beauty, to enjoy the journey. Proud to be an \#unlikelyhiker and show the world that different is beautiful (see Figure 23)

\section{More Community Examples}

These communities also exist through the use of hashtags on social media. These hashtags allow the community to expand to exponential lengths, with the specific pages listed above, Fat Girls Hiking and Unlikely Hikers, a community member must be reposted by the account after either sending their picture directly or being found in the hashtag by the page owners in order to be reposted. Some are associated with the specific organizations mentioned above and some exist on their own, separate from organizations. Hashtags such as: \#fathiker, \#healthateverysize ,\#takethelongway, \#fatandoutdoorsy that allows users to post and connect with others through the virtual community that the hashtag offers. This barrier does not exist when employing any of these hashtags. By using any one of them you can instantly become an image in this community, and whatever story that is highlighted within the caption joins the stories and reaches people who see it.

There are also a multitude of other community pages that have the same functions and serve the same community as Fat Girls Hiking and Unlikely Hikers. Other communities highlight the fat adventurer in different ways, such as @fatwanderbabes that dedicates their page as a "space for all the plus size wanderlust babes out there hiking and traveling. Another page serves as a community for the fat traveler, @ fatgirlstraveling describing themselves as "fat activism through the travel lens". A page called @plussizeretreats covers the fat adventurer in the outdoors, exclaiming “empowering plus size women outdoors. We can do ALL the things!”. 
These communities also promote each other by posting each other's images, tagging their pages, and sharing insights about fat liberation and the fat body. The amount of hashtags to connect fat outdoors people to each other and the amount of accounts that are dedicated to representation of fat bodies in the outdoors shows how vast and expansive this virtual community is. Displaying how a community member or potential community members are never alone in their pursuits of adventuring in the outdoors.

\section{What Makes a Post?}

The posts within these communities consist of three major elements: the person, the location, and the caption. The first element and one of the most important within the context of this study is that of the person's body in the image; the subject most commonly includes their whole body in the frame. This is a radical statement of rebellion, as the display of the entire fat body is an act of visibility and a statement of claiming space. These images where the fat body is unapologetically displayed is then shared with the virtual community of peers as well on a platform that is accessible to millions of people. The declaration of visibility that community members demand with these images is powerful for not only the poster, but also for the viewers. Seeing oneself reflected and represented in full can be life changing. It can grant the viewer permission needed to acknowledge their own body for the possibilities it holds, the physical work it does, and allows for the desire to care for their body as it is.

\section{The Body}

There is an importance in the display of a poster's body and it is integral to the creation of a community for fat people in the outdoors. All of these images are displaying the capabilities of fat bodies while defying the lazy and sedentary stereotypes that adhere to the fat body. Posting these images lets others know that you are aware and embracing your body, that your body does 
not have to be a secret hidden from the world and from yourself. Community members often discuss the power of seeing similar bodies to theirs, explaining this experience in the caption of a picture of their whole body:

I have recently followed a lot of body positivity Instagram pages and they have slowly helped me be more comfortable at the thought of having pictures taken of me while I'm outside doing the things I love. It's hard to feel included in the outdoors when a lot of the photos of women I see on the explore page, and even my own Instagram feed, are almost always of thin, white and usually blond women looking perfectly put together on top of a mountain or something to that effect. It gets tiresome feeling like I don't belong on hiking trails or long hikes until I've 'lost weight' or 'gotten more fit.' Being fat isn't the worst goddamn thing a person can be. Everyone deserves to feel welcome in outdoor spaces. So here's a picture of me, super happy to be hiking again (see Figure 24)

This representation of fat bodies is incredibly forceful and a powerful life changing moment for people who also live in a fat body. They are shown in tight leggings, tshirts, sports bras, shorts, and swimsuits. These clothes further defy the 'norms' of society. Fat people are not supposed to wear anything that lets the world know they're fat, that shows too much of a roll or skin that the world deems deviant. This ideology about policing what the fat body can wear infiltrates people's minds until fat people fear having themselves photographed because of the sustained and now ingrained shame towards their own bodies. One user expresses in the caption of a picture displaying their whole body, "I rarely get photos taken of myself because I am usually out adventuring alone, but the main reason is because I am so self-conscious about my body that I don't like almost every photo taken of me. I am not the typical body you see posted all over Instagram"(see Figure 25). This sentiment is common in these posts. Many fat people 
express that the shame they carry because of their bodies is so strong that they do not even want it photographed. These communities and the representation they provide serve as an integral part of the acceptance of their bodies and allow members to find the strength and courage to take the picture that fear and shame has prevented for so long. One community member reminds herself and others of the work their bodies are doing and how important that is,

Normalize bellies. Normalize rolls. How many times have you not taken a picture because of how your belly looked? How many memories are you willing to not capture to hide your body? When I snapped this backpack on I had a moment of panic. Do I look too big? Will people think I'm too fat to wear this? Should I even take photos? Then I remembered: I'm walking up a mountain with a $201 \mathrm{~b}$ baby strapped to my back. I'M A F*CKING BADA\$\$!! (see Figure 26)

This caption ended with the reminder to "Take the pictures, wear the shorts, know that body rolls 5 are normal!!'(see Figure 26), this is encouragement to actually live in the body you inhabit now and not to wait until an 'ideal' body is achieved. One user discussing the joy she finds in seeing pictures of herself in nature, "I actually like seeing pictures of myself in the cool places I've carried myself to. It's not a complete transformation; I'm still working through lots of hang-ups and shame. But we all deserve to shed those things and heal'(see Figure 5). There is an intense importance to acknowledge and respect (and not resent) the body you're in, to share this feeling, post the photo in the community; to let people see your body and let viewers know that even though it may be scary, it is okay to be visible and go out and physically occupy space.

There is also permission granted to just acknowledge that you live in a fat body and that it's okay, a permission to deweaponize the word fat and the status of the fat body in the world. 
There is a freedom from the pressure of changing the fat body because these communities are not about weight loss, they are about empowerment, inclusion, and representation. One user writes about her journey from viewing hiking as a weight loss venture to realizing that she can enjoy her body as it is now,

...if I'm truly honest, I first viewed hiking as yet another weight-loss venture. Around this time, I began regular strength training and realized how powerful my body is and how important it is for womxn like me to be present on trails, to take up space, and to be unapologetic about our presence. I've moved away from trying to control my shape and size (see Figure 27).

More users express how this community and the act of hiking let them "finally feel comfortable just EXISTING”(see Figure 28) or realize that their fears of entering these spaces was eliminating an entire realm of adventure in their lives because of their perceived limitations (see Figure 29).

\section{The Location}

The second element that is featured most prominently in these images is the location. The act of being outside and the location of being on a trail or in a campsite is important, because, showing the fat body in these outdoor spaces is another act of defiance. The location plus the fat body brings to the forefront the notion of creating representation that is lacking. These locations include trails, summits, mountains, rock climbing, and rivers, all locations enhancing the fact that the fat body is now engulfed in nature. This positioning of fat bodies in the outdoors also shows other community members that it is possible, and encourages them to take up space and reminds viewers and community members that there are no predetermined characteristics of an outdoors 
person or adventurer, one user simply stating, "mother nature embraces us completely as we are"(see Figure 14).

Fat people are taught and expected to deprive themselves of opportunities and adventure because they are fat. There is no room for fat bodies on trails, in oceans, on surfboards, rock climbing, mountain biking, jet skiing, synchronized swimming, or any other adventure activity that mainstream media excludes fat people from. These communities defy preconceived notions, challenging society's views of fat bodies and fat identities, providing representation in these communities, and telling the people in these communities to join them and that their bodies are fine as is. One community member discussed her journey with her body and hiking, A few years ago when the idea of hiking was brought up, my initial reply was that I needed to 'get in shape' first...Last year when I was asked to go hiking my immediate reaction was fear - fear that I would be too slow, that I would have an asthma attack, that I wasn't meant to be on a trail. But I went, and then I kept going. I still have those fears, but it feels different now. I know that my body is capable of taking me great places. I know I can go at my own pace and celebrate my own little accomplishments. I used to let my fears hold me back from the outdoors... [Now] I want to take myself to see all the things, afraid I might lose my momentum. I'm done stopping myself from doing. (see Figure 30)

\section{The Caption}

The third element that is important in these posts though not a part of the image is the caption. The caption brings together the image and the feelings behind it, the importance of the person's feelings and stance about their place on the hiking trail, in the outdoor community, and within the fat outdoors community. Often community members will discuss the ostracization 
they feel on the trail or in life because of their size and how despite this they know they belong there. This acknowledgement of belonging extends into telling the reader of the caption 'you belong too', encouraging anyone who has the desire to go explore and adventure. Some posts directly state this, extending the invitation to the reader stating that if you want to be in the outdoors you can be, encouraging them to go out and take up space. Other posts extend this message in a different way through sharing their struggles in life or on the trail, there still exists the message of 'you are not alone'. The setting of social media also promotes the act of sharing but these communities allow members to share in a safe space where their vulnerabilities can be understood and supported. This encouragement often has tones of defiance and rebellion, with one user declaring:

You belong outside. You can take your shirt off when it's hot. Wear shorts, wear your sports bra, wear tank tops. Let your arms and legs breathe. Stop letting people tell you or make you feel that you can’t wear what smaller people wear. Don't let anyone make you feel like you have to make yourself hidden or uncomfortable"(see Figure 31) These captions can communicate different kinds of meanings. There is a declaration of being visible, taking up space in the outdoors physically and virtually without the need for permission to do so, while simultaneously granting the permission through representation for the people who need it. Another form of community support is also shown through the responses by the page owner to the comments left on these images. There is moderation of the comments to ensure a feeling of support and community is kept, and to ensure that it does not become a space for those who view that fat body with disdain and air their opinions. Edits can be viewed within the caption to posts where this has happened, making statements addressing the comments that took place and why they were removed. Other times when there are specific attacks on the poster's 
body there is a bold statement to deal with it. For example, on a post where a community member is in a sports bra there is an edit added declaring, "ATTENTION: if you are offended by big bodies flaunting themselves, prepare to be BOTHERED ALL SUMMER !!! bc we dgaf anymore! We're out her and we love it" (See Figure 31).

Fat people are not supposed to feel anything but disdain for their bodies, but these communities show appreciation and respect for fat bodies from the person who lives in them while receiving support and encouragement from other community members. One user sentimentally reflects on her body after a hike, "proud of all my curves and folds and rolls $\checkmark$ they blessed me with a beautiful hike today!'(see Figure 32). Posts and declarations like this speak to other members of the community and let them know that you can thank your body and you can be proud of what it does for you.

\section{How These Communities Function}

An important notion that is ingrained in these virtual communities for fat people is that this is not about weight loss, Jenny Bruso, founder of Unlikely Hikers, hopes that this online community cultivates "a relationship with the body [that] is free from the weight of words and made up value judgements...[that] hold us back from loving our bodies and doing something" (Unlikely Hikers Podcast). Fat people are always constantly aware of how much space they are occupying, there is no spontaneity in movement when you are a fat person, every action is thought about, calculated to account for how in order to know how much will be occupied. These communities allow the realization that there is no weight limit or size restrictions on a hiking trail. The representation that these communities curate is empowering and celebratory of being in your body, "Seeing bodies that look like yours move and hike and adapt is powerful...It lets fat people know, we belong here" (Greene, 2019). 
These virtual spaces have the opportunity to be taken offline as well, either individually or through meetups that are organized virtually. The ability to have in-person and organized hikes where your body and ability are taken into account as the day goes on; you don't passively belong in these spaces, you aggressively belong in them, whether that is online or off. Both communities actively address that being out in nature and moving your body is not about losing weight or 'fixing' your body. The briefing before a group hike often contains the rule of no bad body talk; do not wish you were faster or chastise your body for what it is not doing and do not worry about being 'too slow' for the group. Leaders of these hikers often lead from the rear so that no one gets left behind, and there is an acknowledgement of different skill levels and abilities but a mutual understanding that everyone is there to provide support for one another. These offline opportunities bring the online support to the physical space. People who attend are viewing bodies like theirs in the outdoors, physically taking up space at the same time their body is there and doing the same thing. A cycle of empowerment is created from the online community that bleeds over into offline experiences.

\section{Nature as an Entity}

Nature also has a role within this community. It provides the physical setting in this community and does a service for those who make the journey to inhabit it. The process of going into nature provides a physical separation from mainstream society, though even in nature, others bring mainstream ideals into a space that should be neutral ground. For community members, this is almost ritualistic: the shedding of the mainstream media and the fatphobia that is rampant in society and embracing nature as you are. Nature does not impose judgement upon the bodies that come to it, but this does not mean that nature is a judgement free zone. The straight size outdoors people who also inhabit nature still bring their judgements and stigmas onto the trail or 
up onto the mountain. There is an interesting overlap between nature and social media in that they are both public ventures, and in each space a person can be subject to social expectations. Once entering the space, digital or physical, a person is both claiming space and being exposed to either judgement or support.

When fat bodies move through nature they are not afforded the same opportunities that straight sized bodies are, in part because they are seen as 'other' in nature and taboo being on the trail. A space of reclaiming agency for one group is a space of privilege for another. Fat bodies must fight to find the knowledge that they can enter and inhabit nature. The creation of what an outdoors person looks like is a creation by society. It is not a natural or inherent symbol of who belongs or who can enter and experience nature. Fat bodies are not unwelcome outdoors and there is no weight limit to experience nature, and in reality the judgement does not come from nature, but from others. One community member speaks about movement in nature in a fat body: Joyful movement and nature are for everybody and everybody. Media will tell you that living in a fat disabled body means you don't belong on the trail or in the river or pretty much doing anything physical but that is a lie. Your fat, black, disabled body belongs everywhere. Keep trying new things, keep hiking or rolling or driving to and through nature (see Figure 33)

Though fat bodies belong in nature, it does not rid others from thinking they do not belong, and it does not create an environment where all differences are balanced out. These judgements pushed onto fat bodies may not always take the form of a negative comment, they may come from straight sized people who think they are being encouraging. Community members discuss the cheery comments from straight sized hikers like "good for you!", “keep going”, or "it's so amazing you're out here!'. These phrases may be intended as support, but they are actually 
bringing society's process of stripping fat bodies of agency into nature through assuming a fat body's skill level or purpose for being there (see Figure 34).

These communities allow fat people to discover their own capabilities, to realize that they belong there. Nature is not passing these judgments, nature will accept the fat body. A community member writes:

I never saw myself as a hiker. I always thought the term 'hiker' was meant only for athletic, slim people...I did not think the outdoors were meant for me, but something changed a few years ago. I started using hiking as my own personal therapy. The more time I spent in the wilderness, the more I realized that nature does not judge. It does not care about your body type or how many push-ups you can do. It only rewards those who are brave enough to embrace it...(see Figure 35)

Another community member simply sums up her realization as, "That no matter what your body looks and moves like, if you want a relationship with the outdoors, it wants one with you"(see Figure 36). Many note that nature does not judge you and it wants you there, “...as if to say, 'this activity is not for you.' The mountains beg to differ, and these trails are constantly calling us home. They don't care how gay we are, or how fat we are. They don't care how long it takes us to reach a summit, as long as we continue to put one foot in front of the other" (see Figure 37)

\section{Intersectionality}

Virtual communities for fat people in the outdoors are inclusive by design. Though this study focuses on fat bodies, fatness is not the only identity that people within the community have. These virtual spaces are for everyone who is seen as different from the norm. This includes people of color, Black people, disabled people, people with different religions, different genders, 
and sexual orientations. These virtual communities make a point to acknowledge the different identities that exist within people through the way the communities posts, captions and images function in order to acknowledge different identities, because the communities' posts, captions and images function in order to acknowledge intersectionality, Users often explicitly write about their varying identities and how they are often gate-kept from the outdoors because of them. For example, captions often contain the pronouns of the people in the images to include all genders, a detailed description of what the image is, land acknowledgements to honor Indigenous land, and highlighting these different identities throughout the posts.

In addition to highlighting intersectionality in their online communities, these communities also create specific offline experiences that cater to people with different needs. For example, Fat Girls Hiking builds retreats around people with disabilities called 'No Fatty Left Behind' so that people with disabilities can also access the outdoors. One post expresses, "We enjoyed the ADA accessible trail through mossy forest with many benches, the Salmon River and fun features for folks of all ages...”(see Figure 38). Jenny Bruso founder of Unlikely Hikers has also spent time measuring and scouting trails for those who are in a wheelchair. Hashtags such as \#nohikerleftbehind and \#accessibleoutdoors are also used.

Even though there is encouragement to share different experiences a continued focus on whiteness still persists in the outdoor community as well as in the fat liberation community (Hynna \& Kyrola, 2019). Hikers of color or Black hikers are not seen in the outdoor media, and fat or plus size hikers of color are rarely seen in the media. Many Black hikers or hikers of color are actively discriminated against on trails and verbally told that they do not belong. Graham (2020) describes it this way "there are risks to being Black in the outdoors" (p. 3). These risks are rooted in the racism and white supremacy that still exists. Graham (2020) speaks about the 
fear and caution that Black hikers and hikers of color live with; the way they are made to feel like they do not belong even in nature, and the many ways people are murdered for being Black. Graham writes,

If there's anything I appreciate about the crucible we're living in, it's the role of social media in creating a place for us when others won't. We're no longer waiting for outdoors companies to find the budget for diversity, equity, and inclusion initiatives. With the creation of a hashtag, a social media movement, suddenly we are hyper-visible, proud, and unyielding (p.8).

Many posts from community members highlight how these facets of their identity initially made them feel like an outsider in the outdoors. Despite this, users are continuing to carve out a space for themselves both online and offline. One user writes about being a Muslim hiker, "I've always had a love of the outdoors. Being a fat, Muslim woman makes me an Unlikely Hiker. When I started wearing a headscarf and practicing hijab (hijab $\neq$ headscarf) I became apprehensive about hiking. The bias towards Muslim people in the news made me cautious. However, I couldn't see myself *not* exploring the outdoors..."(see Figure 39). Many community members highlight their many existing identities in posts expressing statements like, "I am usually the only brown, fat woman on any trail I hike on and any campsite I set my tent in"(see Figure 40) another other users exclaiming and declaring their place on the trail (see Figure 41 and Figure 42)

Many posts within this community highlight the experience of intersectionality because these identities were not represented in the outdoors, and for many years they never thought the outdoors could be a place for them. Even if they grew up with a love of the outdoors, this love was snuffed out by the judgements of others and the lack of representation. One community 
member expresses, "As a black woman, growing up I used to love the outdoors, including camping \& hiking. But being plus size, I never felt I belonged there as if I could feel the judgment. And being black, I didn't see people of color represented outdoors or in outdoors magazines...'(see Figure 43). Having multiple identities, it can often feel as if you are alone, "When I first started out hiking, I would count to see how many black and fat people were on the trail. Usually, there were none but when I did, they were never both like me...” (see Figure 44) even if physically on the trail there is no one like you, these virtual spaces provide the community to let people know they are not alone in their adventures or desire to be a part of the outdoors.

\section{Not A Magic Fix}

Though these communities serve an important role for people, and it promotes a feeling of belonging and support it is important to know that this is not a cure-all. These communities are not a utopian paradise -- they are not so straightforward. Just because one is involved in this community either actively or passively does not magically mean they are over fat shame and bodies issues. But it does mean that they will have support and people to look to while they try to conquer these feelings. The act of partaking in these communities is a way to manage the exclusion and trauma that fat people are exposed to while moving through society, but these veins of trauma persist. But while these feelings around body shame may persist, it is also important to know that many people involved in these communities are happy with their bodies. Sometimes the shame and happiness exist at once in the same person.

Another important aspect of these communities is that members acknowledge that just because they enjoy hiking and the adventure that comes with it does not mean that they 
magically overcome the physical requirements of it. It just means that they are doing it. One community member states:

At $340 \mathrm{lbs}$, I am not what you think of when you picture a hiker. I am often slow and have to take breaks to let my heart and lungs catch up. I have Asthma, Plantar Fasciitis, bad knees, and a bad hip. But I hike up mountains and I'm not going to let my weight or other issues stop me. Hiking is a way of life for me and my child. It is my primary form of exercise and therapy and it has given me calves of steel. I may be the slowest one on the trail, but I am infinitely faster than those who didn't try (see Figure 45)

Many community members acknowledge that they remain slow, that their breath is ragged as they move on the trail, that they feel the fatigue, they feel the sweat dripping down and still think about the desire to quit, but they do not. They push through and go as far as they can and they feel and acknowledge all these things their bodies are feeling, respect their bodies instead of diminishing their bodies' performance and scolding them for being slower than others. One community member posts her image at a waterfall reflecting on the journey to get there:

Some days I can walk for miles and miles. And some days, it seems that I go nowhere. This weekend, I felt the latter... And that was ok. I took more breaks than I walked miles, and in doing so, I told my body that I cared about it. I cared about how she felt, I cared about her struggles and apprehensions, and I cared about her from a point of love and not hate. And in doing so, I cared about myself and everything that I am... The way that I am. Nothing more. Nothing less. I don't think I've ever felt so liberated (see Figure 46) For many, these fears exist while venturing into the outdoors to claim your space as a fat adventurer but these virtual communities help quiet the fear and promote a change in mindset. There is a whole community of people who want to encourage other fat bodies to shed the 
mainstream notions of what bodies 'should' look like and instead live and embrace the bodies that a person exists in now. Though fears remain, knowing that there are people with fat bodies hiking on trails, rock climbing, summiting mountains, and participating in a variety of other outdoor activities, makes all the difference. That support exists in the virtual community carried in their pocket. The simple declaration of 'fat people hike too' can be life changing.

\section{Conclusion: The Future of Virtual Spaces}

Virtual communities for fat people in the outdoors can only continue to grow and gain more mainstream attention. The only threat to the community (because it is so dependent on social media, and Instagram in particular) is the trend of the masses moving on from social media platforms to newer ones. However, new profiles could be made on new platforms. It seems that fat communities will find a way to exist and reach others in whatever online space that is available. The future of these communities also continues in the fight for representation in the outdoors and visibility of the fat body in general. The potential for growth is there. This expansion aids in the normalization of fat bodies but this increased visibility does not mean that these communities will become irrelevant. Both Fat Girls Hiking and Unlikely Hikers are recent creations, their follower counts, engagement, and recognition continue to increase. The role of social media within this study and its parallel relationship with community members raises an important question: is social media interfering with the experience of being in nature?

In the future there is also the concern of if there will be a turn when branding overtakes what the community is built on, or if expansive branding would be considered as a win for them in terms of representation. This is a complex issue because representation would be greater, but does representation in this form cheapen the result? While Unlikely Hikers has collaborated with 
major brands, these answers still remain unknown because these communities are still growing, evolving, and finding their way.

Virtual spaces for fat people in the outdoors provide an opportunity for connection, comfort, support, inclusion, self-empowerment, and representation. These community images contain three main themes that highlight the importance of how these connections and resulting feelings are fostered. Images consist of the body, the location, and the caption and through these vital pieces, the post creates feelings of inclusion, support, and empowerment.These posts are a chance for fat bodies to obtain permission from other fat bodies to feel empowered and to feel other emotions beside hatred for their bodies. It provides a juxtaposition of giving other fat people the permission to not need permission, and to virtually and physically go out and take up space in the outdoors. This act of taking up space and encouragement to go into outdoor spaces allows fat people to reclaim agency over their fat bodies, to learn about all the things their bodies are capable of rather than being forced by society to think that they are not capable because of their fat body. 


\section{References}

Afful, A. A., \& Ricciardelli, R. (2015). Shaping the online fat acceptance movement: Talking about body image and beauty standards. Journal of Gender Studies, 24(4), 453-472.

Bruso, J. (Executive Producer). (2020, August 27). Where is the plus-size gear? (N0.13) [Audio podcast]. In Unlikely Hikers. Independent production. https://jennybruso.com/2020/08/27/unlikely-hikers-podcast-13-where-is-the-plus-size-ge $\underline{\operatorname{ar} /}$

Chastain, R. (2015). The politics of size : perspectives from the fat acceptance movement Vol 2. Praeger.

Cohen, R., Newton-John, T., \& Slater, A. (2020). The case for body positivity on social media: Perspectives on current advances and future directions. Journal of Health Psychology, 1359105320912450-1359105320912450. https://doi.org/10.1177/1359105320912450

Dickins, M., Browning, C., Feldman, S., \& Thomas, S. (2016). Social inclusion and the fatosphere: The role of an online weblogging community in fostering social inclusion. Sociology of Health \& Illness, 38(5), 797-811. https://doi.org/10.1111/1467-9566.12397

Farrell, A. E. (2011). Fat shame: Stigma and the fat body in American culture. NYU Press. Fat Girls Hiking [@fatsgirlshiking]. (n.d.). Profile, Images, Captions [Instagram]. Retrieved November 2020 - February 2020, from https://www.instagram.com/fatgirlshiking/

Fat Girls Traveling [@fatgirlstraveling]. (n.d.). Profile, Images, Captions [Instagram]. Retrieved February 2020, from https://www.instagram.com/fatgirlstraveling/

Fat Wander Babes [@fatwanderbabes]. (n.d.). Profile, Images, Captions [Instagram]. Retrieved February 2020, from https:/www.instagram.com/fatwanderbabes/ 
Frazer, R. L., \& Anderson, K. (2018). Media representations of race, ability, and gender in three outdoor magazines: A content analysis of photographic images. Journal of Outdoor Recreation, Education, and Leadership, 10(3), 270-273. https://doi.org/10.18666/JOREL-2018-V10-I3-9051

Greene, S. (2019, August 30). Fat Girls Hiking Is the Body-Positive Group Trying to Change the Outdoors Industry. Teen Vogue. https://www.teenvogue.com/story/fat-girls-hiking

Hynnä, K., \& Kyrölä, K. (2019). "Feel in your body": Fat activist affects in blogs. Social Media + Society, 5(4), 205630511987998. https://doi.org/10.1177/2056305119879983

Krueger, A. (2019, May 22). 'Unlikely’ Hikers Hit the Trail. The New York Times. https://www.nytimes.com/2019/05/22/travel/unlikely-hikers-hit-the-trail.html

Kyrölä, K. (2014). The weight of images : affect, body image and fat in the media. Ashgate. Lupton, D. (2017) Digital media and body weight, shape, and size: An introduction and review, Fat Studies, 6(2), p. 119-134, DOI: 10.1080/21604851.2017.1243392

Meadows, A \& Bombak, A. E. (2019). Yes, we can (no, you can't): weight stigma, exercise self-efficacy, and active fat identity development, Fat Studies, 8(2), p. 135-153, DOI: $10.1080 / 21604851.2019 .1550303$

Plus Size Retreats [@plussizeretreats]. (n.d.). Profile, Images, Captions [Instagram]. Retrieved November 2020 - February 2020, from https://www.instagram.com/plussizeretreats/

Striley, K. M., \& Hutchens, S. (2020). Liberation from thinness culture: Motivations for joining fat acceptance movements. Fat Studies, 1-13.

Stanley, P. (2020). Unlikely hikers? Activism, instagram, and the queer mobilities of fat hikers, women hiking alone, and hikers of colour. Mobilities, 15(2), p. 241-256. 


\section{VIRTUAL COMMUNITIES FOR FAT PEOPLE}

Unlikely Hikers [@unlikelyhikers]. (n.d.). Profile, Images, Captions [Instagram]. Retrieved November 2020 - February 2020, from https://www.instagram.com/unlikelyhikers/

Wastradowski. (n.d.) Using Hiking to Promote Body Positivity. REI CO-OP. https://www.rei.com/blog/hike/using-hiking-promote-body-positivity

Webb, J. B., Vinoski, E. R., Bonar, A. S., Davies, A. E., \& Etzel, L. (2017). Fat is fashionable and fit: a comparative content analysis of fatspiration and health at every size ${ }^{\circledR}$ Instagram images. Body image, 22, 53-64. 


\section{Appendix}

\section{Instagram Community Posts}

Figure 1.

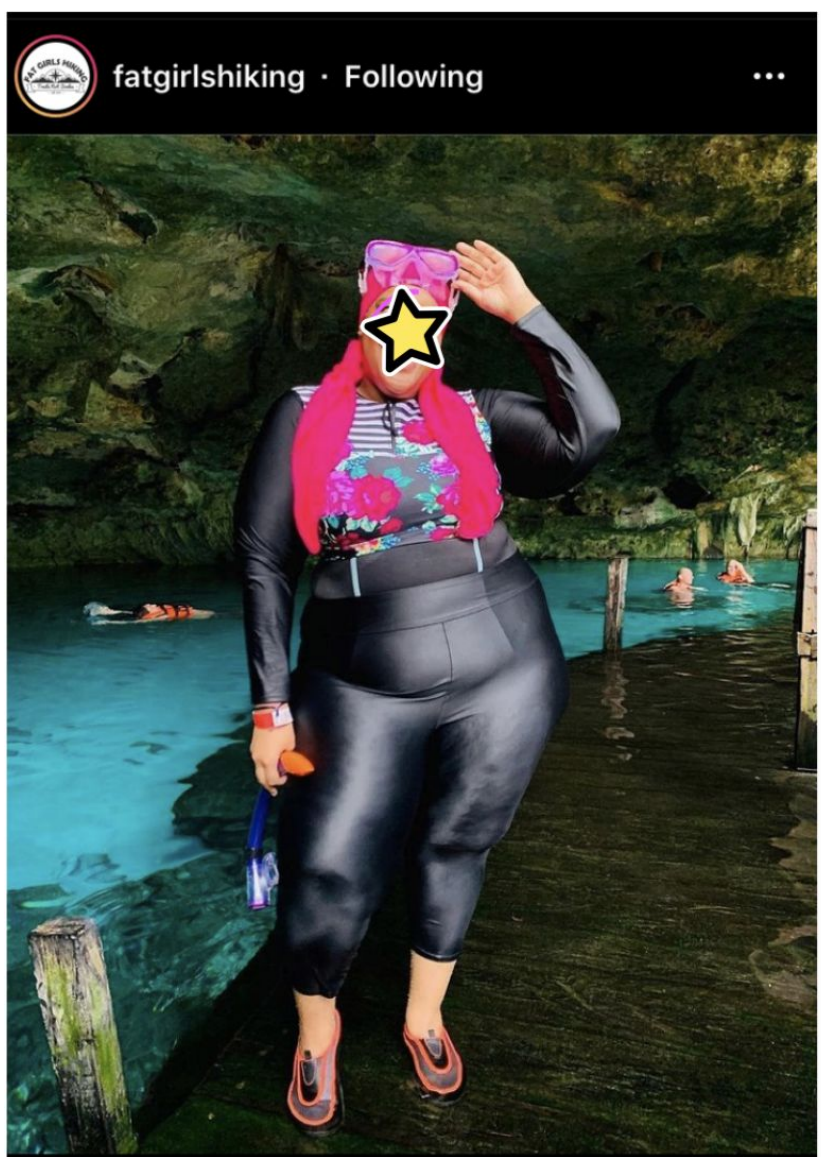

fatgirlshiking

(she/her) says, "Here's

me in my makeshift wetsuit (Cuz they don't make

wetsuits for us large folk) in the Mexican jungle in an

underwater cave about to knock jumping in a cenote

off my bucket list ?

The last time y'all saw me, my fat ass was parasailing

on an island in the Midwest and now here we are. I

am terrified of heights. Y'all be saying I'm

adventurous but I'm the most scared person you'll

ever meet. I hate bugs and I don't do the wilderness

\& But, I'm challenging myself and I'm challenging

the status quo. Fat folks can be

adventurous too

Often times, when we think of traveling adventurers

or water activities, we think of straight size folks

living their best lives. Honestly, that's all they show.

So, I'm on a quest to break the mold as well as face

my own fears. I've always been told what I couldn't

do as a Muslim. As a fat person. Looking down at

those big ass rocks and seeing the fish swimming

around in the water. Chile, I ain't even know how

deep the water was. I kept hesitating. I kept thinking what if I die?

It's a metaphor for life. What if I fail? But, we also

forget that we might also succeed. I wouldn't be able

to afford this trip if I hadn't done it anyway, done it

scared.

I did it. I jumped in. With a huge splash. And, when I

tell you that I was so proud, ecstatic. I was. And, I

didn't die. Lol.

I hope that you take this act of courage and apply it

to your biggest fear. 
VIRTUAL COMMUNITIES FOR FAT PEOPLE

Figure 2.

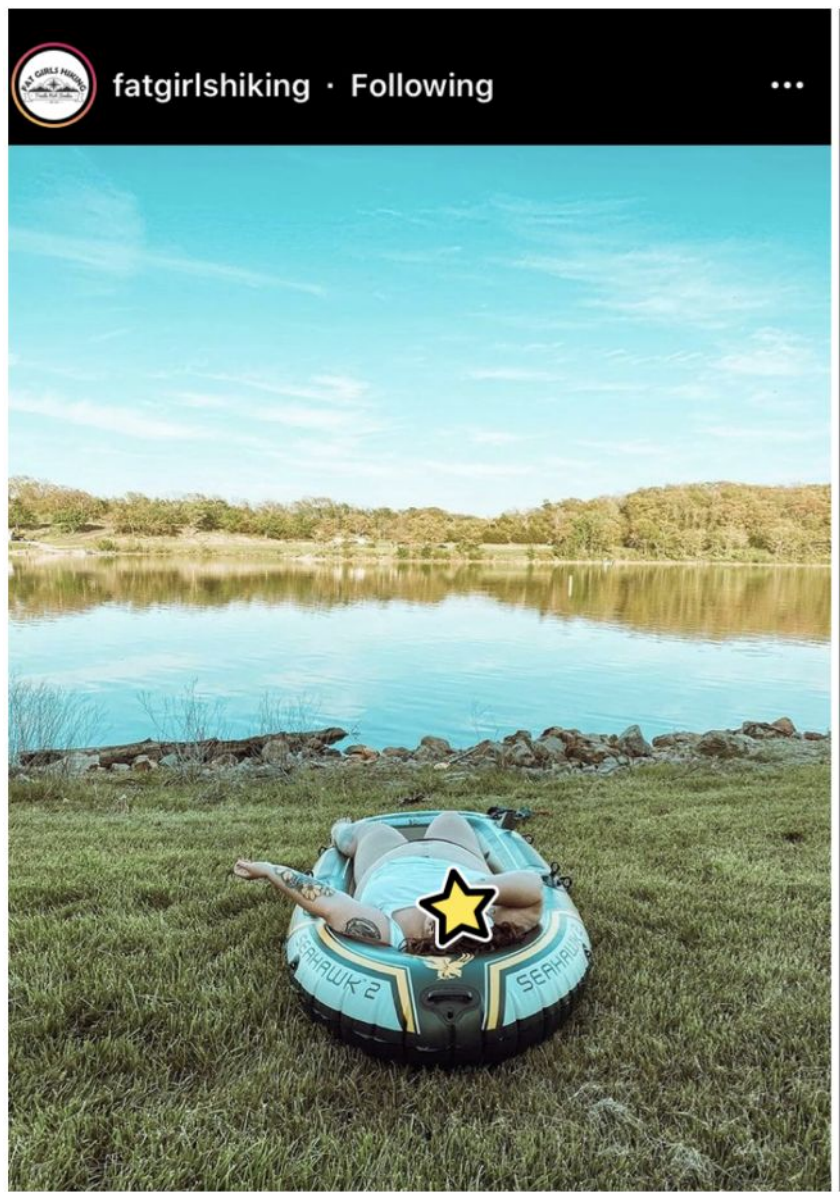

fatgirlshiking Check out

atest outdoor

adventure:

-

I have been on the HUNT for a watercraft that is able to carry my weight (I was looking only at ones that went up to 500 + cause I wanted that thing to be sturdy!) maneuverable with one person, light enough to carry on my own, can fit in my trunk, and affordable. It felt impossible until I found pack rafts. But turns out pack rafts are SO expensive. I wanted to be sure that I could get in and out of a personal size watercraft, because I seriously had no clue how it would go. So I bought this little $\$ 60$ raft (complete with oars) and I'm going to spend the summer getting used to rowing and launching on my own. Do a little crawling before I run ya know? Then decide if I want to invest in a proper pack raft

\section{BUT TONIGHT I GOT IN AND OUT IF THIS THING! helped me a lot and I made the} mistake of trying to get out on rocks which made things significantly harder. But I did it. And I thought of some ways to make it easier next time, and I'm excited to keep trying until I'm way more than only 4 feet from shore $\Leftrightarrow$ does kayaking or rafting sound fun to you? Have you ever done it? If you have any tips and tricks for beginners let me knowwwww

ps- we are practicing social distancing in all the ways right now and are not getting within 100 yards of other lake goers. We're really lucky to live somewhere that is possible right now. \#fatgirlshiking \#fgfgoesoutside \#plussize \#joyfulmovement 
Figure 3.

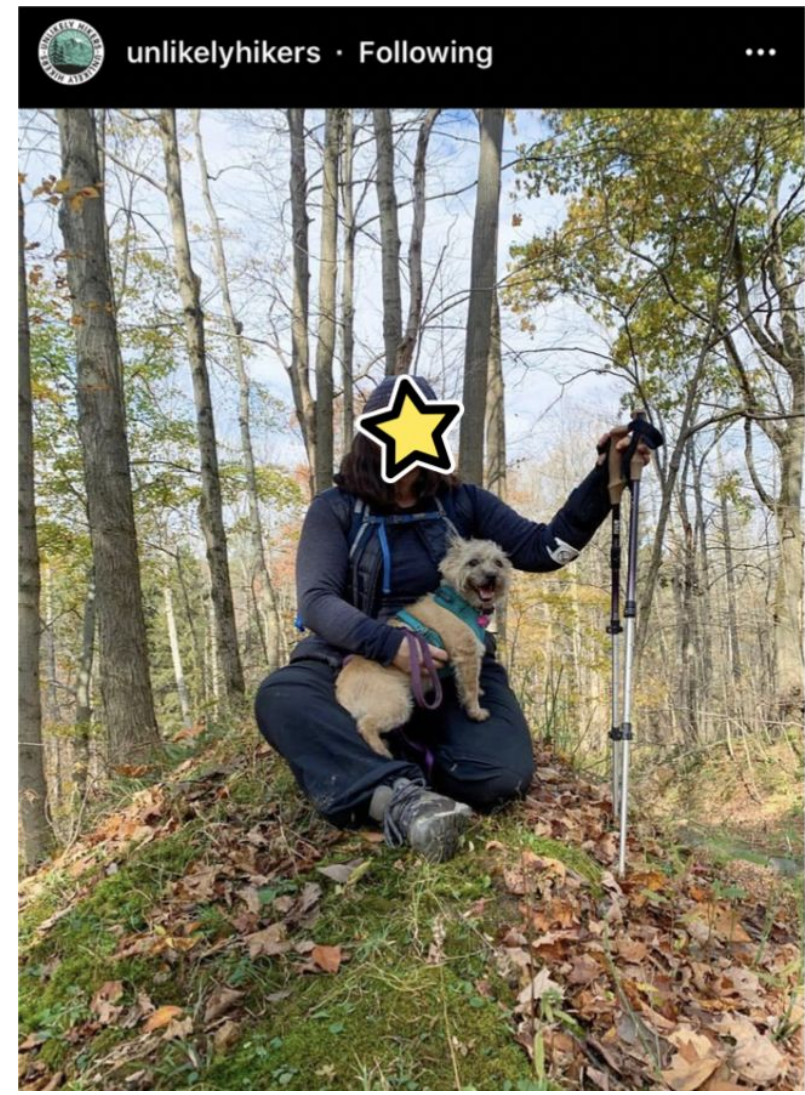

\section{7 likes}

unlikelyhikers "I used to hike about once a month. Then, as I was getting more in to it, I suffered a nasty back injury that took several years to get somewhat squared away. When I was ready to get back on the trails, everything was 10x harder. As a big girl it hadn't exactly been easy before to find gear, and now that I needed lighter gear that didn't rest on my back it was almost impossible. Finding a pack was harder than finishing my degree and I definitely cried more about it. There was more anxiety and comments about how I should limit myself when outside. My experiences made me really think about access to the outside world and the barriers many face getting there. How some need to do it differently once there. Hence, Now every time I hike, it's a success - a reminder my body and I belong." a

2

2 
Figure 4.

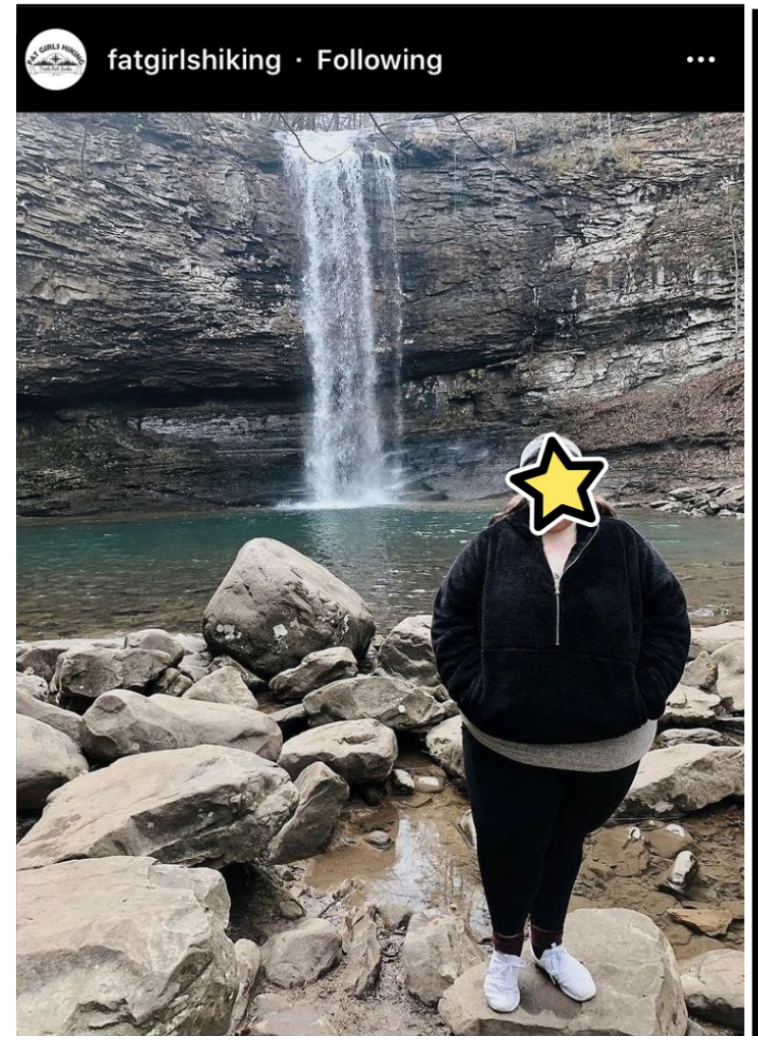

fatgirlshiking ishe/her) says:

I went on a hike for the first time this weekend

Here are some moments of clarity I had in no

particular order:

- hard things are doable and can make you feel

incredibly strong

- you are allowed to take challenges at your own

pace

- comparison won't get you there any faster and it will steal your joy along the way

- your body loves you and wants you to love it back

- fat people do not exist with the sole purpose of striving to take up less space

- you are allowed to seek movement for joy and endorphins rather than diet culture and penance

- nature is for everyone

- having people by your side (physically and/or digitally) to cheer you on during new challenges is a comfort like no other

- there's a lot of beauty on the other side of 600 stairs

ID: [ Hiker stands in front of a waterfall wearing gray headband, black sunglasses, long sleeve shirt and leggings with white sneakers. There are tan/gray rocks in the foreground, aqua colored pool with the waterfall falling in front of gray/black layered cliff. ]

Figure 5.

unlikelyhikers · Following

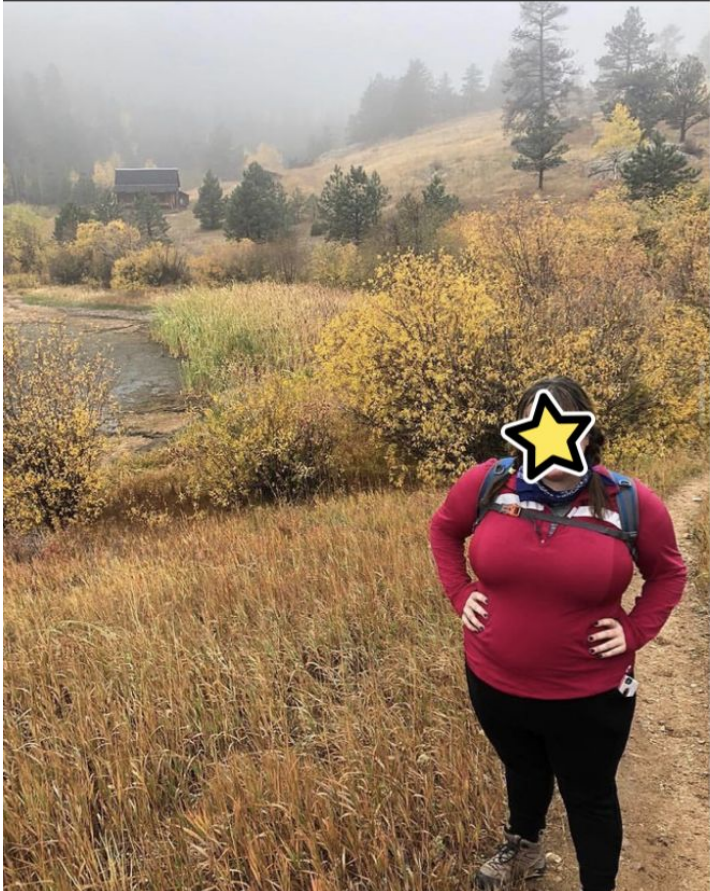

unlikelyhikers "Hiking helps free me from

soundtrack of 'too fat' that has been constant in my life. I have spent a lot of time trying to hide my size, as if I could spare people the inconvenience of seeing me. It's an exhausting way to live. But out in nature, I've realized I can just concentrate on what I'm doing and I don't feel too fat. In fact, I feel like the right size as just a part of our big, amazing, complex world, like a tree or a bird or a flower. I actually like seeing pictures of myself in the cool places I've carried myself to. It's not a complete transformation; I'm still working through lots of hang-ups and shame. But we all deserve to shed those things and heal. This past year I completed 35 hikes to celebrate 35 years of life, and my wish for 2019 is even less hiding, even more hiking!"

Pronouns: she/her

Location: Golden Gate Canyon State Park, Golden Colorado. Ancestral lands of the Cheyenne, Núuagha-tuvt-p甘(Ute)+ \#goldengatecanyon \#goldengatecanyonstatepark 
Figure 6.

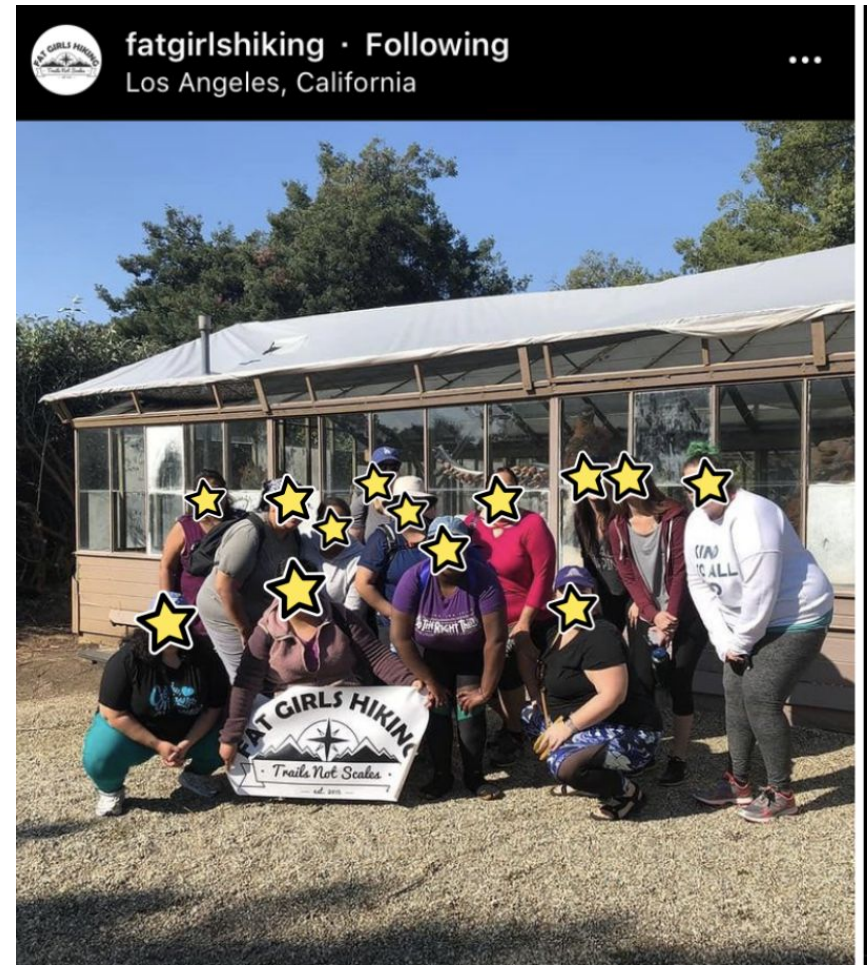

fatgirlshiking Fat Girls Hiking is fat activism. We are radical. We are fat positive. We are body liberation.

We celebrate fat bodies $\&$ other marginalized bodies. We want to upset the mainstream narrative that fatbodied folks should try to change their bodies. If you'd like to consume media that perpetuates fatphobia...you're in luck--it's EVERYWHERE. Look for weight loss stories in our culture; look for ads that say you'd be more attractive or healthy if only you changed your body to fit into society's standards. Diet and weight loss culture is inherently toxic and oppressive.

At Fat Girls Hiking, we will continue to celebrate fat bodies just as they are and not a watered-down version of body positivity that is so rampant today. Unconditional celebration, support \& love is our birth right. We are here for fat \& other marginalized bodies. We invite non-fat allies to listen \& support \& use your privilege to make the outdoors a more accessible, safe space for us.

Summer, FGH Founder

Ancestral land of the Togva People

Figure 7.

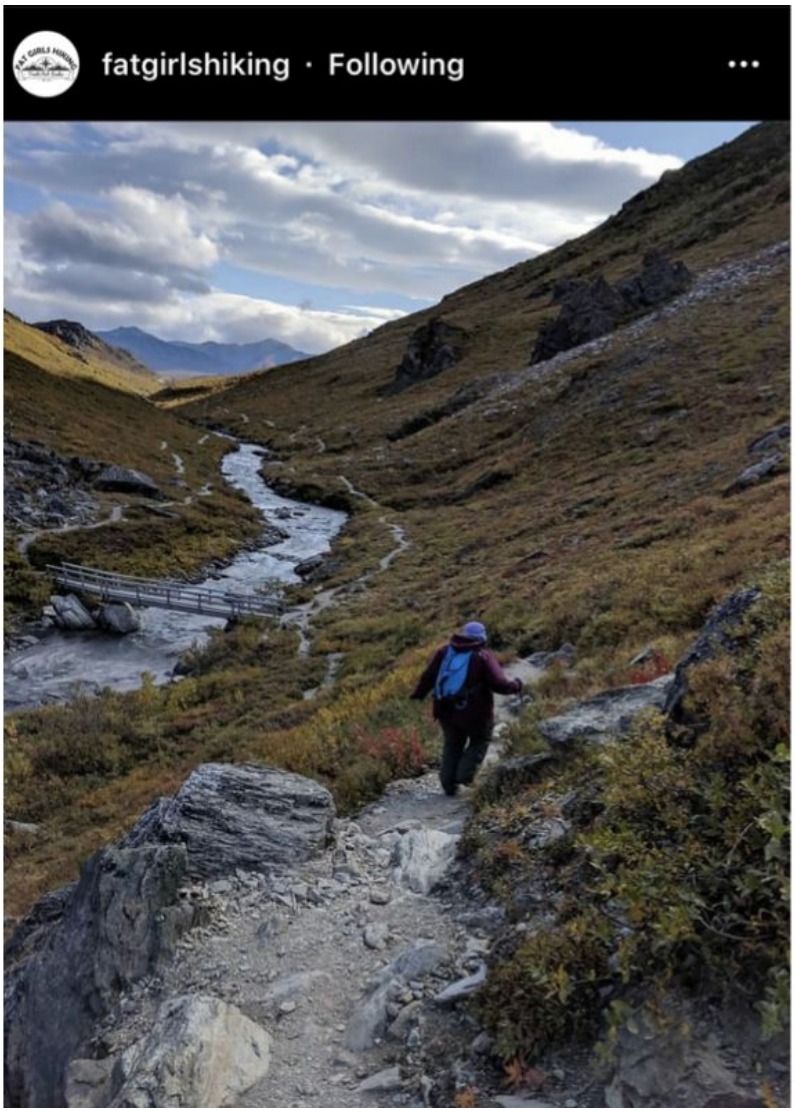

fatgirlshiking "My husband is an Eagle Scout. Until we got together, I'd never really camped. Hiking is pretty new to me, but I fell in love with it.

But it's not easy to be a \#fatgirlhiking. Especially one with asthma. Sometimes I'm so self-conscious on the trail when I have to stop and others stroll by. But that's why @fatgirlshiking is so important to me. I get strength from knowing I'm not alone. In seeing other \#BAMF women out on the trails. To know that every step we all take outdoors is political and personal and subversive and makes a difference. It's important to take up space and disprove stereotypes and maybe make it a bit easier for the next group of bad-ass girls. I find comfort and sisterhood and motivation from this diverse and amazing group of people.

I chose this picture because on this day I was wheezing within our first 20 minutes of hiking at @denalinps and I was so worried I was going to ruin our trip. Instead, I rested, had my inhaler, and hiked 8 more miles that day. This is probably about mile 7 and just remembering how much ground we covered that day and what we saw long after I doubted myself is the reminder I sometimes need of who I am and what I'm capable of." !'

is the \#FGH2OKGIVEAWAY winner! Thank you all who participated...we loved seeing your photos \& inspiring captions. 
Figure 8.

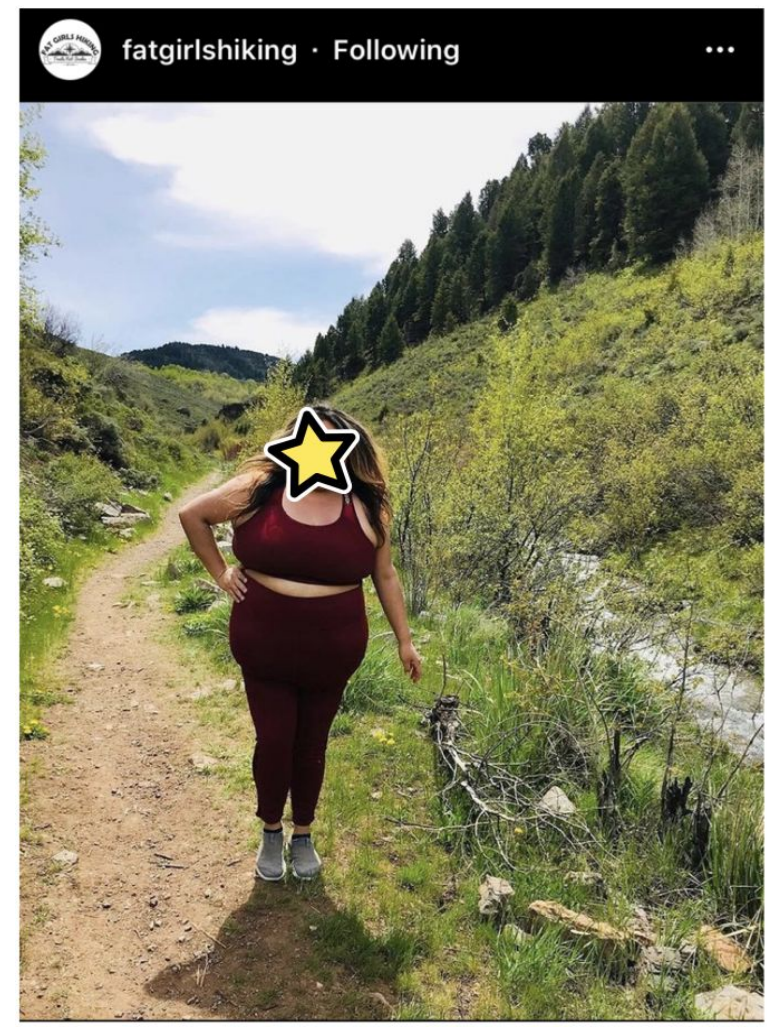

fatgirlshiking "This summer I declare trying things and being confident in what I want ! Attaining our goals takes time and dedication! $\nu^{\prime \prime}$ This weekend I Hiked 11 miles !!! : * * Never did I ever think I would be able to do that and I know if we put our mind to it everyday and try we can!!! 0 Also I have felt the stigma of being a plus size girl and feeling I dont belong in the fitness world or can't wear or look cute doing things!!! My tummy may be accentuated and my arms exposed but I'm beautiful and You are beautiful and wear those cute workout outfits!!! $\bigcirc$ Workout outfit Sports bra and pants : @torrid" || Repost from

Tag @fatgirlshiking or \#fatgirlshiking in your outdoor photos and IG stories to be featured.

ID: [ Hiker stands with one hand on hip smiling on a trail. Hiker has long brown hair and wears matching dark red leggings and sports bra, gray sneakers, earrings. There is greenery in the surrounding area

Figure 9.

\section{fatgirlshiking $\cdot$ Following}

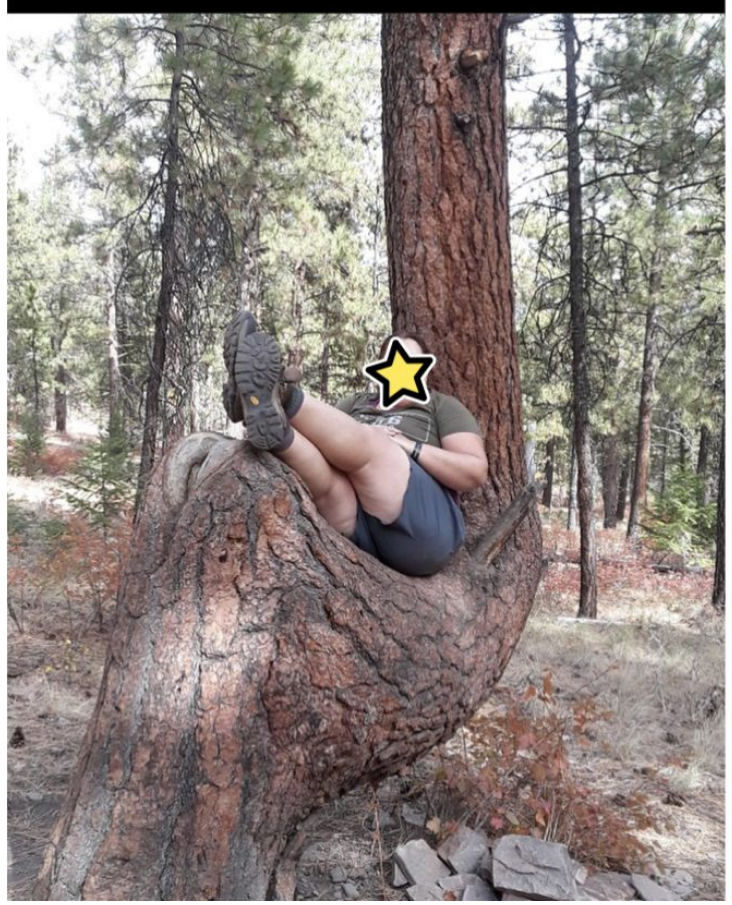

\section{fatgirlshiking Meet} ambassador for the FGH (she/her), the cochapter! She

says, "Being out in nature doesn't require me to defend or deny my size. I got grit, and I got girth. The outdoors has helped me live in that largeness. I'm already taking up more space, so I like to tell myself, 'GIRL, START TAKING UP SPACE!' Inhabit it. Live large in it."

Join

the

tomorrow, July 27 , for a hike on

Click "get tickets" on the homepage to register!

\section{Ktunaxa and Pend d'Orielles Land}

ID: [ Hiker reclines on tree branch with feet up, smiling. She is wearing gray shorts, a green $t$ shirt, hiking boots, dark blonde hair tied back. In the foreground are some gray rocks. In the background is a forest. ] 
Figure 10.

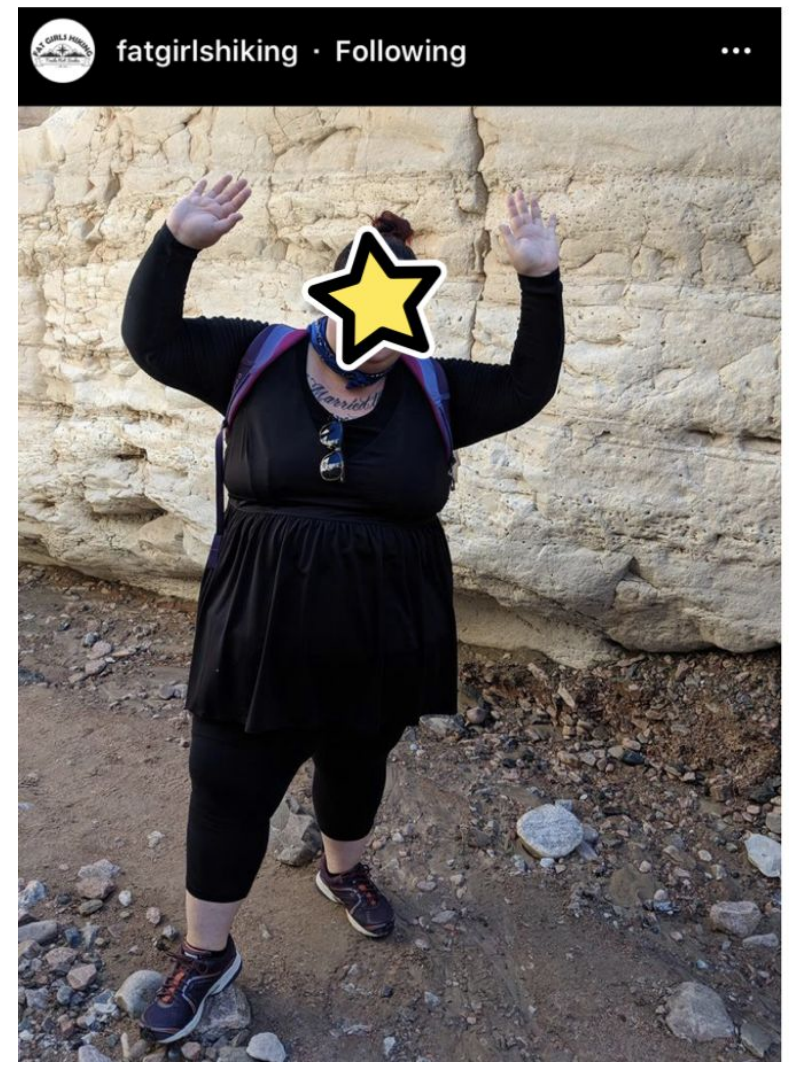

\section{fatgirlshiking}

${ }^{\circ} \mathrm{GH}$ ambassador for the

chapter. Says, "I am a fat woman, a person of color, and slow as heck on the trail - and that's ok! We all deserve to be there, taking up space and connecting with nature in the bodies we have today."

\section{Sana, Atakapa and Karankawa Land}

Image Description: [ stands on a brown trail with smaller gray rocks around it, next to a big tan rock wall with her hands up, smiling. She has her dark hair in a bunch, a black dress and black leggings, sunglasses clipped on her dress, a bandana around her neck, black sneakers and blue-purple backpack straps. ] 
VIRTUAL COMMUNITIES FOR FAT PEOPLE

Figure 11.

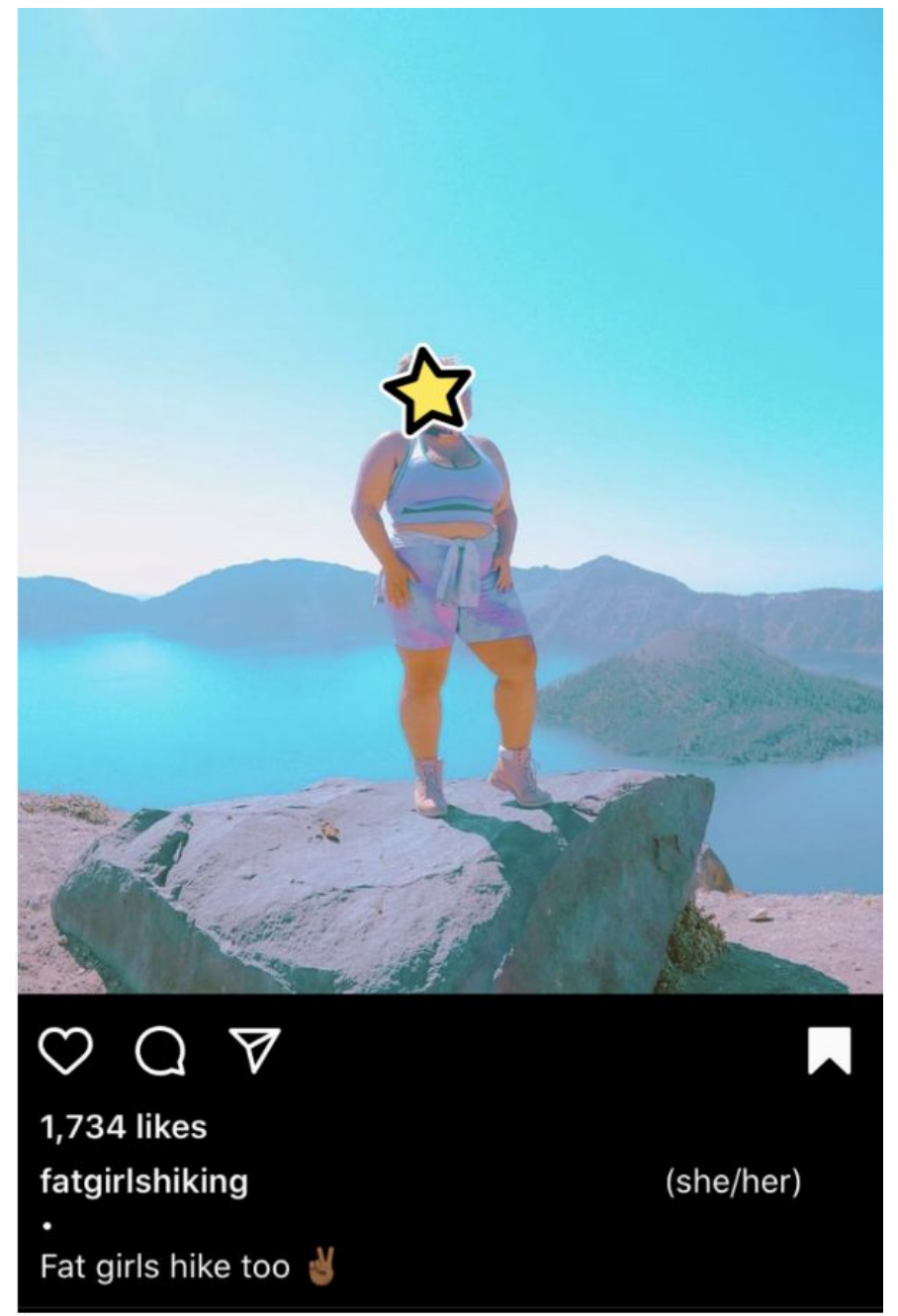


Figure 12.

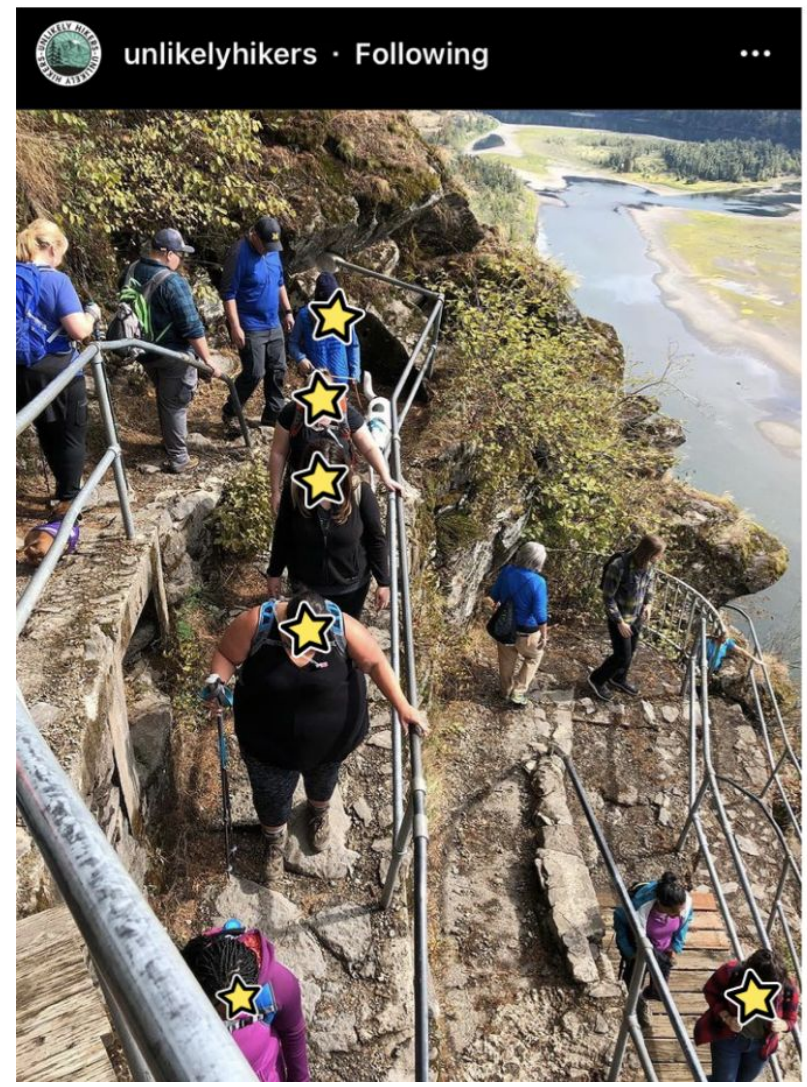

unlikelyhikers I saw people dig deep and really push themselves, accepting support and advice from their fellow hikers, some of whom they were just meeting for the first time. Witnessing this kind of teamwork is pure joy. Two people even said they wouldn't have done this challenging of a hike on their own, but knowing what Unlikely Hikers is about they felt motivated to try. When they thank me for organizing these treks, I often tell them to thank themselves because they are a vital part of the experience.

Many joyful thanks to @Merrell for supporting our hike!

Che-Che-Op-Tin, now known as

Yakama, Wasco, Wishram+ lands.]

[Chinook,

Group hike series: Low Intensity - slower paced with elevation gains under 500 feet, around 3-5 miles long. Low Intensity does not mean "easy!" All of our hikes are body- $\&$ fat-positive, but this series has an even stronger emphasis on this. We offer three different hiking series to suit your unique needs. Read more about them and find out about upcoming hikes on the blog (linked in profile)!

Tag \#unlikelyhikers or \#unlikelyhiker to be featured!

Figure 13.

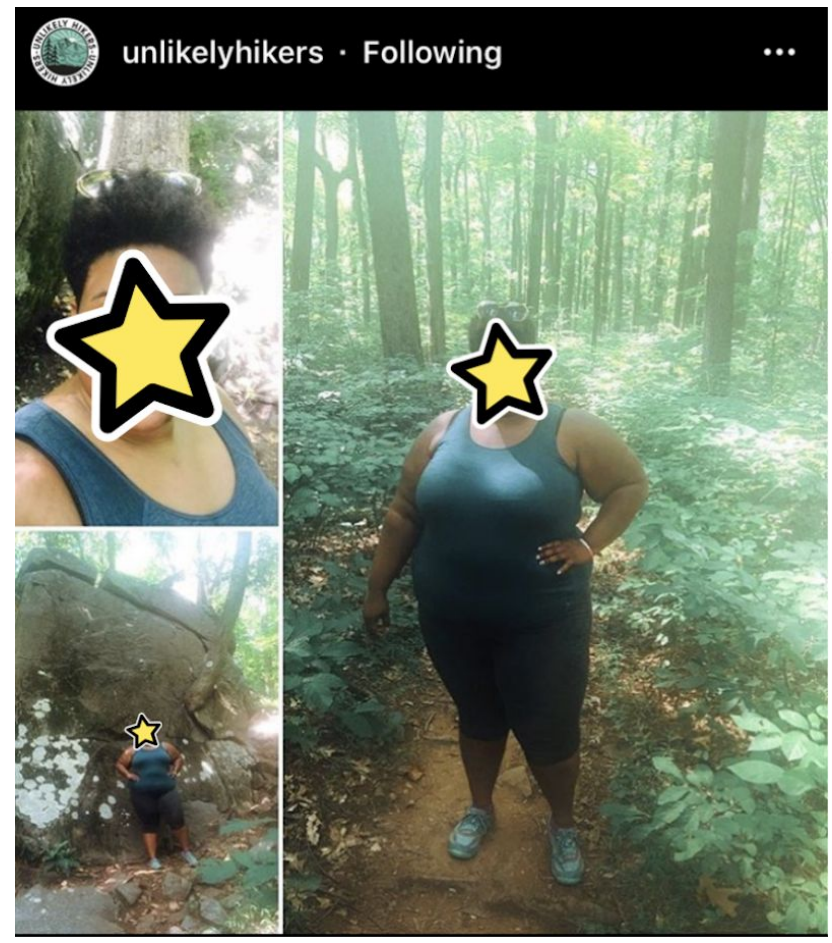

unlikelyhikers Good morning, everyone! I hope you're having an adventure-filled holiday weekend. Today's fabulous Unlikely Hiker shared with me that Unlikely Hikers inspired her to get out and hike for the first time! How cool and inspiring is that?! I'm so happy to introduce, "First time out hiking - misread the trail map and ended up in some challenging bouldering section, but I came and I conquered. Throw some respeck on these quads." \#dontwaitonyourweight \#fatgirlhiking \#outdoorafro \#watchoutforthebiggirl

Location: Sourland Mountain Preserve, New Jersey

(7) Tag \#unlikelyhikers or \#unlikelyhiker to be featured! 
Figure 14.

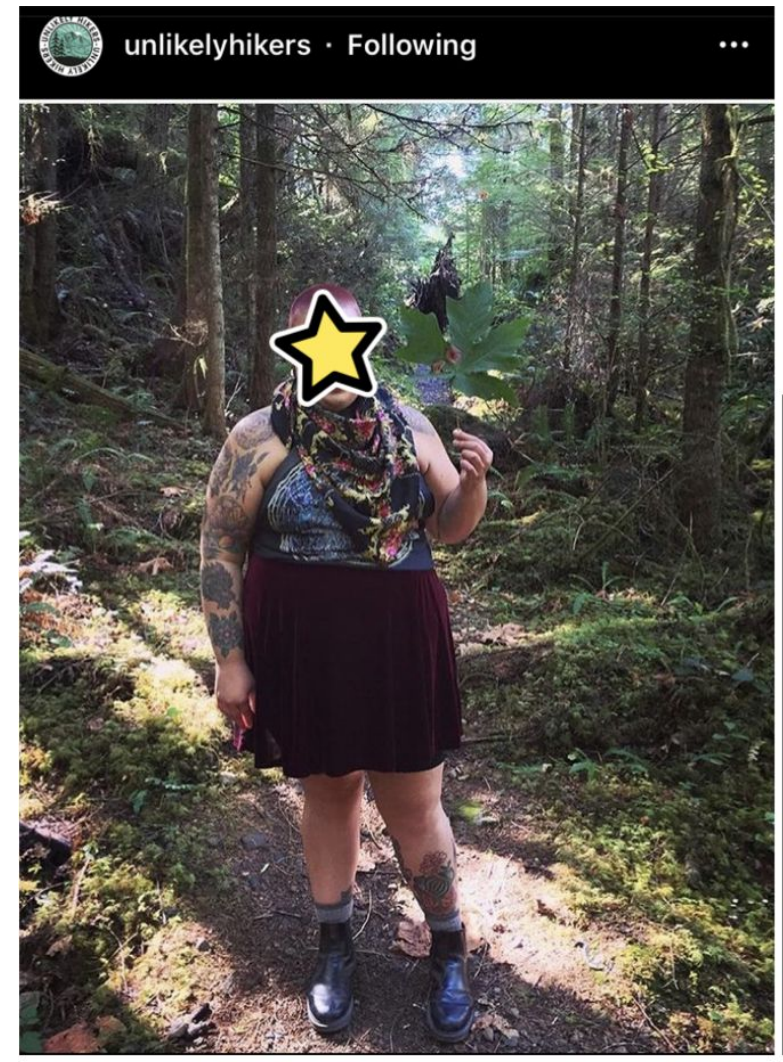

unlikelyhikers "I started hiking a few years ago after horseback riding in the Blue Ridge Mountains for the first time $\&$ realizing how much you can really miss out on if you're just sticking to the road on a roadtrip. The experiences \& memories you gain exploring new places are so much more intimate while on the trail. Being queer, fat, \& also battling chronic autoimmune conditions + chronic pain, I face quite a few challenges, but mother nature embraces us completely as we are. Following communities of other unlikely hikers has really been SO inspiring. I'm in the process of planning my first backpacking trip and couldn't be more excited to start my thru-hiking adventures!" -

-

Tag \#unlikelyhikers or \#unlikelyhiker to be featured!

Figure 15.

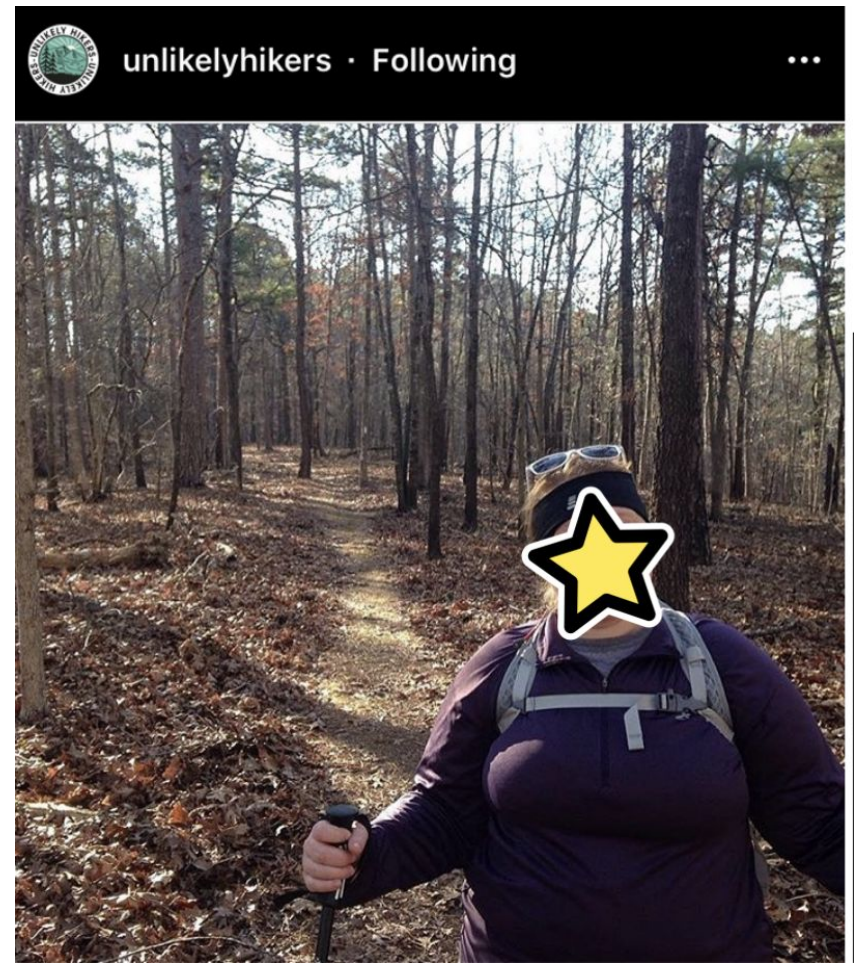

unlikelyhikers Very happy to introduce this Unlikely Hiker, meet "Hiking is helping me gain my health and confidence back. I've overcome so many insecurities while hiking. I'm still a work in progress. I love seeing other unlikely hikers and reading their stories. I love that I found this group of folks who don't fit the mold. I love that hiking is a whole body and mind experience."

(i) to be featured:

ci. follow @unlikelyhikers

tag \#unlikelyhikers or \#unlikelyhiker

\#itakethelongway \#switchbacklifestyle \#mentalhealth \#mentalwellness \#exploretocreate 
Figure 16.

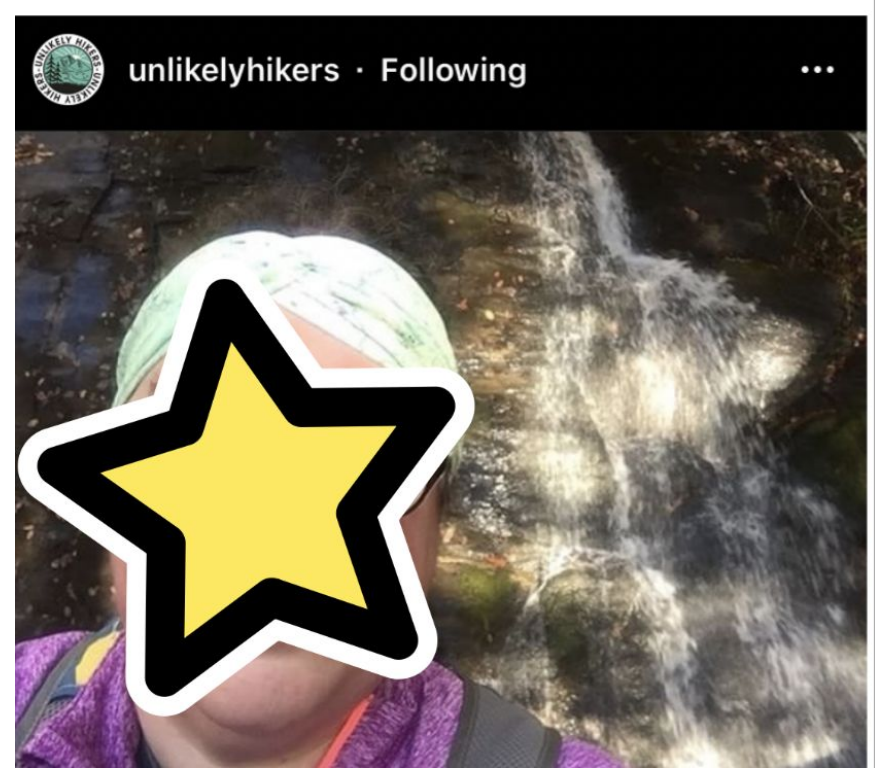

\section{8 likes}

unlikelyhikers "Growing up I was always outdoors with family, fishing, hunting, hiking, camping,

trapping. For most of my life being outdoors was a touchstone, a way of knowing I was okay. Then I stopped spending so much time outdoors. I let my career, my weight, and my everyday life get in the way. Now I'm finding my way back into the woods and back to myself. I may be slow, but hiking is just about putting one foot in front of the other afterall."

Pronouns: she/her

Location: Deep Creek, Great Smoky Mountains National Park, North Carolina \#greatsmokymountains

Tag \#unlikelyhikers or \#unlikelyhiker to be featured!

[image description: person in sweatband and glasses in classic selfie pose. Sunlit sparkling whisp of a waterfall in background framed by slick dark rock and green moss.]

Figure 17.

\section{unlikelyhikers · Following}

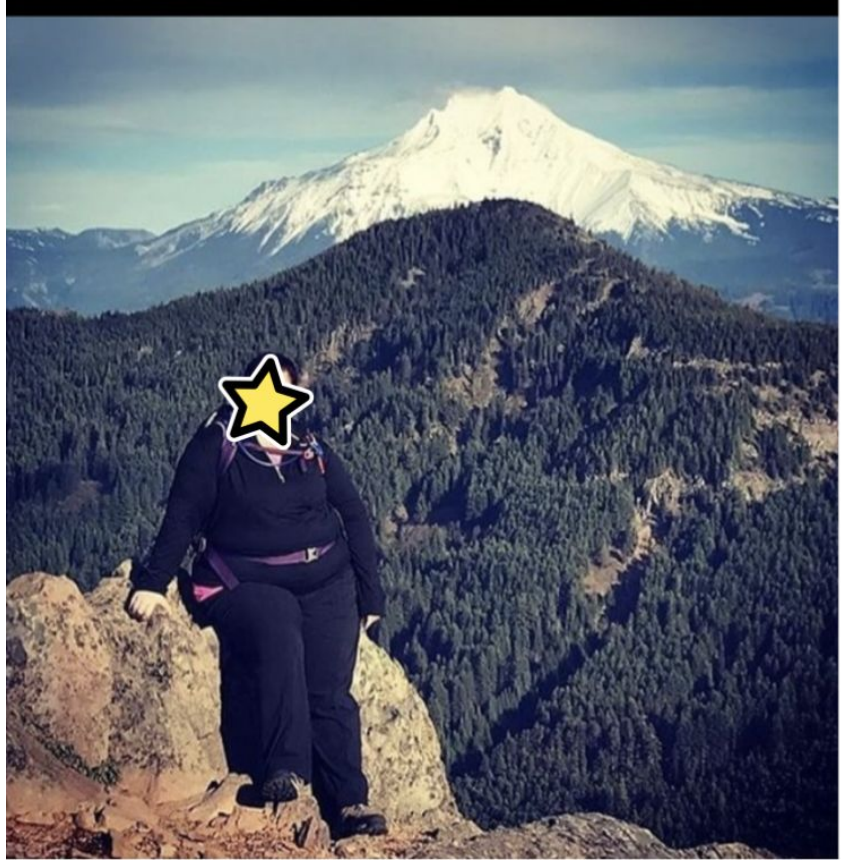

\section{2,658 likes}

unlikelyhikers "I completed the 52 hike challenge in December. I didn't break any records in distance or elevation gain, I am almost always in the back and I complain a lot. I worry so much about being able to accomplish things that others do to the point of not wanting to even try. I have spent most of my life looking forward to a time when I will be at some ideal weight or aesthetic and my life can begin. I have apologized in so many ways for just taking up space and even existing. I think hiking has taught me that I am more capable than I imagined, I deserve to feel free and to move. I deserve to take up space and enjoy my life now because it is happening and there is no looking back."

Pronouns: she/her

Location: Coffin Mountain, Oregon. Ancestral land of the Molalla \& Kalapuya. \#coffinmountatin

Tag \#unlikelyhikers or \#unlikelyhiker to be featured!

[image description: person sits on rock smiling after a big climb. Mountains in background, including massive, snow-covered Mt. Jefferson.] 
Figure 18.

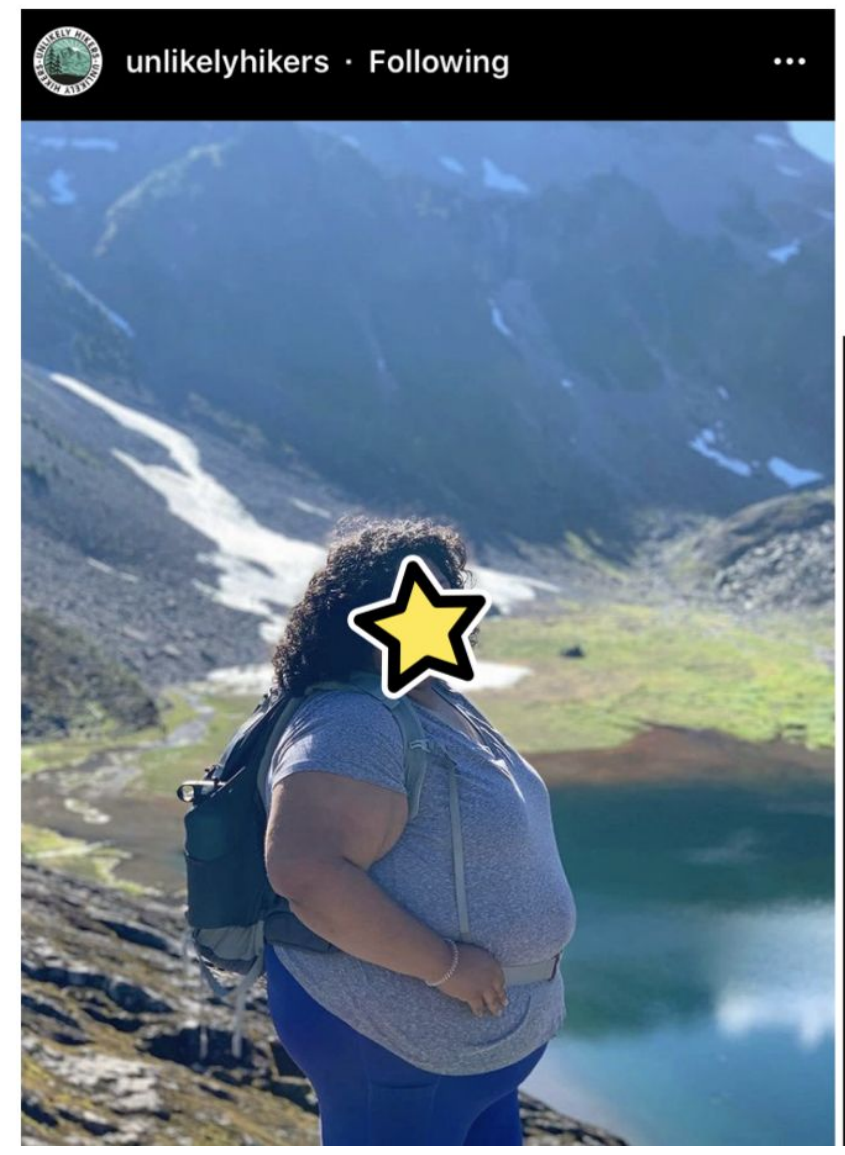

unlikelyhikers Dearest Unlikely Hikers who are plussize, fat, chubby, curvy, [whatever-you-respectfullycall-your-body],

Do you ever find yourself hiding your body in photos? Imagine feeling free enough to be your entire, worthy self. Here's what

\section{has to say:}

"I rarely post full-body pictures of myself. They make me uncomfortable. That being said, I have found happiness in recognizing my own strength; the strength this body and spirit have. I have overcome so many physical, mental and emotional obstacles with this body. I am learning to appreciate it, forgive it and love it, one day at a time."

\section{Give this post a share $\mathbb{d}++i$}

Be a part of the community! Tag \#UnlikelyHikers 
Figure 19.

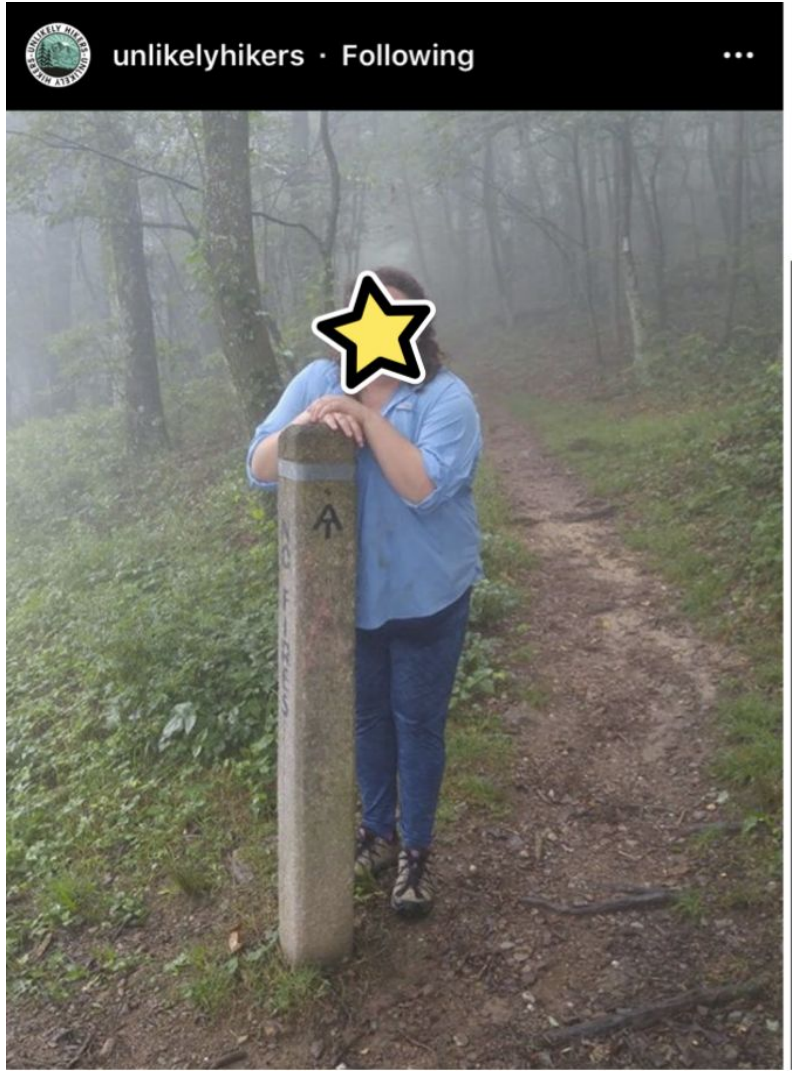

unlikelyhikers This morning's Unlikely Hiker is "In case people didn't notice, I'm fat. Yup, and I still hiked 5 days on the AT. We saw no people of color. After the hike, I felt enlivened, empowered, proud of my accomplishment and inspired to challenge myself to more. I joined an Appalachian Trail Section Hikers fb site to share stories and information. Today, I asked if there were any people of color in the group because I had noticed a lack of diversity on the trail. The responses were abusive, trolling and fat bashing. Usually, I don't take other people's small minded insults to heart - I know who I am. However, this morning's trolling left me in tears. I felt the accomplishment of completing my section and my interest in diversity of hikers was discredited because as a fat woman, my voice is worthless. The day before I was being congratulated and accepted into the group. Just asking about diversity threatened these people so much they had to try and tear me down because of my appearance."

Appalachian Trail \#appalachiantrail \#atthruhike

Figure 20.

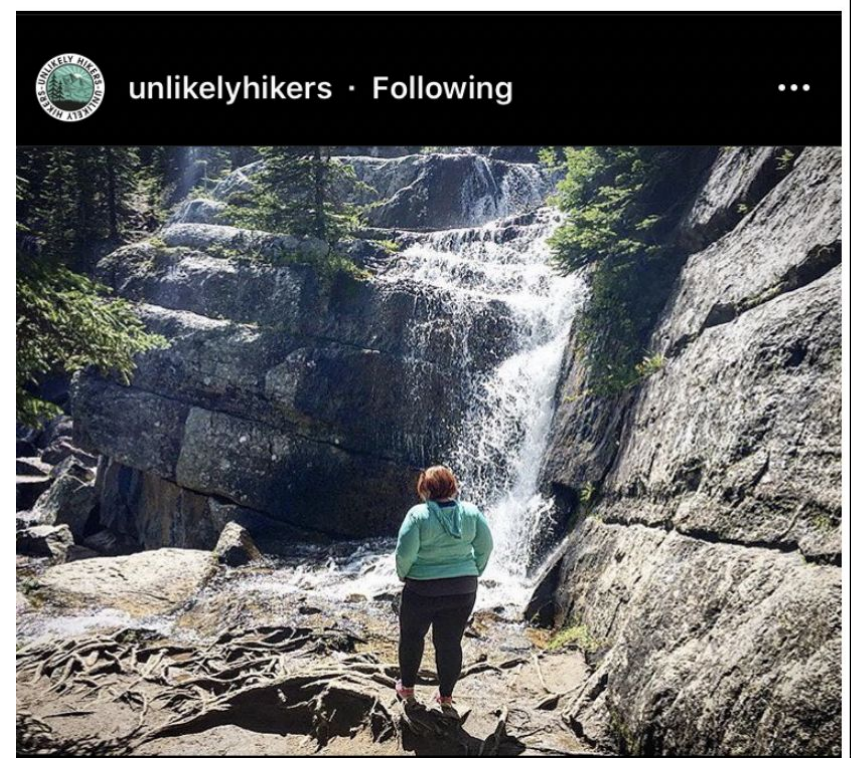

unlikelyhikers Today's Unlikely Hiker

"When people look at me, they don't see a hiker, to be honest neither did I. I used to love hiking but I've always been afraid of what other people thought when they saw me huffing and puffing on a trail. However, this last year, after multiple visits to the hospital for various things, I knew I needed to get my act together and to do so I went back to my routes, hiking and swimming. Now I don't care what people think, my health has improved and so has my relationship with my fiancé."

Location: Lake Louise, Alberta, Canada \#lakelouise \#albertacanada

8 to be featured:

ili) follow @unlikelyhikers

tag \#unlikelyhikers or \#unlikelyhiker

\#itakethelongway \#switchbacklifestyle \#hikealberta \#hikecanada \#travelalberta \#exploretocreate \#everytrailconnects \#fatgirlscan \#fathiker \#fatgirlscanhike \#oiwc \#bodypositive \#trailmavens \#noBS \#womenwhohike \#choosemountains \#optoutside \#gooutside \#psblogger \#theoutbound \#staywild \#wildernessculture \#hikeyourownhike \#diversifyoutdoors 
Figure 21.

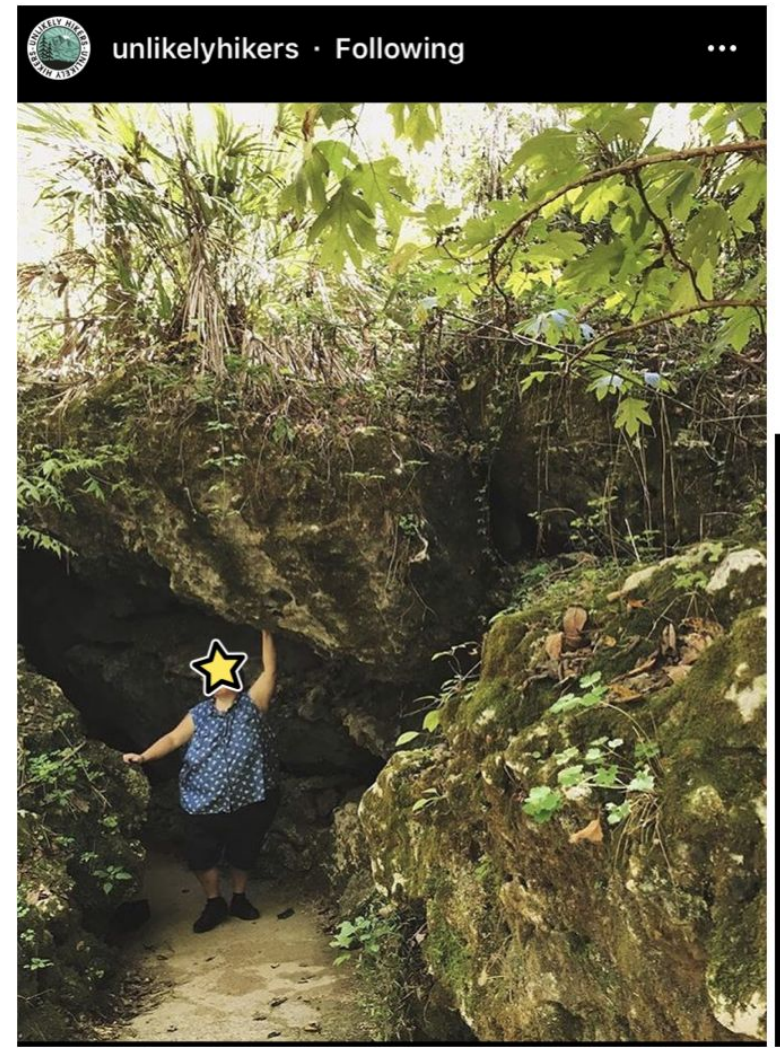

unlikelyhikers "I am thankful I didn't let society's influence tell me that I couldn't go hiking in a 'moderately strenuous' cavern with my $330 \mathrm{lb}$ body because I did it and was rewarded greatly by beautiful stalactites and stalagmites. I am grateful that other fat folks, differently-abled folks and other unlikely hikers around me prove daily the outdoors is for all of us!"

You must check out more of pictures on Instagram and at And follow the hashtags of

current projects:

Tag \#unlikelyhikers or \#unlikelyhiker to be featured!

Figure 22.

unlikelyhikers - Following

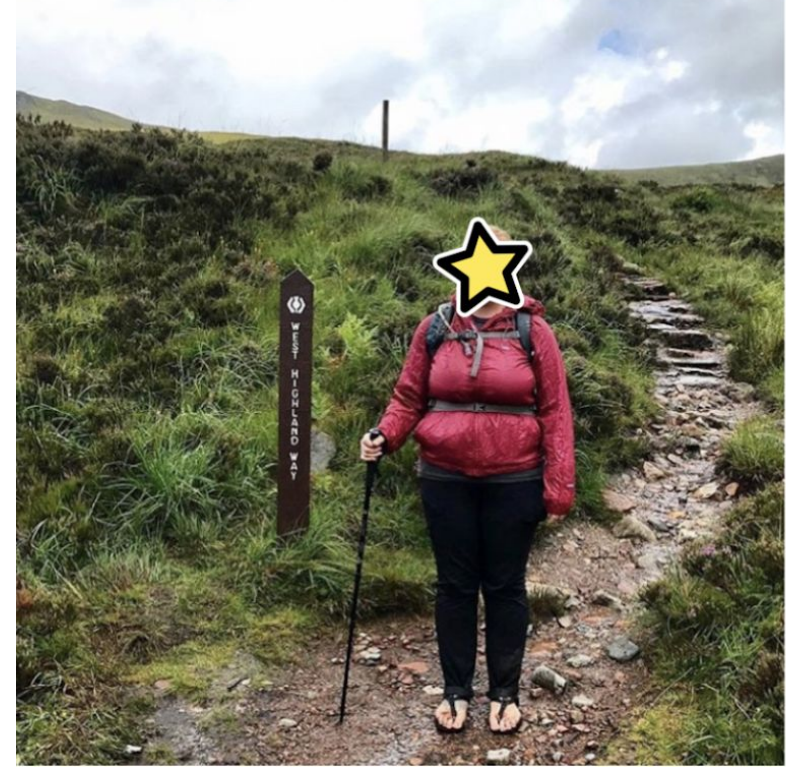

unlikelyhikers "I've always been a big person. My thighs have always rubbed together and I've always had to breathe harder because I have more body that needs more oxygen. I've often heard whispered doubts about my ability because of my size. But getting out on the trail, I feel small in a good way. My thighs rub the branches and ferns and the oxygen that fills my lungs is restorative. And I always make it to where I need to go."

Location: West Highland Way, Glencoe, Scotland \#westhighlandway

Tag \#unlikelyhikers or \#unlikelyhiker to be featured! 
Figure 23.

\section{unlikelyhikers · Following}

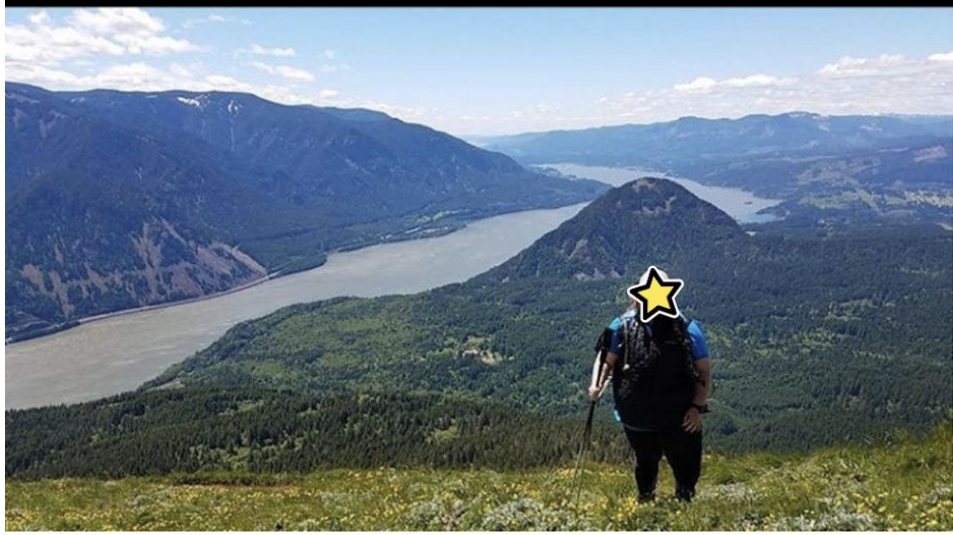

unlikelyhikers "Being plus-size my entire life, I belived in the lie that I could never lead an active life that I didn't belong to that 'club.' Once I discoverd the great outdoors, my life was forever changed. Never would I have thought that my legs would carry me along dirt paths, meadows, along high ridges, or through deep valleys. Or that my lungs would breathe in deep mountain air and my eyes would gaze upon the darkest of nights as stars danced above my tent. Being out on the trail has given me freedom, love, and joy. When I'm covered in sweat and dirt I feel the most beautiful and strong. It has been a joy to discover that my body is capable of so much more than I ever imagined. We are blessed with our bodies, no matter size, race, or gender we are all capable of so much more. To discover, to see beauty, to enjoy the journey. Proud to be an \#unlikelyhiker and show the world that different is beautiful." -

Pronouns: she/her

Figure 24.

unlikelyhikers · Following

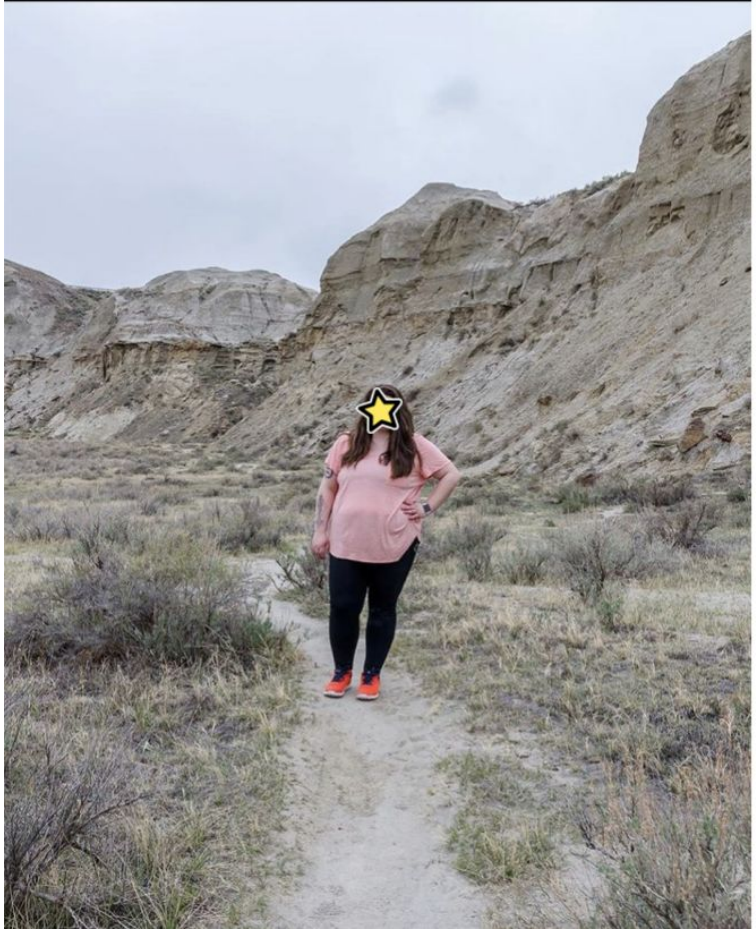

unlikelyhikers "I have recently followed a lot of body positivity Instagram pages and they have slowly helped me be more comfortable at the thought of having pictures taken of me while I'm outside doing the things I love. It's hard to feel included in the outdoors when a lot of the photos of women I see on the explore page, and even my own Instagram feed, are almost always of thin, white and usually blond women looking perfectly put together on top of a mountain or something to that effect. It gets tiresome feeling like I don't belong on hiking trails or long hikes until I've 'lost weight' or 'gotten more fit.' Being fat isn't the worst goddamn thing a person can be. Everyone deserves to feel welcome in outdoor spaces. So here's a picture of me, super happy to be hiking again."

Pronouns: she/her

Location: Dinosaur Provincial Park, Alberta, Canada. This is Niitsitpiis-stahkoii $\left.N^{\prime}\right\rfloor \cdot-d \cdot h^{\prime \prime} h^{\prime}$ (Blackfoot / Niitsítapi $\left.\left.N^{\prime}\right\rfloor \cdot 7 d\right)$, Métis, Očeti Šakówin (Sioux)+ land. 
Figure 25.

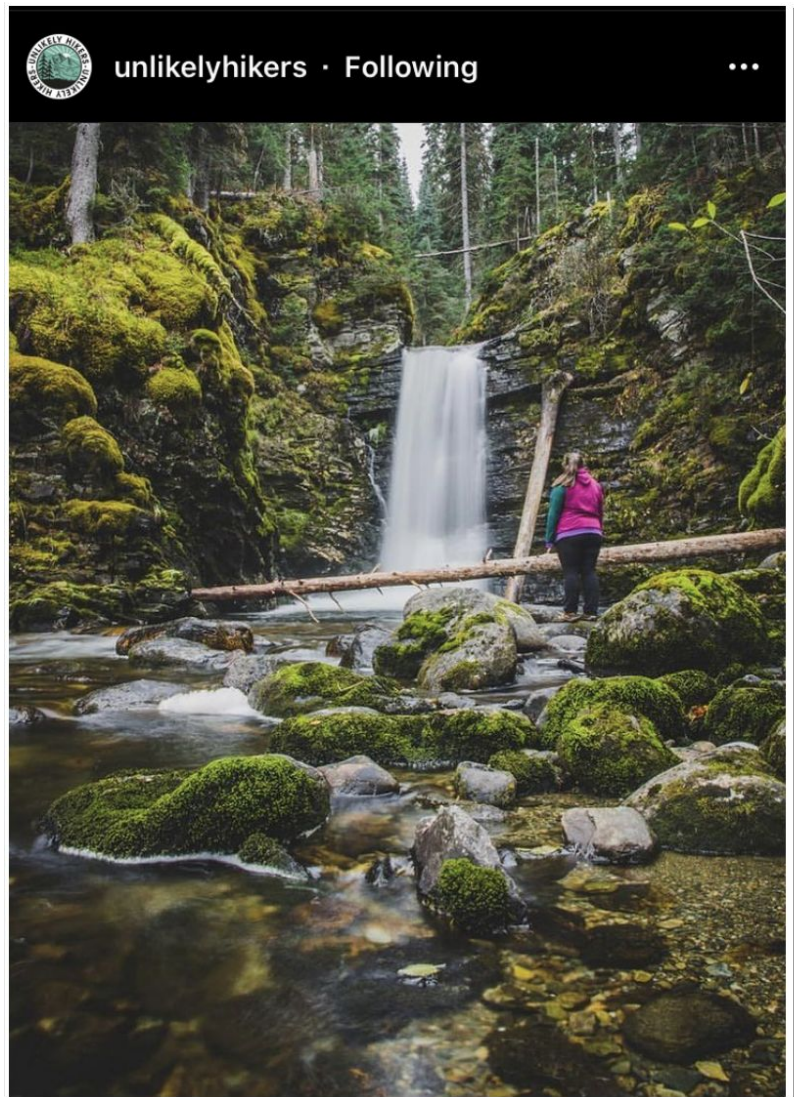

unlikelyhikers "Here's a rare photo of my in front of the camera and staring at one of my favourite waterfalls in Northern British Columbia. I rarely get photos taken of myself because I am usually out adventuring alone, but the main reason is because I am so self conscious about my body that I don't like almost every photo taken of me. I am not the typical body you see posted all over Instagram. It's taken a long time for me to be okay enough to have photos taken of me and, to be honest it's still hard to look at them and not say 'oh yeah, that's a good photo, but would be way better if I wasn't in it.' I know I'm not skinny, or super fit and all my life l've had people be so rude to me about my weight. I've been told l'd be prettier if I lost weight, if I lost weight l'd have a boyfriend and guys would pay attention to me. If I lost weight it would be easier to get a job. Over time that shit wears a person's self-esteem down so much it takes a long time to come back from it and every day for me is a work in progress. Every body is beautiful to someone."

Location: Northern British Columbia, Canada. Ancestral Land of the Wet'suwet'en (Gilseyhu, Laksilyu, Gitdumden, Laksamshu, Tsayu clans).

Tag \#unlikelyhikers or \#unlikelyhiker to be featured!

[image description: person stands to the right of a waterfall in a moss-covered ampitheater. Logs smoothed by time and water crisscross splashpool. Moss covered rocks break up water's movement.]

Figure 26.

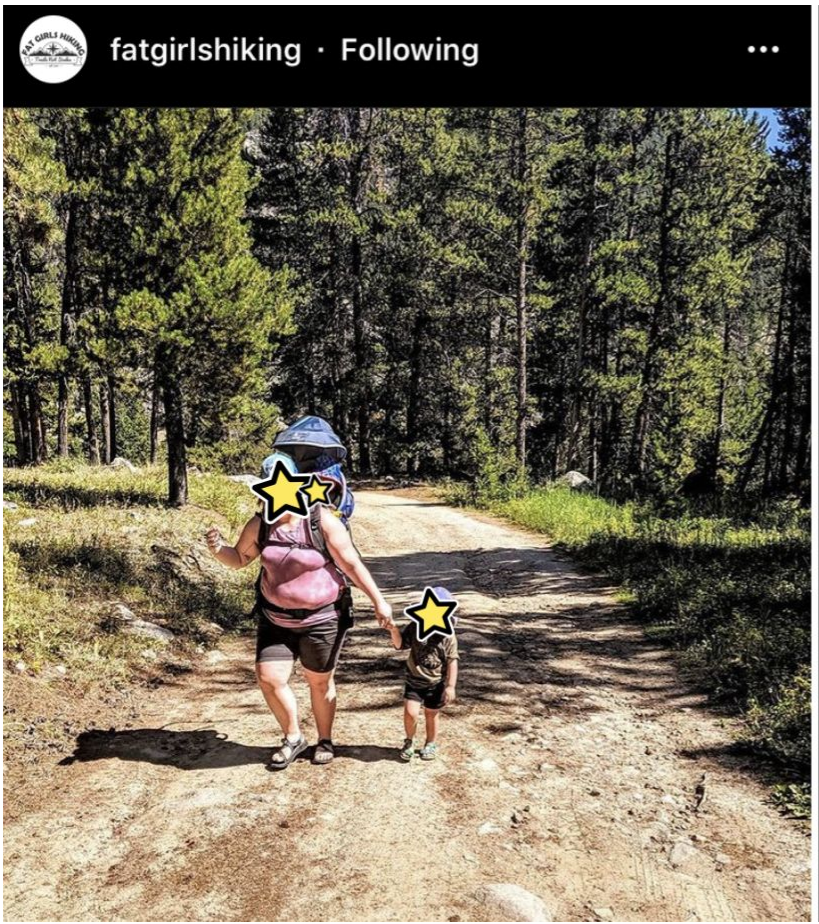

fatgirlshiking (she/her) says,

"Normalize bellies. Normalize rolls. How many times have you not taken a picture because of how your belly looked? How many memories are you willing to not capture to hide your body?

When I snapped this backpack on I had a moment of panic. Do I look too big? Will people think I'm too fat to wear this? Should I even take photos? Then I remembered: I'm walking up a mountain with a $20 \mathrm{lb}$ baby strapped to my back. I'M A F*CKING BADA\$\$!

Take the pictures, wear the shorts, know that body rolls 5 are normal!!

I wish for you today to see a your strengths and your powerful body."

ID: [ is on a wide gravel road/trail holding a young kiddos hand with a baby in a blue pack on her back. She wears a pink shirt with black shorts, hiking sandals and a blue baseball hat. She is a fat white woman with brown hair peeking out from her hat and is smiling with sunglasses on. In the background the road/trail continues and there are green trees and some gray rocks. ] 
Figure 27.

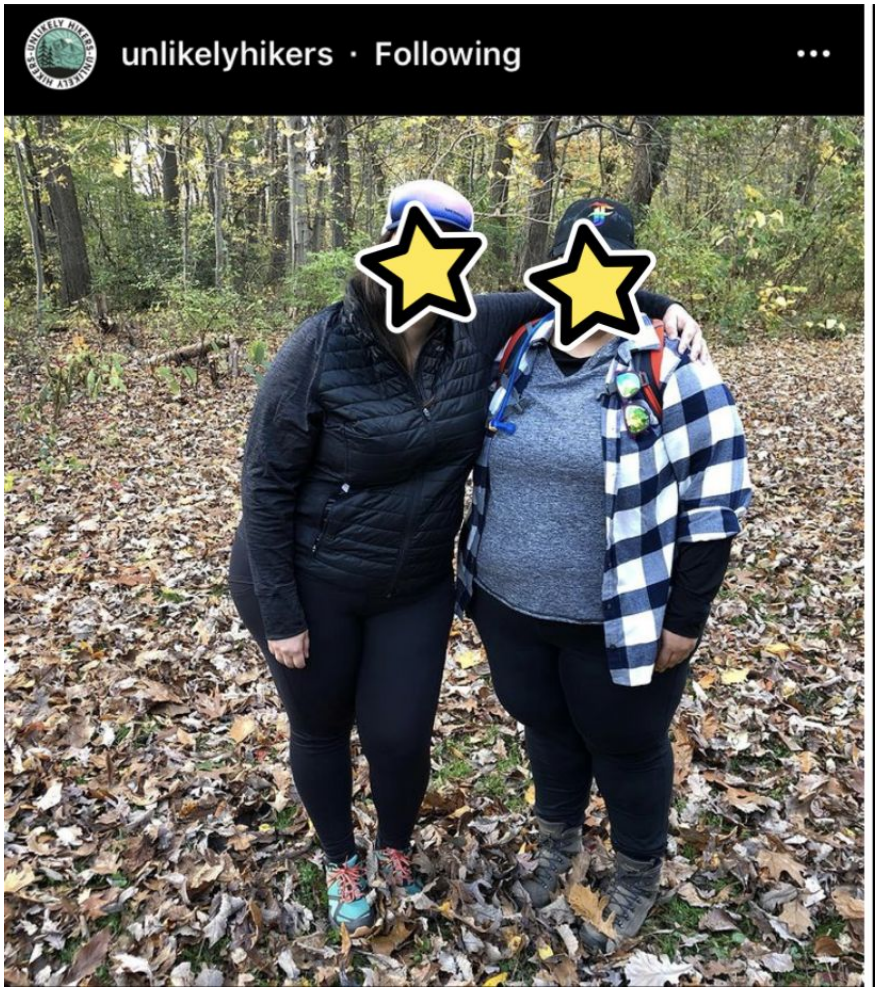

unlikelyhikers "I came to hiking as a way to enjoy the rich natural heritage of the Philadelphia-area with friends, but if I'm truly honest, I first viewed hiking as yet another weight-loss venture. Around this time, I began regular strength training and realized how powerful my body is and how important it is for womxn like me to be present on trails, to take up space, and to be unapologetic about our presence. I've moved away from trying to control my shape and size. I enjoy exploring different landscapes through hiking and love the way trails change throughout the seasons of the year. Spending time in nature helps me to process the daily traumas I absorb as a healthcare provider who serves a diverse, inner city population. The biggest challenges I've met in outdoor culture have been the lack of body diversity/ representation and lack of access to size-inclusive gear. Now that I see so many other individuals with similar bodies on trails all over the country, I have a greater sense of belonging. I feel more connected than ever to the land I visit through my hikes." $\nabla$

$\nabla$

This photo of 2 our recent

$\nabla$

Tag \#unlikelyhikers to be featured!

Figure 28.

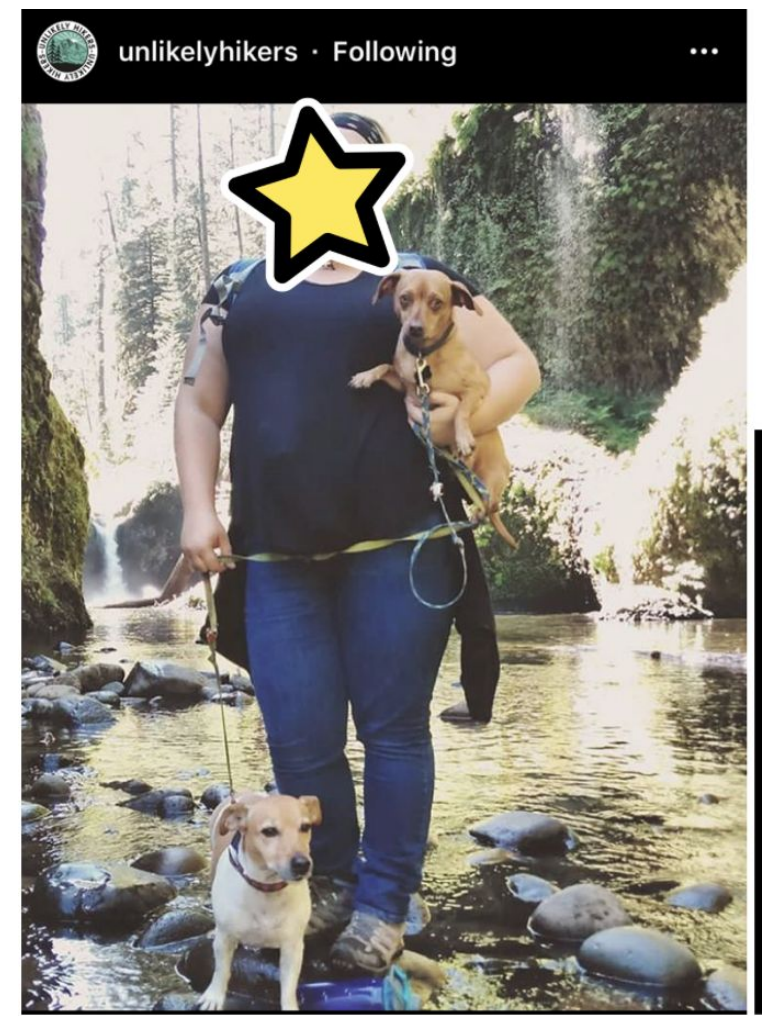

unlikelyhikers "Going outside was not always something I did. I lacked family support. I worked 2-3 minimum wage jobs, trying to put myself through school. I experienced body shaming, causing selfdoubt in my physical ability. I was in an unhealthy romantic relationship with an alcoholic. I struggled with the stigma of being a lesbian in a conservative community. After moving to Oregon, I finally feel comfortable just EXISTING. I am in a big phase of rediscovering who I am and outside is the best place I have found to do that. I love challenging myself and pushing my limits. I love doing things with my body that society says I cannot do. I especially love taking my dogs with me. They make me a better human!" 
Figure 29.

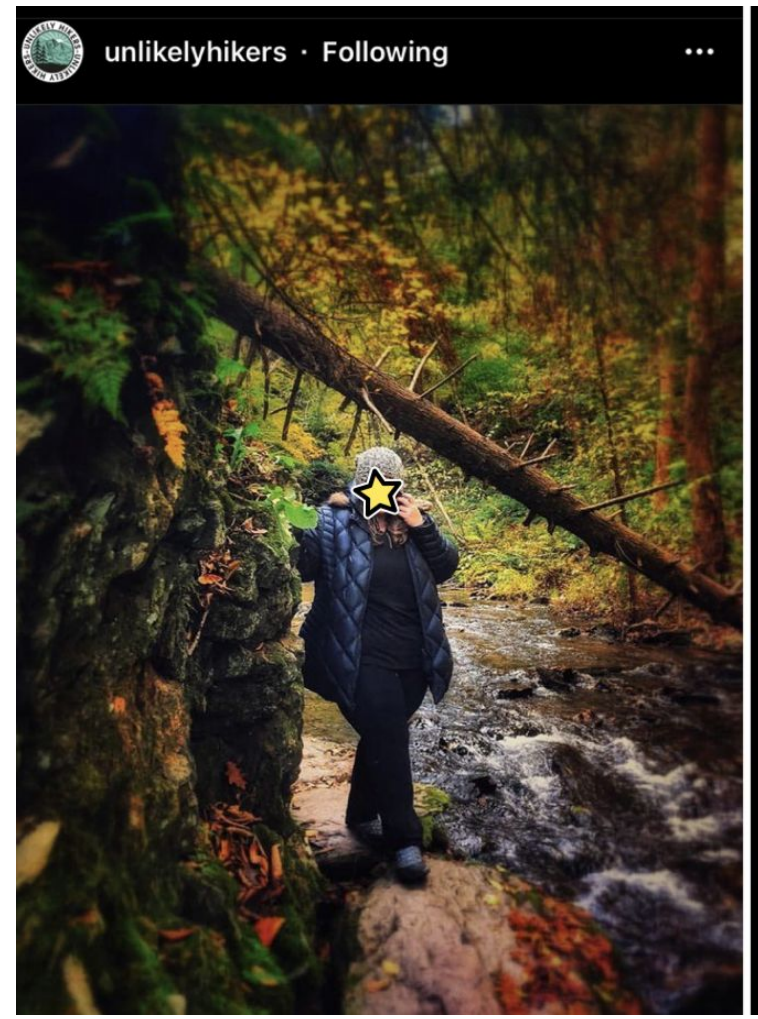

unlikelyhikers "I may not look like the typical hiker that you find on the trails especially in an intense hiking destination like Patagonia. And to be honest, I grew up hating hiking and resenting the fact that my body had to work so much harder fighting against gravity to get myself up the mountain. Then something changed and I realized avoiding things because they were challenging was robbing me of countless opportunities to see the world and that my perceptions of my own limitations were self-imposed illusions. I never imagined I could hike 17 miles in a day and survive and yet here I am."

Pronouns: she/her

Location: Dover Stone Church, Dover Plains, New York. This is Mohican, Lenape+ land. \#doverstonechurch

Tag \#unlikelyhikers or \#unlikelyhiker to be featured!

[image description: person, all bundled up in winter layers, walking on trail along a mossy stone wall on one side and a rushing creek on the other. Old downed tree crosses from stone wall over creek. Wet fall leaves stick to any surface they can.]

Figure 30.

\section{unlikelyhikers · Following}

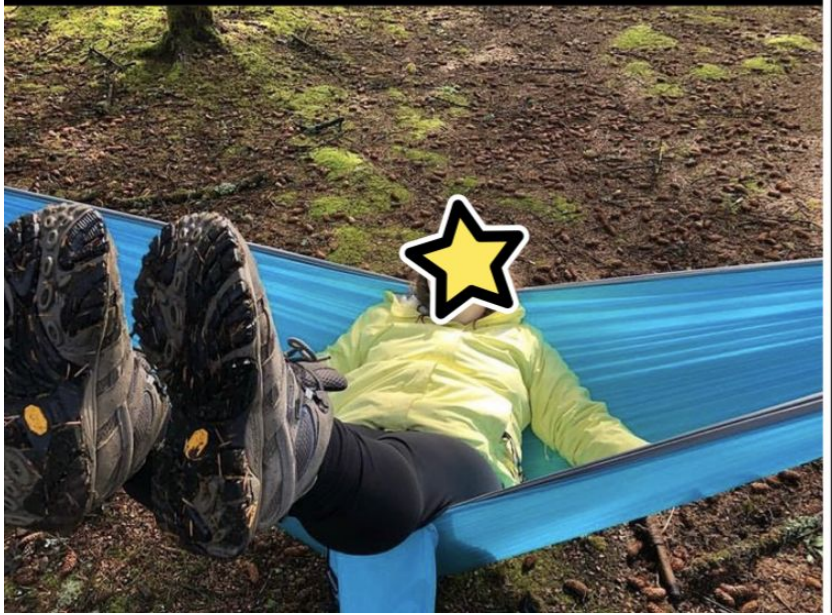

unlikelyhikers "A few years ago when the idea of hiking was brought up, my initial reply was that I needed to 'get in shape' first. The thought of walking up a hill for a long time only made me think of an asthma attack. Last year when I was asked to go hiking my immediate reaction was fear - fear that I would be too slow, that I would have an asthma attack, that I wasn't meant to be on a trail. But I went and then I kept going. I still have those fears, but it feels different now. I know that my body is capable of taking me great places. I know I can go at my own pace and celebrate my own little accomplishments. I used to let my fears hold me back from the outdoors. Now, I have half our summer planned ahead with camping and hiking trips. I want to take myself to see all the things, afraid I might lose my momentum. I'm done stopping myself from doing."

\section{Location:}

This is Chinook+ land. \#capedisappointment

Tag \#unlikelyhikers or \#unlikelyhiker to be featured!

[Image description: person smiling looking as though she just fell into her hammock. Hiking boots up in the air. The sun shines through trees onto her raincoat.] 
Figure 31.

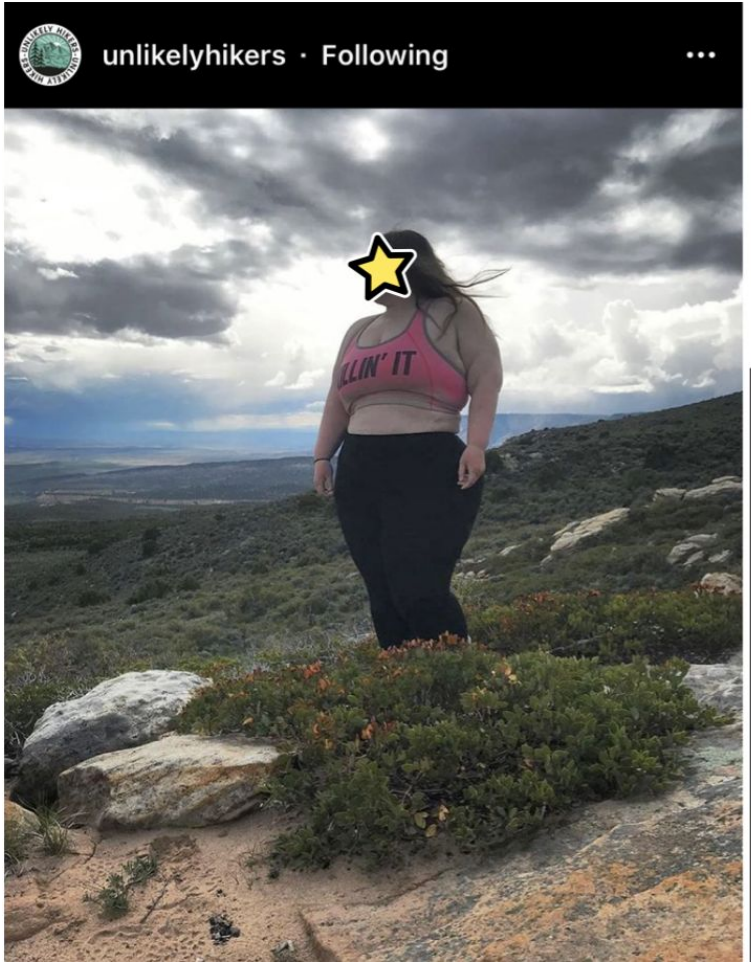

unlikelyhikers "You belong outside. You can take your shirt off when it's hot. Wear shorts, wear your sports bra, wear tank tops. Let your arms and legs breath. Stop letting people tell you or make you feel that you can't wear what smaller people wear. Don't let anyone make you feel like you have to make yourself hidden or uncomfortable. !! !! !! ATTENTION: if you are offended by big bodies flaunting themselves, prepare to be BOTHERED ALL SUMMER !! !! !! Bc we dgaf anymore! We're out here and we love it."

\section{Pronouns: she/they, her/them}

Tag \#unlikelyhikers to be featured!

Figure 32.

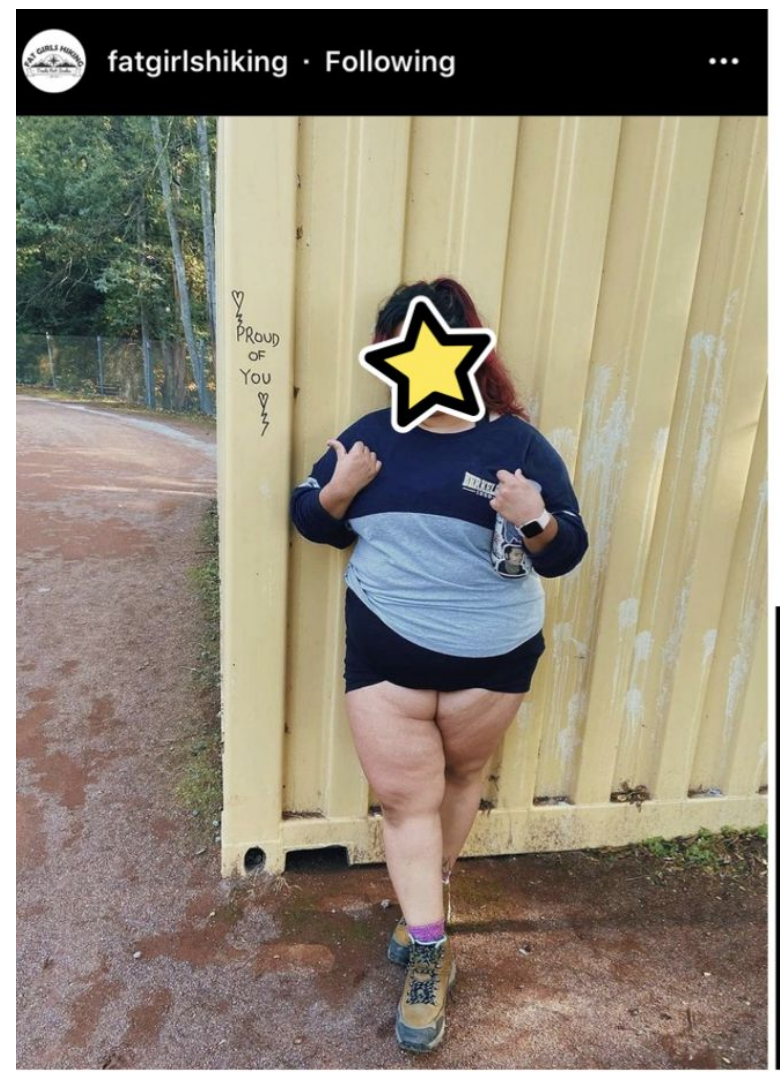

fatgirlshiking (she/her) says, "Proud of you +t proud of all my curves and folds and rolls 0 they blessed me with a beautiful hike today!"

ID: [ hiker leans against yellow wall with the words "proud of you" written in marker, next to a trail. Hiker is wearing her long black and red hair in a ponytail with a gray face mask. She wears a navy and gray baseball style shirt, black shorts and brown hiking boots. She holds a water bottle in one hand has her thumb out pointing to the "proud of you" writing. ] 
Figure 33.

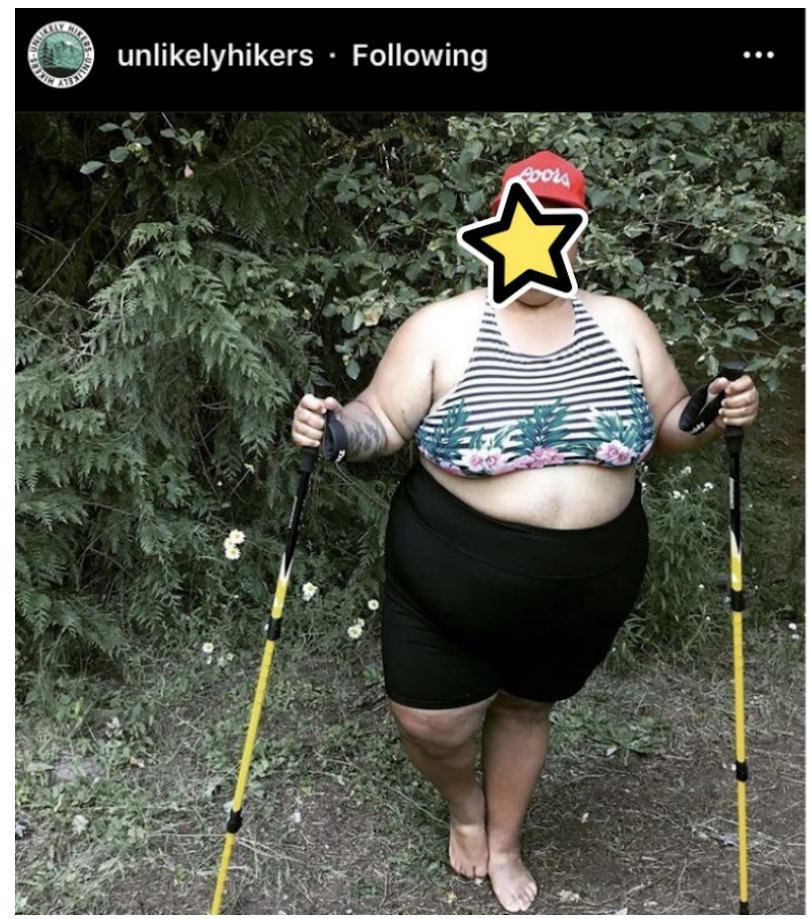

unlikelyhikers "Joyful movement and nature are for everybody and every body. Media will tell you that living in a fat disabled body means you don't belong on the trail or in the river or pretty much doing anything physical but that is a lie. Your fat, black, disabled body belongs everywhere. Keep trying new things, keep hiking or rolling or driving to and through nature. Keep finding what brings you joy and know that giving yourself permission to enjoy your body dispels the lie that you don't belong. Not just for you but for every person $Q$ "

(3)

- $\quad$ | they/them/theirs |

Tag \#unlikelyhikers to be featured! (3)

[Image description: barefoot person poses for photo

Figure 34.

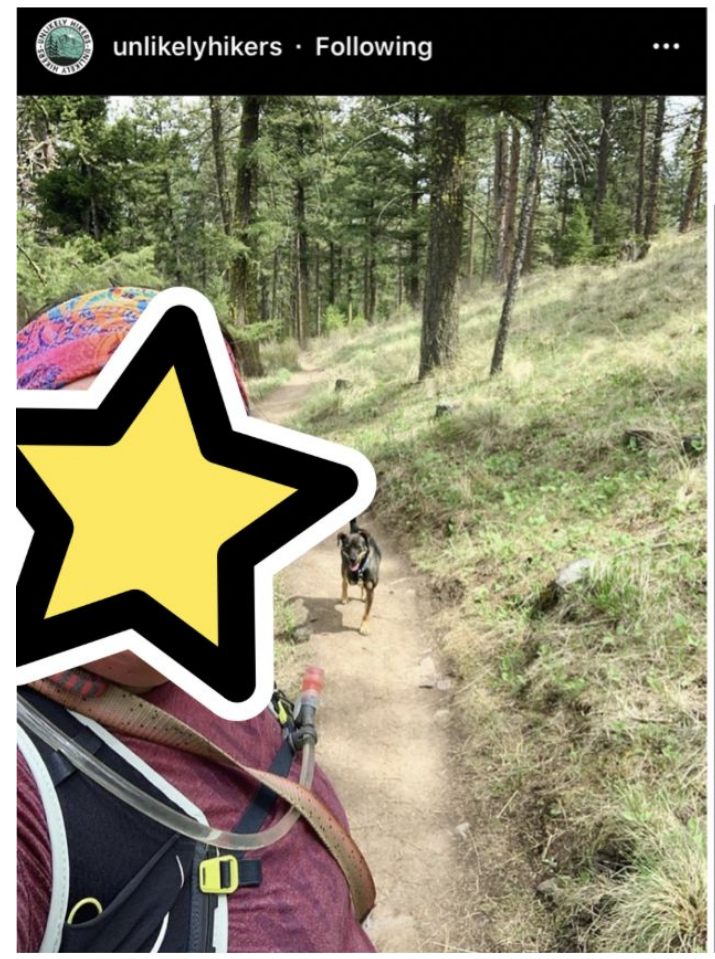

3,155 likes

unlikelyhikers "Every size human is in relationship with their body. As a fat person, the public feels as though they to get to have a relationship with my body. It's common to hear statements of surprise that folks would never make to straight size people when I'm being active. When I am hiking people pass me on the trail and say, 'great job! You are almost to the top. Way to go!' If my body was not this size, I don't believe people would say that. Feel free to greet me on the trail the way you would any other person. 'Hello' works just as well for fat people as it does for everyone else. My body is strong. Your fat bias is showing. $\bigcirc$ Big Love."

Tag \#unlikelyhikers - be a part of the community!

[image description in comments] 
Figure 35.

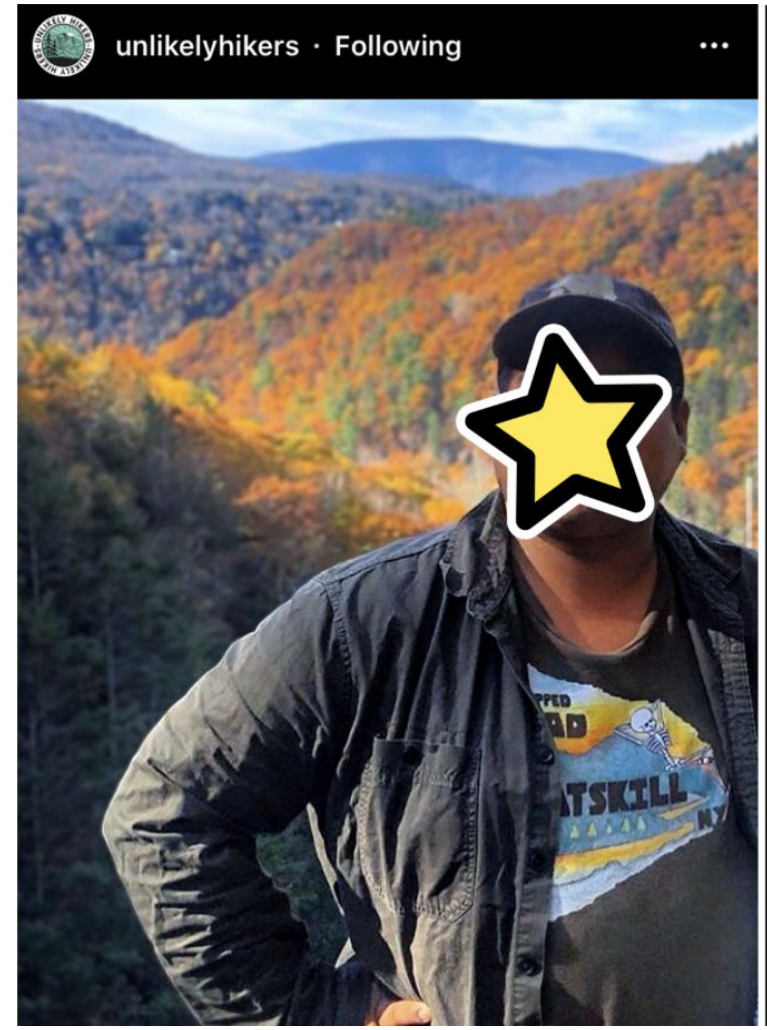

unlikelyhikers "I never saw myself as a hiker. I always thought the term 'hiker' was meant only for athletic, slim people. Social media didn't help either. I only saw models, personal trainers and influencers enjoying the trails, hiking up mountains and frolicking in forests. I did not think the outdoors were meant for me, but something changed a few years ago. I started using hiking as my own personal therapy. The more time I spent in the wilderness, the more I realized that nature does not judge. It does not care about your body type or how many push-ups you can do. It only rewards those who are brave enough to embrace it. Every summit I climb to, every lake I discover, every breath of fresh mountain air is a reward to me from Nature for having the strength to get myself out into the Wild world. And thanks to \#UnlikelyHikers I have found other explorers just like me. It is so refreshing to see real people, of every body type and creed enjoying their time on this beautiful planet. We are allowed to celebrate ourselves in outdoor life because the outdoors are for everyone."

Catskill Mountains, New York. This land is ancestral to the Mohican people and possibly others.

Tag \#unlikelyhikers to be featured!

Figure 36.

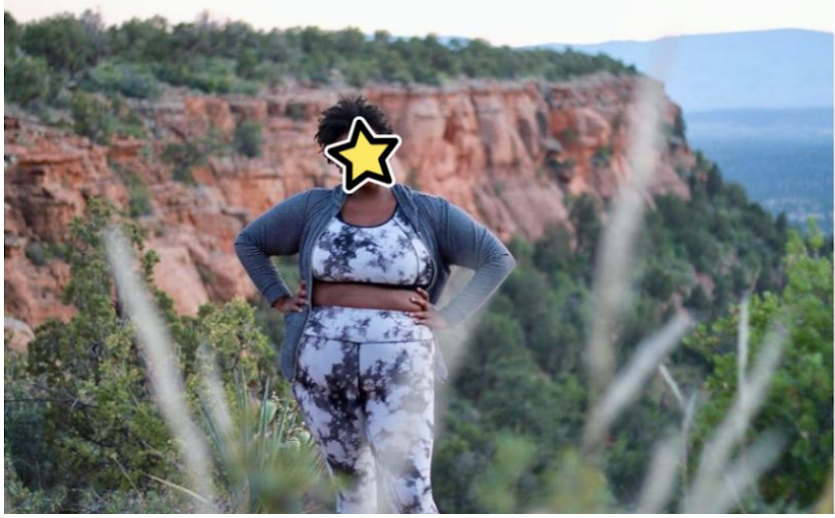

unlikelyhikers "I want everyone to know that they're welcome in the outdoors. That no matter what your body looks and moves like, if you want a relationship with the outdoors, it wants one with you. You have a right to that access. It's an injustice that anyone is considered unlikely in nature at all when we're all a part and product of it. That's why I make a point to take up space unapologetically. I want to right societal wrongs and communicate through my presence and confident enjoyment in the outdoors that there is no one aesthetic, ability, shape, race, or level of financial privilege that 'belongs.' That belief has to end. It keeps far too many people from the power and wellness that is a day spent in the arms of Mother Nature."

$\nabla$

$\nabla$

\section{| she/her/hers |}

Sedona, Arizona. This land belongs to the Hopi, Yavapai, Pueblos, Western Apache, Hohokam, Diné and possibly other tribes.

$\nabla$

Tag \#unlikelyhikers to be featured! 
Figure 37.

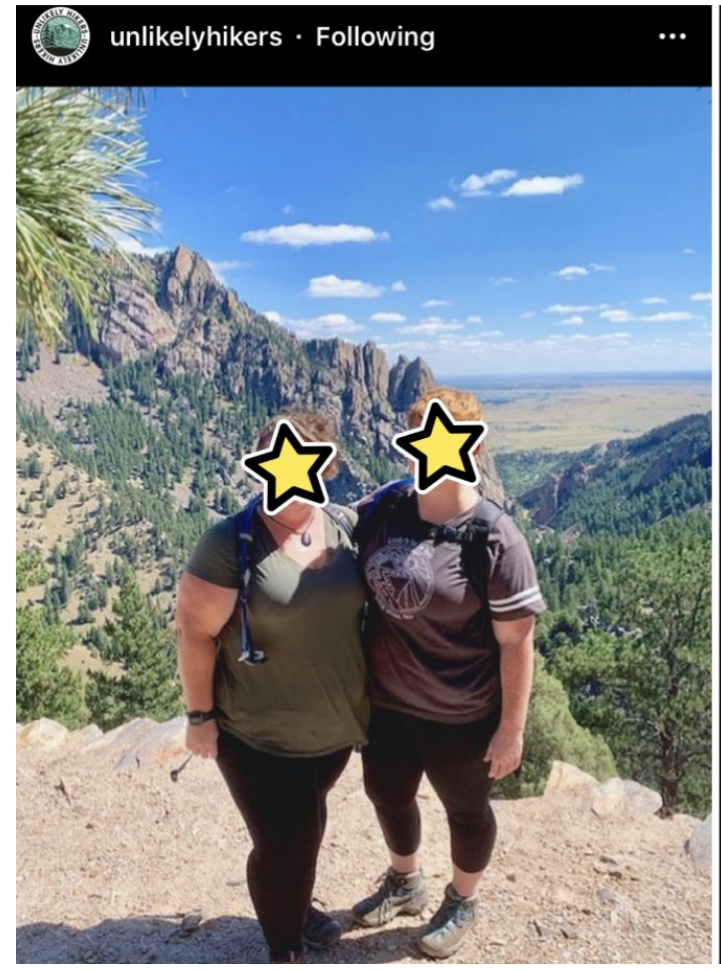

unlikelyhikers "As plus-sized, queer women, we don't see ourselves represented in hiking culture very often. Complete strangers question our ability to hike trails with challenging elevation gains or terrain. Popular brands of outdoor apparel are not made to fit our bodies, as if to say, 'this activity is not for you.' The mountains beg to differ, and these trails are constantly calling us home. They don't care how gay we are, or how fat we are. They don't care how long it takes us to reach a summit, as long as we continue to put one foot in front of the other. Being \#unlikelyhikers can be a source of power if you want it to be. Out on the trail we can educate, inspire, and change the definition of what it looks like to be outdoor women."

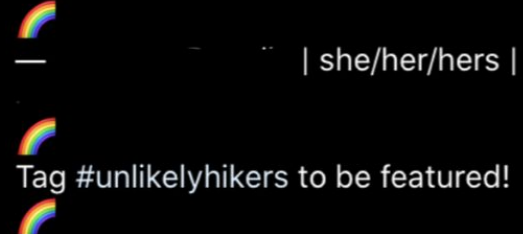

[Image description - couple smiles while posing for photo at scenic viewpoint. Jagged rock pinnacles in near background along with sparse pines. A great valley in far distance suggests higher elevations.]

Figure 38

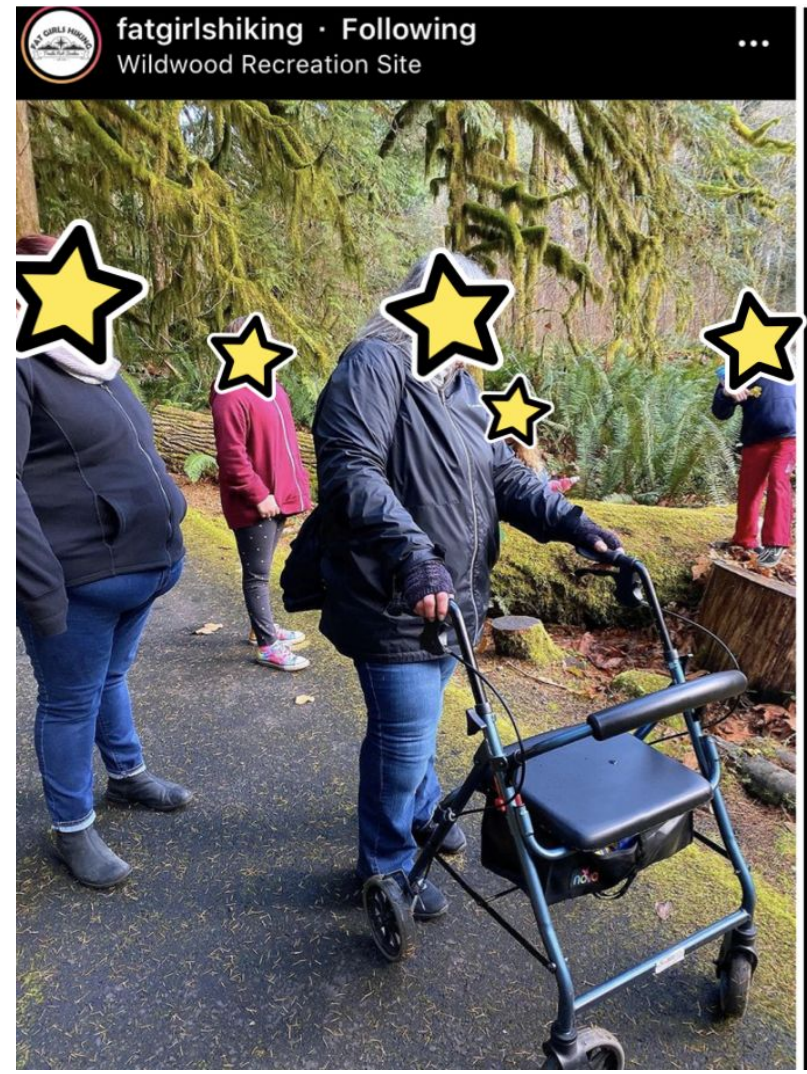

C Chinook Land, now known as Wildwood Recreation Site in Oregon

For Saturday's event 'ead a workshop about reclaiming our fat rolls and bodies. We talked about fat phobic messages we receive about our bodies and how we can reframe those messages to reclaim our fat bodies as sacred vessels. Mikalina taught us how to make body salve as a radical act of care and love for our bodies. Because chafing skin needs our care and attention. We then made labels for our salve tins with intentional messages that we are worthy of care, love and attention. The link to make the salve: https://blog.mountainroseherbs.com/ diy-herbal-salves $\mathbf{A}$ And we made some extras! So if you're interested in purchasing one of the lavender scented body salve tins, Venmo $\$ 10$ to @fatgirlshiking with your name and address. (Includes shipping for US addresses.)

After the workshop we had an opt-in hike. We enjoyed the ADA accessible trail through mossy forest with many benches, the Salmon River and fun features for folks of all ages. The hikes are opt-in because we want everyone to be able to enjoy nature in a way that meets the needs of their body and also be part of this community. So people who can't or don't want to hike, can have a place to do an activity while others hike. Offering multiple options for folks is a way to make this community more inclusive and accessible. And, as always, while hiking, we lead from behind and our motto is \#nohikerleftbehind. 
Figure 39.

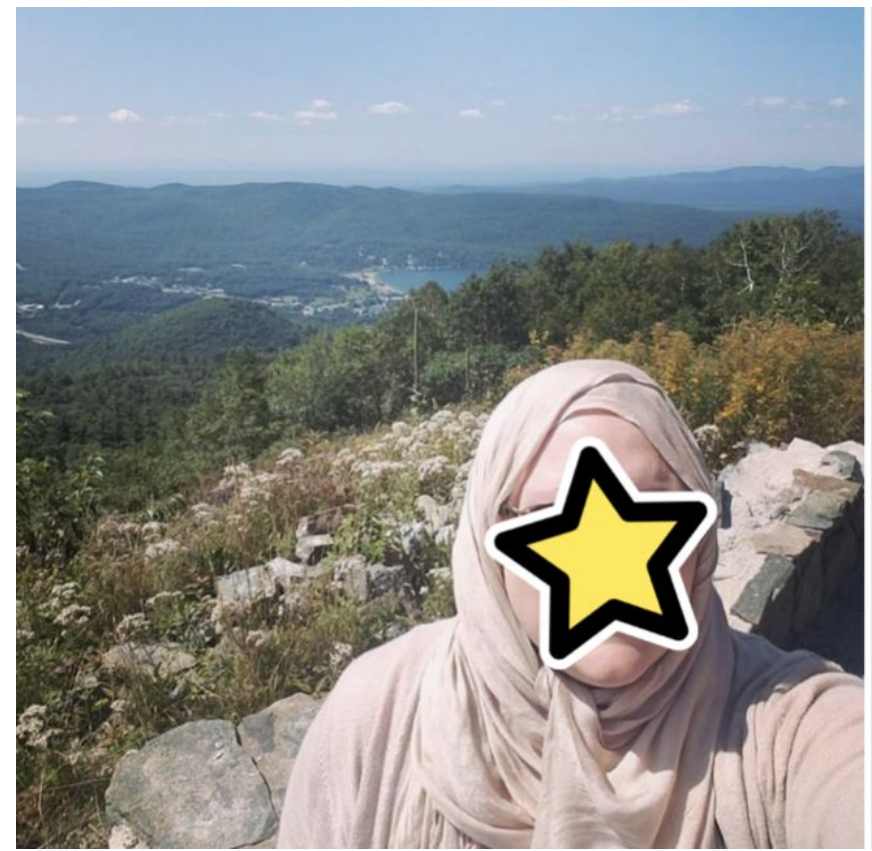

Figure 40.

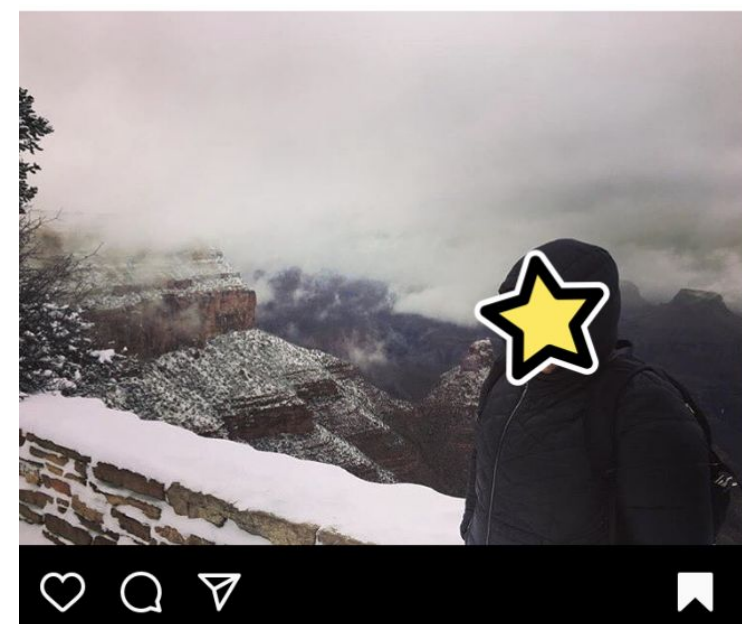

259 likes

unlikelyhikers "I'm used to surprising people,

including myself. I am usually the only brown, fat woman on any trail I hike on and any campsite I set my tent in. Sometimes, it's nerve wracking and I've met a few folks who are surprised by my love of the outdoors or question my ability to do certain things, but I was lucky enough to be instilled with the idea that being outside is healing and empowering. I have found myself here, amongst the trees and I don't see myself going back anytime soon." -

-

Location: Grand Canyon, Arizona \#grandcanyon unlikelyhikers "I've always had a love of the

outdoors. Being a fat, Muslim woman makes me an

Unlikely Hiker. When I started wearing a headscarf

and practicing hijab (hijab $\neq$ headscarf) I became

apprehensive about hiking. The bias towards Muslim people in the news made me cautious. However, I couldn't see myself *not* exploring the outdoors, hiking, swimming, kayaking, etc. So I decided that I have to do those things for my mental health and to not let fear stop me." -

9 Prospect Mountain, New York. This land belongs to the Mohican, Mohawk, Abénaquis,

Haudenosaunee and possibly other tribes. \#prospectmountain

Tag \#unlikelyhikers to be featured!

[Image description: person wearing headscarf takes classic selfie on a rocky outcropping. She is

squinting in the bright sun. Trees and mountains in background appear and small as if she is at a great height.] 
Figure 41.

unlikelyhikers · Following

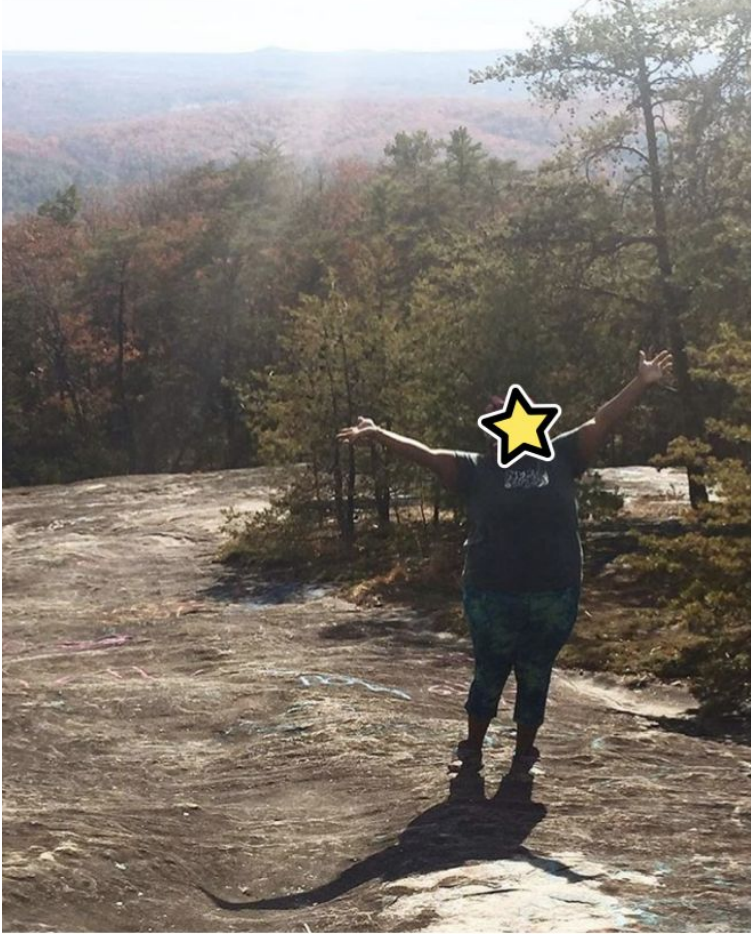

Figure 42.

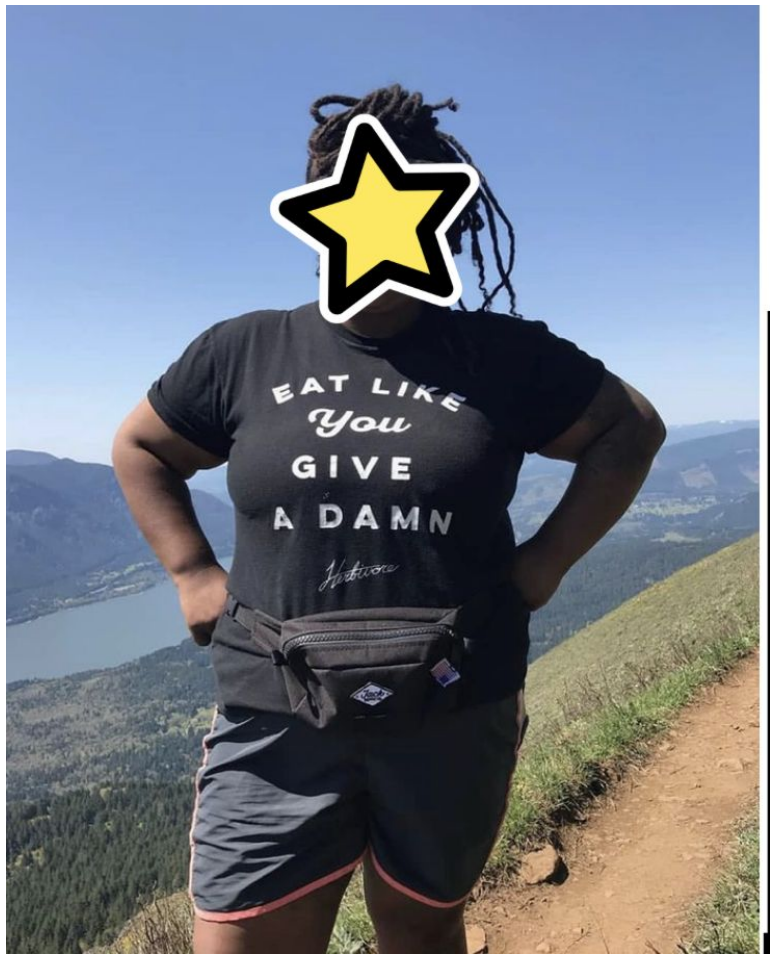

unlikelyhikers "True adventure began when I

stopped limiting myself based on what I thought a hiker had to look like. Once you find yourself looking over miles of mountain and hilltops, the urge to explore far outweighs any preconceived notions. The world belongs to you too, regardless of your background, body size, or skin color. Just go!"

Location: Bald Rock Heritage Preserve, South Carolina \#baldrock

-

Tag \#unlikelyhikers or \#unlikelyhiker to be featured! unlikelyhikers "As someone who is fat and black, I'm an unlikely hiker and an unlikely vegan! We exist! I'm proud to be out and loud about my adventures because REPRESENTATION MATTERS!"

\section{Pronouns: she/her}

Location: Dog Mountain, Washington \#dogmountain [Chinook, Klickitat + territories.]

Tag \#unlikelyhikers or \#unlikelyhiker to be featured

[image description: person stands smiling on trail on clear, sunny day. Large river far below in backgroundcuts through low mountains.] 
Figure 43.

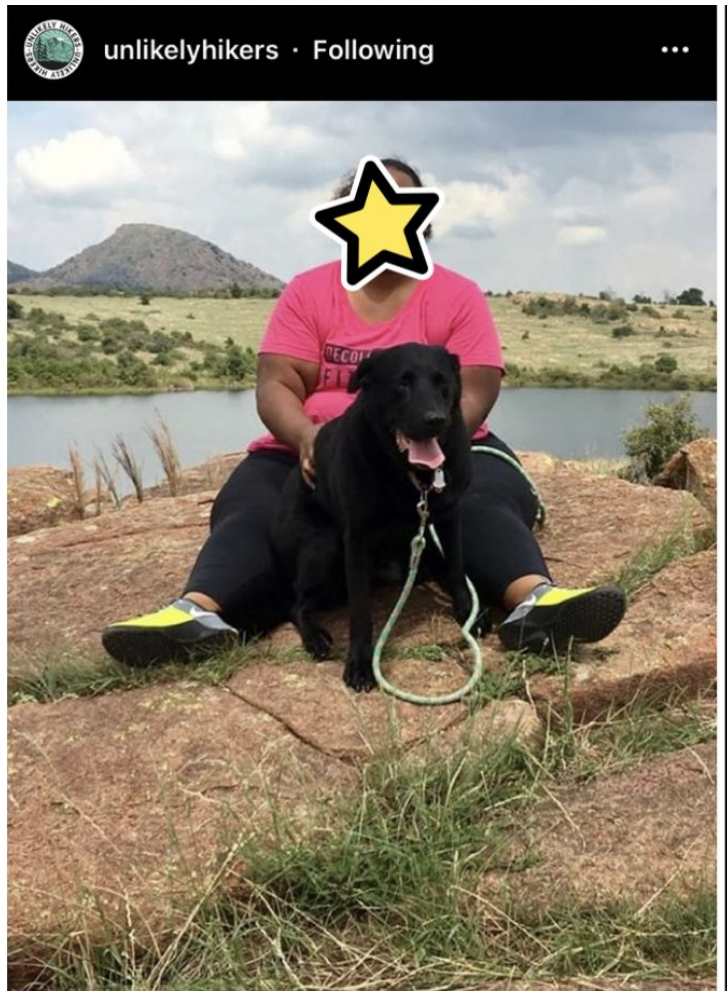

\section{1,154 likes}

unlikelyhikers "As a black woman, growing up I used to love the outdoors, including camping \& hiking. But being plus size, I never felt I belonged there as if I could feel the judgment. And being black, I didn't see people of color represented outdoors or in outdoors magazines. One day I just decided to put myself out there. I went hiking in Virginia some years ago with a big group of people from my old dance class. I didn't think I could do it but I did it and I never felt so proud. Recently I moved back home to Oklahoma \& realized even more how much I missed the outdoors \& wide open spaces. Me \& my dog just went to the mountains and wildlife refuge. It was beautiful. I can't wait to get outside more."

Pronouns: she/her

Tag \#unlikelyhikers or \#unlikelyhiker to be featured!

[Image description: person smiling and holding their dog sits on flat rock with wild grasses growing through cracks. Grasslands, river and rocky hills in background.]

Figure 44.

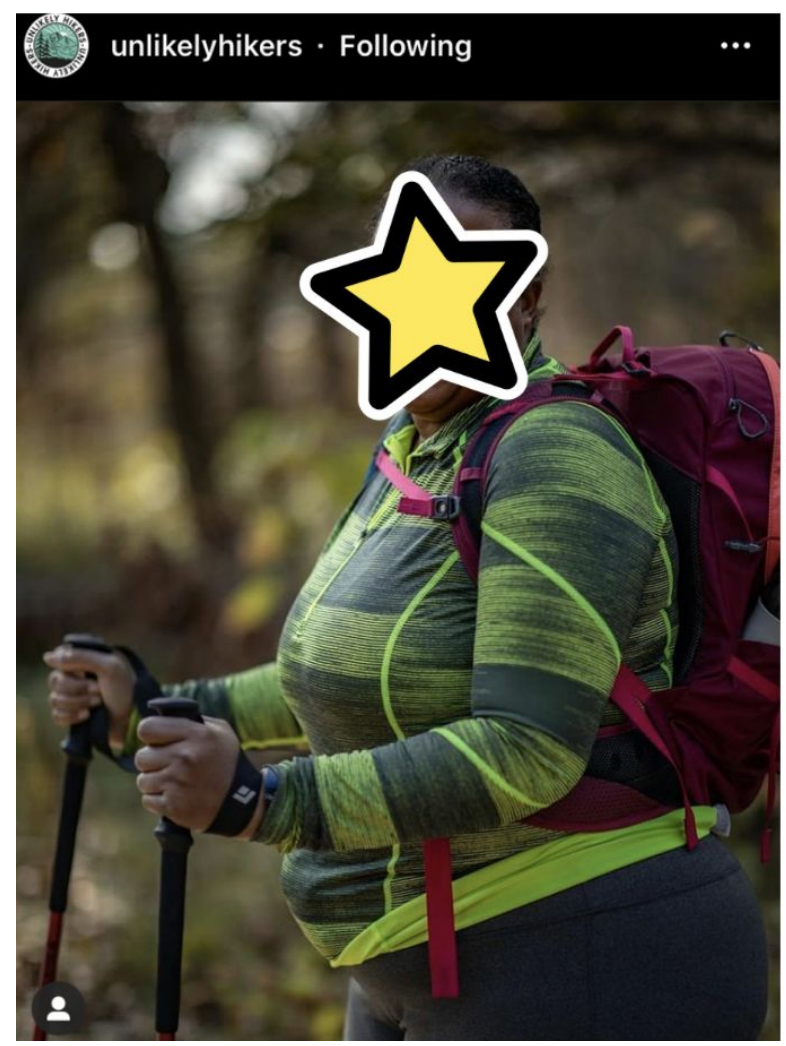

unlikelyhikers "When I first started out hiking, I would count to see how many black and fat people were on the trail. Usually, there were none, but when I did, they were never both like me. I also get excited to see someone who had on a breast cancer t-shirt. I think to myself, there goes another survivor like me. I was searching for a sign that I was just like everybody else. Of course, they didn't know I was doing that. It was me looking for proof that I belonged. I still get stares, but I smile and keep going. I started hiking to train for the Mt Kilimanjaro trek with the @CurvyKiliCrew, but I discovered something I love doing, and it helps calm my anxiety." 
Figure 45.

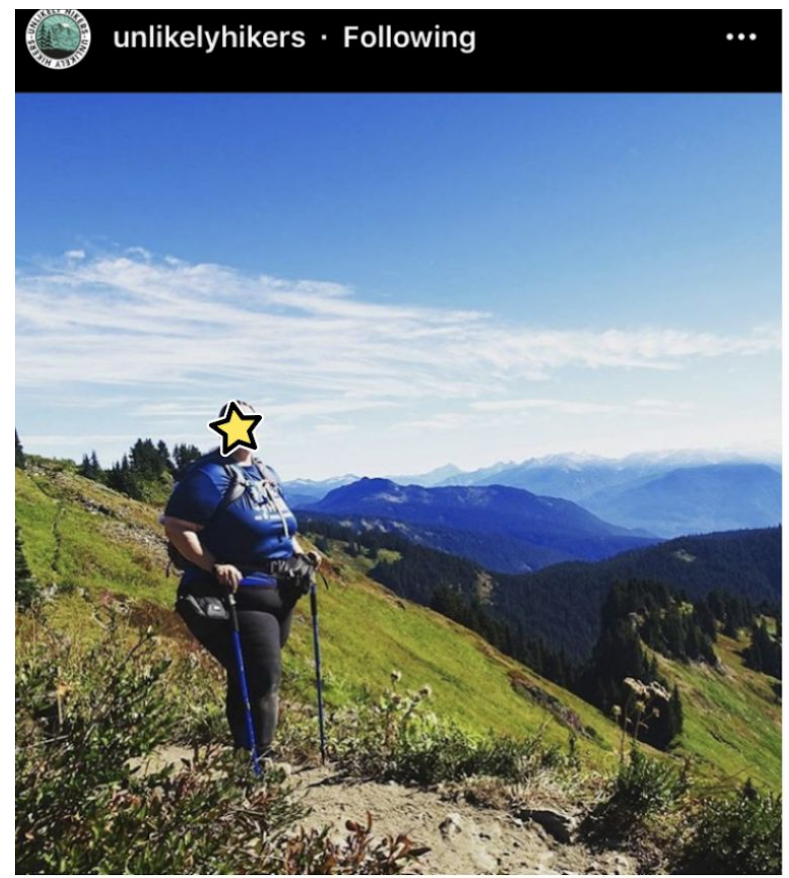

unlikelyhikers "At 340lbs, I'm am not what you think of when you picture a hiker. I am often slow and have to take breaks to let my heart and lungs catch up. I have Asthma, Plantar Fasciitis, bad knees, and a bad hip. But I hike up mountains and I'm not going to let my weight or other issues stop me. Hiking is a way of life for me and my child. It is my primary form of exercise and therapy and it has given me calves of steel. I may be the slowest one on the trail, but I am infinitely faster than those who didn't try."

Pronouns: she/her

Location: Sauk Mountain, Washington

\#saukmountain

is a branch ambassador for also has a blog:

Tag \#unlikelyhikers or \#unlikelyhiker to be featured!

Figure 46.

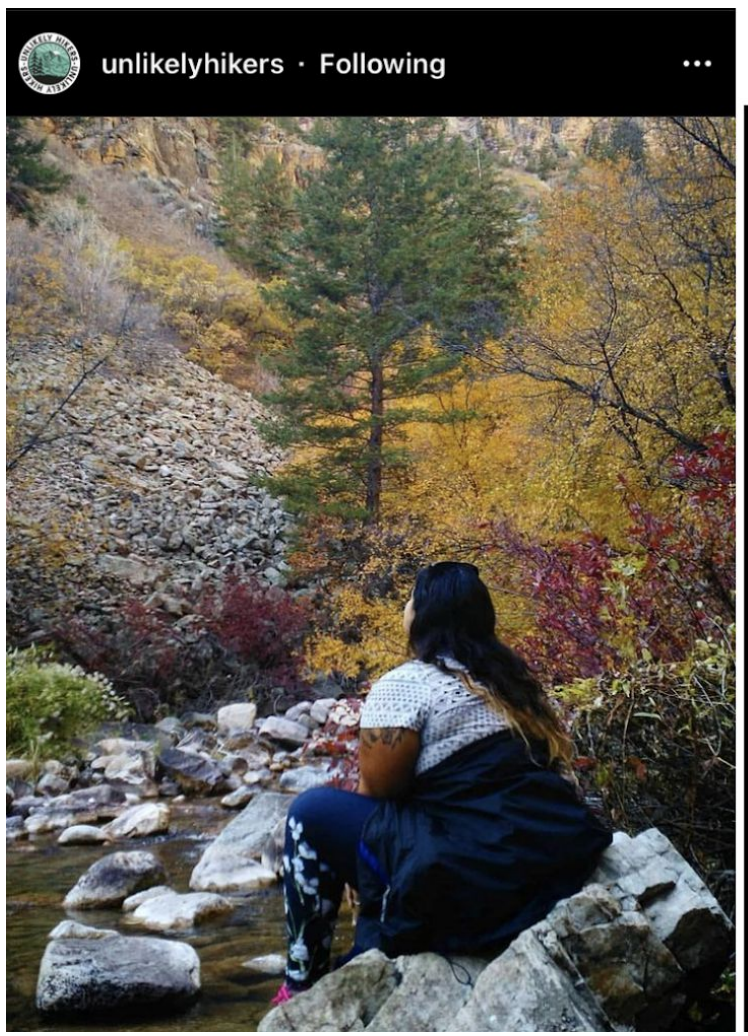

unlikelyhikers "Some days I can walk for miles and miles. And some days, it seems that I go nowhere. This weekend, I felt the latter... And that was ok. I took more breaks than I walked miles, and in doing so, I told my body that I cared about it. I cared about how she felt, I cared about her struggles and apprehensions, and I cared about her from a point of love and not hate. And in doing so, I cared about myself and everything that I am... The way that I am. Nothing more. Nothing less. I don't think I've ever felt so liberated."

Pronouns: she/her

Location: Grizzly Creek Trail, Glenwood, Colorado. Ancestral land of the Ute+ \#grizzlycreek \#ute

Tag \#unlikelyhikers or \#unlikelyhiker to be featured!

[image description: person sits on rock, looking out at a creek in a rocky gorge surrounded by fall's changing leaves. The mood is serene, thoughtful.] 
VIRTUAL COMMUNITIES FOR FAT PEOPLE 
VIRTUAL COMMUNITIES FOR FAT PEOPLE 